\title{
Seismic and Geodetic Observations of Accelerated Sliding at Haupapa/Tasman Glacier, New Zealand
}

By

Sam Taylor-Offord

\author{
A thesis \\ submitted to Victoria University of Wellington \\ in partial fulfillment of the requirements for the degree of \\ Master of Science in Geophysics.
}

Victoria University Wellington

2017 


\section{Abstract}

Rain-induced accelerations of Haupapa/Tasman Glacier are accompanied by abundant seismicity. This seismicity reveals some of the glacial processes occurring at times of accelerated glacier sliding and those related directly to surficial water inputs. To study the processes occurring during rain-induced accelerations a network of seismic and geodetic sensors was deployed on the lower Haupapa/Tasman Glacier for four months in 2016. Seven categories of seismicity were defined during the study period. Glacier source processes were inferred for these categories based on their waveform characteristics, and each source was then compared to meteoric and geodetic data to discern spatial and temporal relationships. Of the seven categories of seismicity only the seismic events associated with crevasse opening were found to correlate with rain rate. Increased crevassing rate likely results from two factors: 1) increased extensional strain rates following the propagation of a subglacial cavitation front during transient accelerations and 2) hydrofracture due to the accumulation of rain in crevasses. Strain-driven crevassing is associated only with glacier acceleration, but crevasse opening via hydrofracture is inferred to occur independently of strain changes such that it is an active process at any point following heavy rainfall. Basal seismicity was not observed to respond to changes in glacier velocity or inferred subglacial water pressure, although this may be due to limitations in the seismic event detection technique. 


\section{Acknowledgments}

I would like to thank firstly my supervisors Huw Horgan and John Townend for their efforts and support over the course of my Master of Science degree.

Funding for my studies was received from Victoria University of Wellington as the Master's by Thesis Scholarship. Fieldwork funding was provided by the Geoscience Society of New Zealand with the John Beavan Geodetic Fieldwork Award. Funding and support from the Geoscience Society of New Zealand also gave me the opportunity to attend the Summer of Applied Geophysical Experience (SAGE) in New Mexico which was an invaluable experience. Seismic instruments were provided by Jennifer Eccles at the University of Auckland, Victoria University of Wellington, and the Incorporated Research Institutions for Seismology. Thank you to all these institutions for their support, without which I would likely be a pauper walking to glaciers and trying to discern ice breaking with a very cold ear.

Thanks also, in no particular order, to:

- Brian Anderson, Sean Barberie, Troy Feck, Huw Horgan, and Merijn Thornton for their direction and assistance in the deployment, maintenance, and retrieval of sensors used in the Rain-Induced Seismogenic Sliding of Ice Network. In particular, thanks to Brian for our discussions on Haupapa/Tasman Glacier and his continued skepticism of seismology.

- Becky Goodsell, Huw Horgan, Darcy Mandeno, and Matt Vaughan for their companionship on our adventure to the end of the earth, in particular Huw who gave me the opportunity to experience the Antarctic.

- Aleksandr Beliaev and Adrian Benson for their invaluable assistance with the 
computing and construction needs of my thesis.

- Paul Winberry who provided me with his beamforming and grid search code and all the users of the geophysics server which I later crashed with my expanded version of this code.

- For those who helped me with technical aspects of coding and seismology: Carolin Boese, Calum Chamberlain, Dominic Evanzia, Hamish Hirschberg, and Konstantinos Michailos.

- To my office-mates: Rachel Barrett, Andy McNab, Nicolas Oestreicher, and Merijn Thornton for their entertaining conversation, scientific discussion, and solidarity during the 2017 coffee crisis.

- Jesse Kearse for allowing me to accompany him during the Kekerengu Fault slickenline study following the Kaikoura Earthquake.

- To my friends and family, in particular my cousin Shane for his proof by contradiction that geophysics is indeed the pinnacle of earth science disciplines. 


\section{Contents}

1 Introduction $\quad 1$

1.1 Objectives and Importance . . . . . . . . . . . . . . . . . . . 1

1.2 Haupapa/Tasman Glacier . . . . . . . . . . . . . . . . . . . 5

1.3 Thesis Structure . . . . . . . . . . . . . . . . . . . . 8

$\begin{array}{llr}2 & \text { Background Theory } & 10\end{array}$

2.1 Glacier Hydrology . . . . . . . . . . . . . . . . . . . . . . . . . . . 10

2.2 Glacier Dynamics . . . . . . . . . . . . . . . . . . 15

2.3 Glacial Seismicity . . . . . . . . . . . . . . . . 20

3 Methods $\quad 30$

3.1 Instrument Network (RISSIN) . . . . . . . . . . . . . . . 30

3.2 Data Processing . . . . . . . . . . . . . . . . . 35

3.3 Event Detection Algorithm . . . . . . . . . . . . . . . . . 37

3.4 Beamforming and Grid Search . . . . . . . . . . . . . . . . 44

3.5 NonLinLoc . . . . . . . . . . . . . . . . . . . . 47

3.6 Seismic Event Categorisation _. . . . . . . . . . . . . . . 48

4 Results $\quad 50$

4.1 Seismic Event Categories . . . . . . . . . . . . . . . . . 50

4.2 Category Simplification . . . . . . . . . . . . . . . . 61

4.3 Geodetic Timeseries . . . . . . . . . . . . . . . 67

4.4 Seismic-Geodetic Correlation . . . . . . . . . . . . . . 70

4.5 Crevasse Opening . . . . . . . . . . . . . . . . . . . 75

4.6 Icequake Locations . . . . . . . . . . . . . . . . . . . . . 80

5 Discussion $\quad 85$

5.1 Geodetic Relationships . . . . . . . . . . . . . . . . 85

5.2 Accelerated Sliding . . . . . . . . . . . . . . . . . . 87 
5.3 Strain-Driven Crevassing . . . . . . . . . . . . . . . . . . . 90

5.4 Water-Driven Crevassing . . . . . . . . . . . . . . 91

5.5 Basal Seismicity . . . . . . . . . . . . . . . . . . . 95

$\begin{array}{lll}6 & \text { Conclusion } & 99\end{array}$

$\begin{array}{ll}\text { Bibliography } & 101\end{array}$

$\begin{array}{lr}\text { Appendices } & 114\end{array}$

A Manual Inspection Seismograms . . . . . . . . . . . . . . . . 115

B Timeseries Plots. . . . . . . . . . . . . . . 120

C Crevasse Water Storage and Hydrofracture Model . . . . . . . . . . . 125 


\section{List of Figures}

1.121 st century global mean sea level rise projections . . . . . . . . . . 3

1.2 Annotated map of Haupapa/Tasman Glacier . . . . . . . . . . . . . . 6

1.3 Surface velocity field of the Haupapa/Tasman Glacier and its tributaries 7

2.1 Simplified longitudinal cross section of a temperate alpine glacier . . . 10

2.2 Plan view and side view of hypothetical crevasse drainage systems and their connection to the glacial drainage system . . . . . . . . 11

2.3 Idealised plan view of subglacial drainage systems . . . . . . . . . . . 12

2.4 Schematic diagrams of channels and cavities showing their shape and growth/collapse processes . . . . . . . . . . . . . . . 13

2.5 Plan view and cross sections of a linked cavity network . . . . . . . 13

2.6 Schematic diagrams of subglacial drainage pathways . . . . . . . . . . 14

2.7 Components of glacier motion in a temperate glacier . . . . . . . . 15

2.8 Vertical component seismograms for shallow and deep glacial seismicity 21

2.9 Vertical component seismograms of subaerial calving events . . . . . . 22

2.10 Seismic signal of repeated basal asperity rupture . . . . . . . . . . 25

2.11 Deep seismic event classes with dominant frequency shown to the left of each waveform . . . . . . . . . . . . . . . 26 26

2.12 Vertical component seismograms of two basal cracking events . . . . . 27

2.13 Tremor spectrograms formed by crack closing . . . . . . . . . . . . 28

2.14 Vertical component spectrogram showing the seismic signature of a

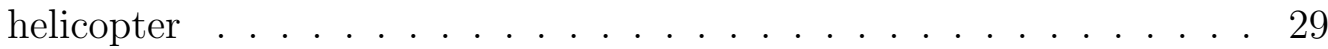

3.1 Map of all RISSIN seismic and GNSS sensor positions . . . . . . . . . 32

3.2 STA:LTA algorithm detection example . . . . . . . . . . . 38

3.3 Sketches of a wavefront arriving at an array in the vertical and horizontal planes . . . . . . . . . . . . . . . . . . 45 
4.1 Spectrograms for all category example waveforms at TSNC1 . . . . . 52

4.2 Example seismogram and beamforming and grid search cross-correlation value plot for category $\mathbf{A}$ seismic events . . . . . . . . . . . 53

4.3 Example seismogram and beamforming and grid search cross-correlation value plot for category B seismic events . . . . . . . . . . . . . . . 54

4.4 Example seismogram and beamforming and grid search cross-correlation value plot for category $\mathbf{C}$ seismic events . . . . . . . . . . . . 55

4.5 Example seismogram and beamforming and grid search cross-correlation value plot for category $\mathbf{D}$ seismic events . . . . . . . . . . . 56

4.6 Example seismogram and beamforming and grid search cross-correlation value plot for category $\mathbf{E}$ seismic events . . . . . . . . . . . . . . 57

4.7 Example seismogram and beamforming and grid search cross-correlation value plot for category $\mathbf{G}$ seismic events . . . . . . . . . . . . 58

4.8 Example seismogram and beamforming and grid search cross-correlation value plot for category $\mathbf{H}$ seismic events . . . . . . . . . . . . . . 59

4.9 Example seismogram and beamforming and grid search cross-correlation value plot for category $\mathbf{J}$ seismic events . . . . . . . . . . . . . 60

4.10 Example seismogram and spectrogram for a single station observing a category $\mathbf{K}$ seismic event . . . . . . . . . . . . . . . . . . 61

4.11 Development of a category $\mathbf{G}$ waveform during wave propagation from a repeating crevasse opening episode . . . . . . . . . . . . 63

4.12 Timeseries of category event counts and rain rate . . . . . . . . . 66

4.13 Influence of sampling window size on calculated velocity . . . . . . . 67

4.14 Velocity uncertainty distribution for upper and lower glacier sensors . 68

4.15 Rain rate, geodetic measurements, and lake level data with velocities calculated over 3 hour sampling intervals . . . . . . . . . . . . . . 69

4.16 Rain rate, geodetic measurements, and seismicity counts with velocities calculated over 3 hour sampling intervals . . . . . . . . . . . 71

4.17 Rain rate, geodetic measurements, and seismicity counts focused on the heavy rainfall event of day 125 with velocities calculated over 3 hour sampling intervals . . . . . . . . . . . . . . . . 72

4.18 Rain rate, geodetic measurements, and seismicity counts focused on the heavy rainfall event of day 132 with velocities calculated over 24 hour sampling intervals . . . . . . . . . . . . . . . 73 
4.19 Distribution of non-zero crevassing event counts over the RISSIN deployment . . . . . . . . . . . . . . . 75

4.20 Plot of crevassing distance from the terminus following initiation of a crevassing rate peak . . . . . . . . . . . . . 77

4.21 Crevasse opening locations for six episodes of crevassing rate peaks . 78

4.22 Crevasse opening locations for five episodes of crevassing rate peaks • 79

4.23 Icequake epicentres over lower Haupapa/Tasman Glacier and its trib-

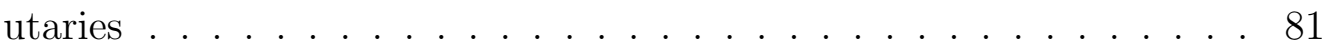

4.24 Icequake epicentres over lower Haupapa/Tasman Glacier tongue . . . 82

4.25 Icequake hypocentres scaled relative to their RMS arrival time residual 83

4.26 Distribution of PDF points for the $95 \%$ confidence interval of a networkexternal icequake . . . . . . . . . . . . . . . . 84

5.1 Block model for accelerated sliding at Haupapa/Tasman Glacier . . . 89

A.1 On-glacier sensor seismograms over two minutes of helicopter noise on day 200. Seismograms are normalised independently. . . . . . . . . 116

A.2 On-glacier sensor seismograms over two minutes of near-station impulsive seismicity on day $122 . \ldots$. . . . . . . . . . . . . 117

A.3 On-glacier sensor seismograms over two minutes of the near-station seismicity near the rainfall peak on day 123. . . . . . . . . . . . . 118

A.4 On-glacier sensor seismograms over two minutes of the crevassing rate

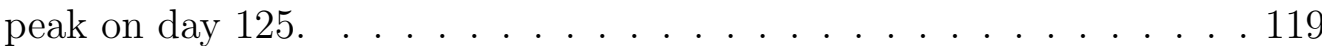

B.1 Rain rate, geodetic measurements, and lake level data for smoothed 24 hour velocities . . . . . . . . . . . . . . . . . . 121

B.2 Rain rate, geodetic measurements, and lake level data for smoothed 24 hour velocities focused on the heavy rainfall event of day 125 . . . 122

B.3 Rain rate, geodetic measurements, and lake level data for smoothed 24 hour velocities focused on the heavy rainfall event of day 132 . . . 123

B.4 Rain rate, geodetic measurements, and seismicity counts for smoothed 24 hour velocities . . . . . . . . . . . . . . . . . . . 124

C.5 Schematic diagram for a one-dimensional crevasse water storage model 125

C.6 Schematic diagram for a one-dimension crevasse hydrofracture model 129

C.7 Simplified combined water storage and hydrofracture model result for days $131-134 \ldots \ldots$. . . . . . . . . . . . . . . . 131 


\section{List of Tables}

2.1 Summary of accelerated sliding literature . . . . . . . . . . . . . . 19

3.1 Summary of sensor features for L-28 geophones and T-120 seismometers. 33

3.2 RISSIN deployment summary . . . . . . . . . . . . . . . 34

3.3 STA:LTA algorithm parameters. . . . . . . . . . . . . . 41

4.1 Summary of category characteristics for observed seismicity. . . . . . 51

4.2 Cross-correlation lag times and normalised correlation coefficients between rainfall, velocity, and crevassing timeseries . . . . . . . . . . 74

5.1 Crevasse rate peaks and rain rate relationships . . . . . . . . . . . 92 


\section{Chapter 1}

\section{Introduction}

\subsection{Objectives and Importance}

\section{Thesis Motivation and Goals}

The motivation of this thesis is to provide a greater understanding of the processes occurring during the accelerated sliding of glaciers. By combining seismic and geodetic observations I aim to constrain these processes in a study of the rain-induced accelerated sliding of Haupapa/Tasman Glacier. The high-magnitude uplift and velocity response of Haupapa/Tasman Glacier to meteoric water inputs (Horgan et al. (2015) observe $>0.5 \mathrm{~m}$ uplift and $>2 \mathrm{~m} \mathrm{~d}^{-1}$ velocity following heavy rainfall) suggests a seismic signature of such an event is likely to exist. Such seismicity would provide insight into glacial processes across and beyond the extent of the seismic network, thus offering acuity of those glacial processes active during periods of accelerated sliding.

The goal of this thesis is to produce a detailed conceptual model describing the glacial processes occurring during accelerated sliding at Haupapa/Tasman Glacier that is readily applicable to glacial environments worldwide. A secondary goal of this thesis is to investigate the role of water in the expansion of crevasses, a process hypothesised to occur in response to rapid and sustained surface water inputs (Van der Veen, 2007) such as those seen during heavy rainfall episodes at Haupapa/Tasman Glacier. I aim to achieve these goals by the use of a combined seismic and geodetic instrument network established on Haupapa/Tasman Glacier. Seismic event detection and location techniques, combined with geodetic observations of glacier motion, will be used to discern the nature of background glacial processes and glacial processes related to accelerated sliding. Comparison of each process 
with rainfall will then allow any relationships with water to be determined for that process. Explicitly, the objectives of this study are:

1. To create a catalogue of seismicity at Haupapa/Tasman Glacier.

2. To investigate the relationship between glacier processes, observed as seismicity, and accelerated sliding.

3. To investigate the relationship between glacier processes, observed as seismicity, and rainfall.

\section{Accelerated Sliding Overview and Importance}

Ice loss from mountain glaciers and ice sheets will constitute the greatest contribution to sea level rise over the coming century (Meier et al, 2007; Marzeion et al., 2012; Radic et al., 2014). Expected future increases in global temperature and rainfall over this period (Collins et al., 2013) will lead to higher glacial melt volumes and ice flux into the world's oceans.

One important mechanism for enhanced ice discharge is accelerated sliding: the rapid increase in the basal slip velocity of a glacier. Accelerated sliding can manifest as a steady and continuous glacier movement or as transient accelerations superimposed on a glacier's background velocity (Iken and Bindschadler, 1986; Zwally et al., 2002; Horgan et al., 2015). Accelerated sliding is often triggered by the flooding of a subglacial drainage system. The water required for flooding can come from the initiation of the melt season, transient high temperatures, supraglacial or subglacial lake drainage, and surface water driven hydrofracture (Iken and Bindschadler, 1986; Zwally et al., 2002; Doyle et al., 2015; Bartholomaus 2015; Siegfried et al., 2016; Das et al., 2008).

Current understanding of accelerated sliding is limited (Church et al., 2013) and its potential for displacing large ice volumes is great (Bindschadler et al., 2013; Pfeffer et al., 2008). This limited knowledge leads to much of the uncertainty in the rate of future sea level rise (Figure 1.1). It is my hope that the outcome of this study can contribute to the collective knowledge of accelerated sliding and aid in constraining future sea level rise estimates. 


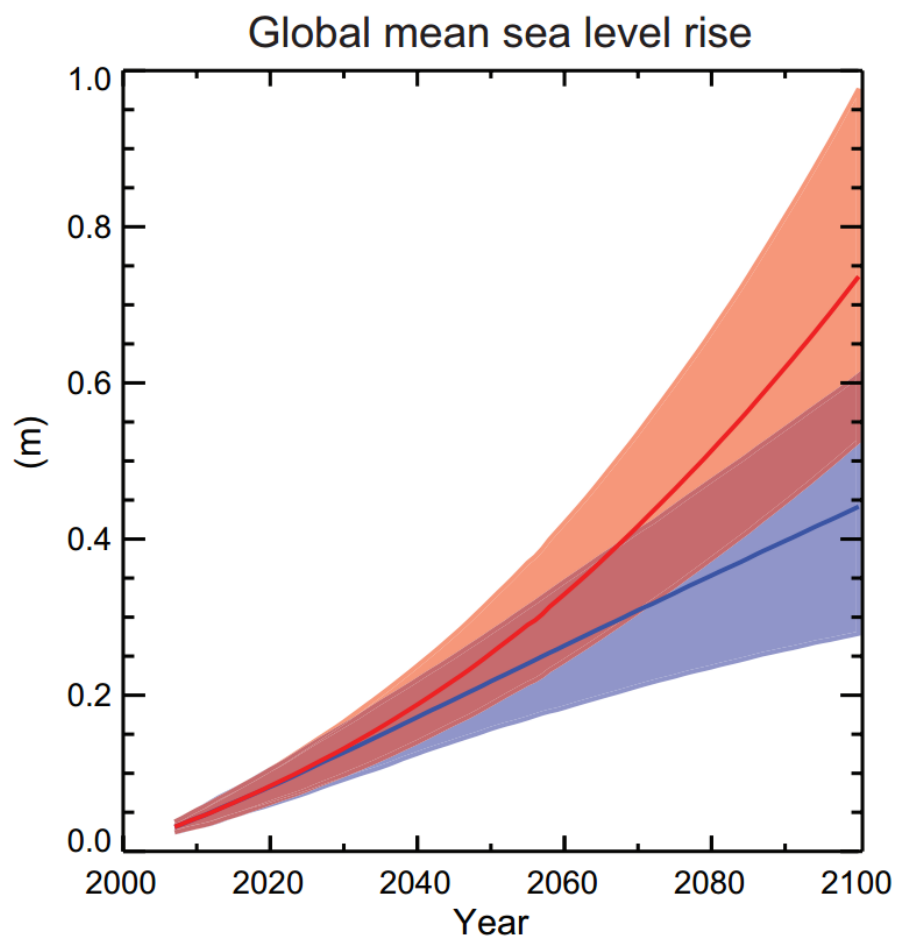

Figure 1.1: 21st century global mean sea level rise projections relative to 1986-2005. For each RCP (Representative Climate Pathway) the likely range of sea level rise is shaded and the median value is plotted as a bold line. The two RCPs shown are for radiative forcing values 2.6 and $8.5 \mathrm{~W} \mathrm{~m}^{-2}$ for year 2100 (IPCC5 models RCP 2.6, RCP8.5) in blue and red, respectively. Figure from IPCC5 Summary For Policymakers (2013).

\section{Hydrofracture Overview and Importance}

Crevasses are fissures exposed at a glacier's surface. Crevasses contribute to glacial hydrology, glacier calving, and in some cases ice shelf collapse (Benn et al., 2007,Benn et al., 2009; Scambos et al., 2009). Crevasses are a principal pathway by which water enters the glacial drainage system (Stenborg et al. 1973, Hubbard et al., 1997), and the hydraulic connectivity of crevasses with the glacial drainage system suggests a dependence exists between glacier surface drainage rate and crevasse development (Zwally et al., 2002; Fountain et al. 2005, Benn et al. 2009). While crevasse depth is typically limited to the upper 10s of meters in glaciers and ice sheets (Patterson, 1994), crevasses form the detachment interface in calving events, and the deepening of terminal crevasses is a critical step in the progression of glacier and ice shelf calving (Benn et al., 2007; Scambos et al., 2009). Perhaps the most high-profile example of crevassing in the cryosphere is its role in ice shelf collapse. On the Antarctic Peninsula, the pooling of seasonal melt water has driven crevasses to greater depths than would otherwise be possible, leading to ice shelf collapse and the acceleration of adjacent land based ice (Scambos et al., 2000; Scambos et al., 2004). 
Crevasse expansion following the accumulation of water in a crevasse occurs through a process termed hydrofracture (Van der Veen, 1998). During hydrofracture, hydrostatic pressure aids existing opening stresses and results in crevasse expansion (Van der Veen, 1998). If the water-level in a crevasse is near the glacier surface, hydrofracture can become sustained and result in crevasse penetration through a glacier's full thickness (Van der Veen, 2007). The large surface water inputs that initiate some glacier speed-up events can trigger hydrofracture (Sole et al., 2011). When through-glacier crevasse penetration results, further acceleration can occur down-glacier owing to the delivery of floodwater to the subglacial drainage system by the hydrologically-efficient crevasse (Boon et al., 2003; Sole et al., 2011; Stevens et al., 2015). In this study I hope to provide some greater understanding of crevasse expansion and its relationship with water to aid in the collective understanding of how surface water inputs can affect glacier disintegration and hydrologic development.

\section{Climate Change: Increasing Global Temperatures}

By 2100 global mean temperatures are likely to exceed between 1.5 and above $2{ }^{\circ} \mathrm{C}$ given a continued increase in greenhouse gas emissions (Collins et al., 2013). These temperature increases will be around 1.5 times more focused over land than over the ocean and will be amplified in polar regions (Collins et al., 2013). This means increases in temperature will be accompanied by a rise in the number, duration, and magnitude of extreme hot weather events as well as a synchronous decrease in the same attributes of cold weather extremes (Collins et al., 2013).

\section{Climate Change: Increasing Global Precipitation}

The result of increasing global temperatures is higher net evaporation and specific humidity in the troposphere. These changes may result in an increase in global precipitation of between 0.5 and $4 \%{ }^{\circ} \mathrm{C}^{-1}$ by 2100 (Huntington, 2005; Collins et al., 2013). This precipitation increase will likely be localised to the Arctic, high latitude landmasses, and moist mid-latitude regions (Collins et al., 2013).

\section{Climate Change: Temperature and Rainfall Relationships with Acceler- ated Sliding and Hydrofracture}

Current glacier mass balances have increased seasonal amplitudes compared to previous decades, owing to a combination of higher winter snowfall and greater summer ablation rates (Dyurgerov, 2003; Bliss et al., 2014). In subpolar and mountain 
glaciers this mass gain and loss is unbalanced with net mass loss occurring globally as ablation rates outstrip accumulation rates (Dyurgerov, 2003; Oerlemans, 2005; Bliss et al., 2014). The resulting high summer ablation can promote accelerated glacier sliding due to the greater availability of water that can flood subglacial drainage systems. Similarly the greater availability of surface water can promote the opening of crevasses through hydrofracture (Van der Veen, 2007; Moore et al., 2013). This said, the relationship between increasing subglacial water inputs and accelerated sliding is complex, with large subglacial water inputs sometimes reducing net seasonal glacier displacements (Section 2.2).

Ultimately transient glacier accelerations in the form of accelerated sliding have implications for the future rate of sea level rise due to their promotion of ice motion towards terminal fronts. Though this is contested by some models (Goelzer et al., 2013), the model results of Bindschadler et al. (2013) suggest that accelerated sliding will result in upwards of $0.3 \mathrm{~m}$ of sea level rise from polar ice sheets by 2100. Similarly Pfeffer et al. (2008) suggest between 0.8 and $2.0 \mathrm{~m}$ of sea level rise will result from the accelerated sliding of all global glacial ice by 2100 . This range in estimates reiterates the poorly known nature of future sea level rise. A greater understanding of the process of accelerated sliding, and the relationship between accelerated sliding and surface water inputs, is thus warranted to better constrain such estimates.

\subsection{Haupapa/Tasman Glacier}

Haupapa/Tasman Glacier is a temperate, mid-latitude, freshwater terminating glacier. It is located east of the Southern Alps/Ka Tiritiri o Te Moana main divide in Aoraki/Mount Cook National Park (Figure 1.2). It descends from $2400 \mathrm{~m}$ a.s.l. at its upper snow-covered reaches to $800 \mathrm{~m}$ a.s.l. at its debris-covered lower region (Kirkbride, 1989). The length of the glacier is approximately $25 \mathrm{~km}$, with widths in its trunk increasing from 1 to $2 \mathrm{~km}$ from the upper to the lower glacier. Near the beginning of the 21 st century the glacier hosted $30 \%$ of the perennial ice volume in New Zealand and had an area of $95 \mathrm{~km}^{2}$ (Chinn, 2001; GLIMS and NSIDC, 2005), since then the glacier has experienced significant downwasting and calving retreat, the latter resulting from the formation of a proglacial lake, Tasman Lake (Kirkbride, 1995b; Hochstein et al., 1995; Kirkbride and Warren, 1999; Purdie and Fitzharris, 1999; Dykes et al., 2010; Dykes et al., 2011). 


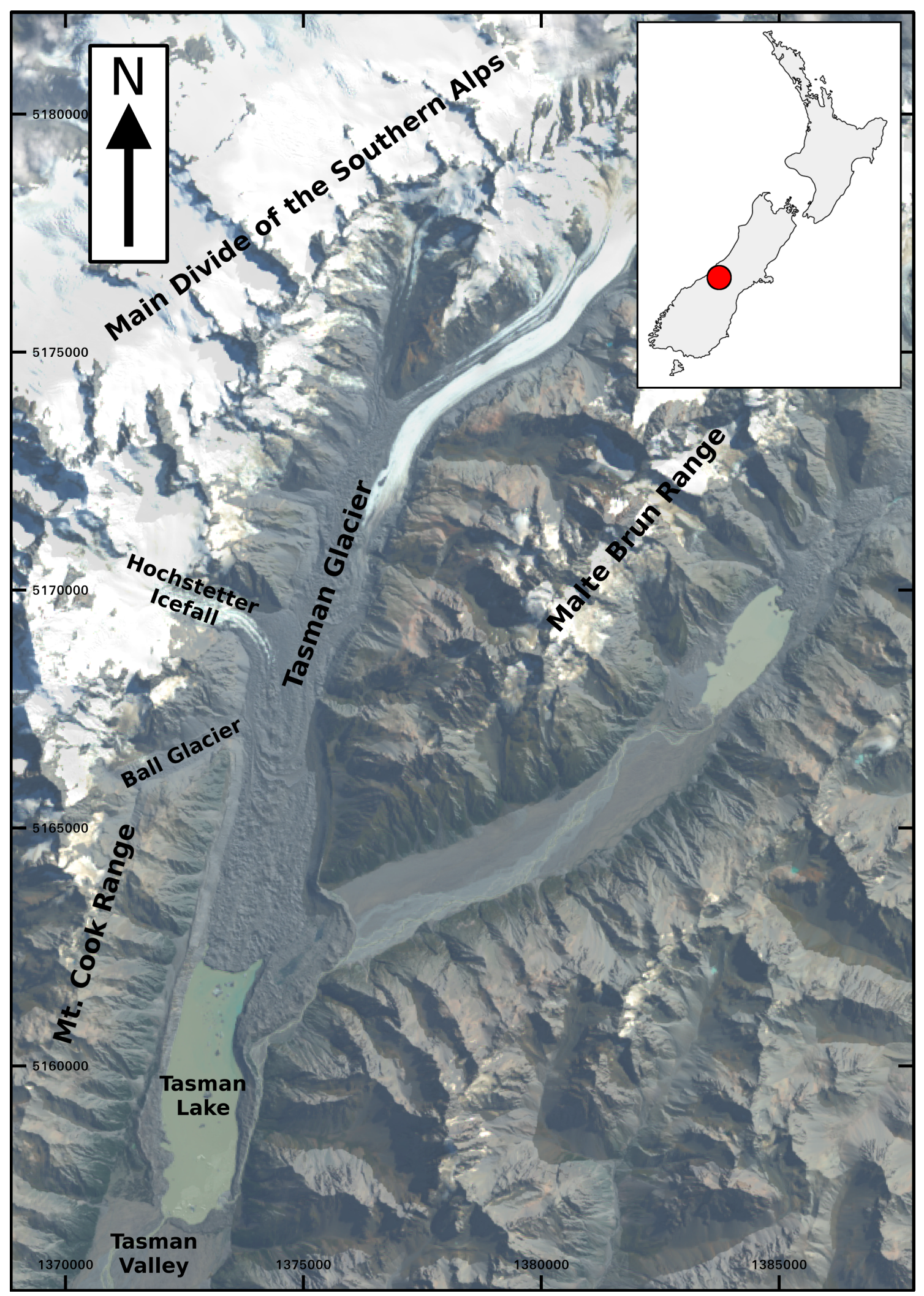

Figure 1.2: Annotated map of Haupapa/Tasman Glacier showing the position of geographic features referenced in this thesis.

Many small tributary glaciers flow into Haupapa/Tasman Glacier from the main divide of the Southern Alps/Ka Tiritiri o Te Moana, the Kirikirikatata/Mt. Cook Range, and the Malte Brun range (Figure 1.2). The upper Haupapa/Tasman Glacier 
is driven principally by flow from its main accumulation zone while the lower glacier is fed mostly by its tributaries (Figure 1.3), chiefly the Hochstetter Icefall (Quincey and Glasser, 2009; Redpath et al., 2013).

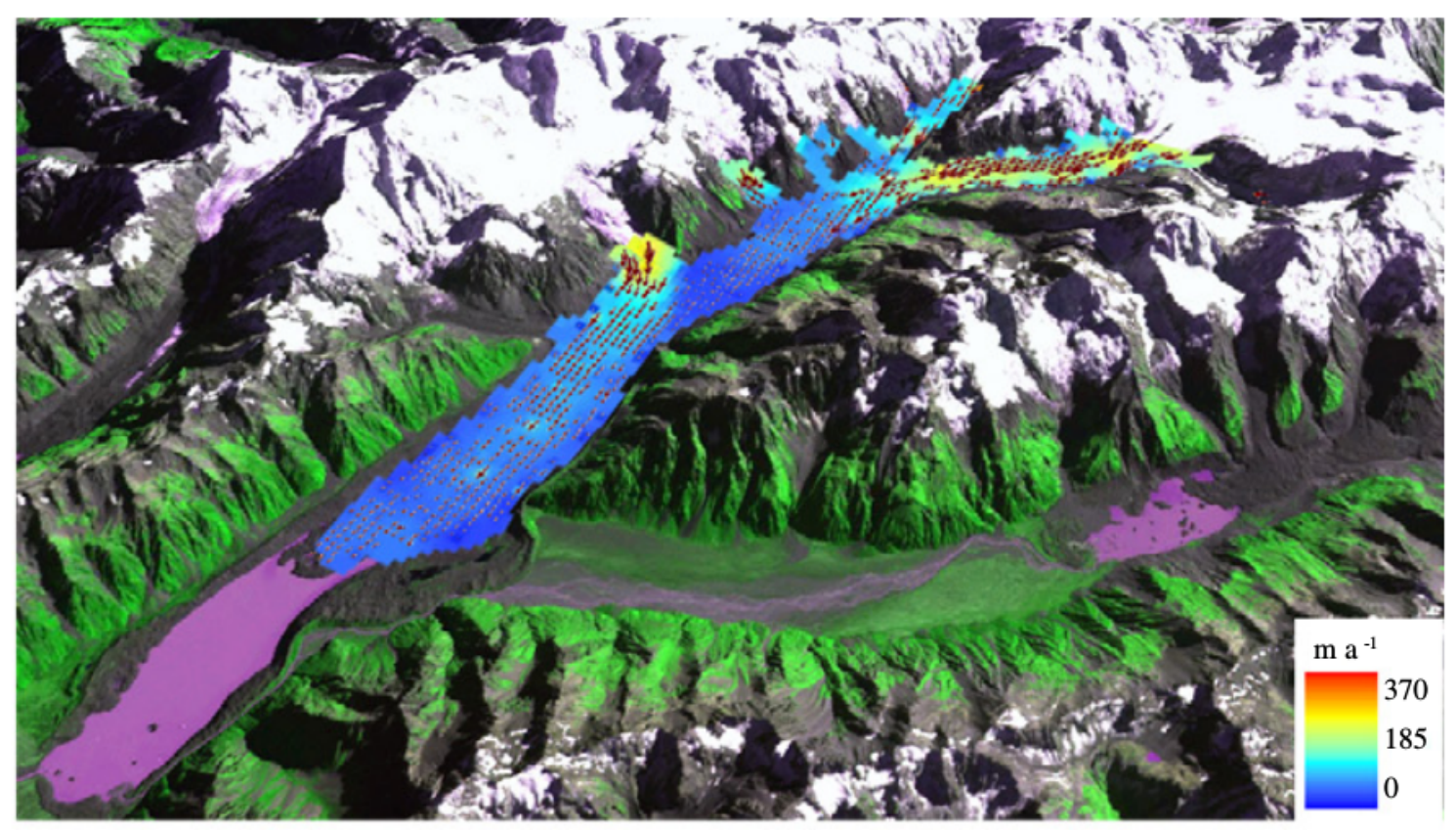

Figure 1.3: Surface velocity field of the Haupapa/Tasman Glacier and its tributaries derived from ASTER images. Figure from Redpath et al. (2013).

The Southern Alps/Ka Tiritiri o Te Moana are being uplifted at a rate of $10 \mathrm{~mm}$ $\mathrm{yr}^{-1}$ due to the convergence of the Australian and Pacific tectonic plates (Wells et al., 1999). This uplift manifests as continued folding and faulting of the rock near the Southern Alps/Ka Tiritiri o Te Moana, thus causing the region to be highly seismogenic (Allen et al., 2009; Boese et al. 2012). The steep and fractured slopes of the region frequently experience rock mass failures (Allen et al., 2009), producing additional seismicity (Deparis et al., 2008) and adding material to the talus slopes and fans that litter the valley walls (Allen et al., 2009).

As Haupapa/Tasman Glacier is a temperate glacier it is at the melting point throughout. The thick debris cover over the lower glacier hinders ice melting (Purdie and Fitzharris, 1999), causing the lower Haupapa/Tasman Glacier to experience low ablation rates as heat propagates at low rates through the debris cover to the underlying ice (Purdie and Fitzharris, 1999; Benn and Evans, 2010).

Rainfall on the Haupapa/Tasman Glacier and its catchment is orographic in origin and sums to about $4 \mathrm{~m} \mathrm{yr}^{-1}$ at the central glacier (Henderson and Thompson, 1999) with precipitation in the surrounding catchment at around $4-10 \mathrm{~m} \mathrm{yr}^{-1}$ (Kirkbride, 1995b). A strong leeward gradient in rainfall causes most meteoric water to fall on 
the western side of the main divide $\left(>12 \mathrm{~m} \mathrm{yr}^{-1}\right)$ and thus regular rainfall events are greatly diminished when they reach the Haupapa/Tasman Glacier catchment (Henderson and Thompson, 1999). Large storms are often driven north-east along the Southern Alps/Ka Tiritiri o Te Moana due to the passage of cold fronts from the south. Generally it takes less than 12 hours for these fronts to traverse the $400 \mathrm{~km}$ length of the mountain belt, meaning that the initiation of rainfall in any basin draining from the main divide occurs within a 3 hour period. Therefore, heavy rainfall can be considered to begin simultaneously in any such catchment (Henderson and Thompson, 1999) and so in storms Haupapa/Tasman Glacier is frequently inundated with rainwater across its full extent.

The bed topography of Haupapa/Tasman Glacier is poorly known and is constrained only by a few studies. Near the Ball Glacier confluence the glacier bed is significantly over-deepened and the glacier is very thick ( $\sim 700 \mathrm{~m}$ in the early $1970 \mathrm{~s})$, while in most of the deglaciated Tasman Lake region estimates of glacier thickness and icefree lake depth are similar at 200-220 m (Broadbent, 1973; Claridge, 1983; Watson, 1995; Hart, 2014; Purdie et al., 2016). These results have lead to the interpretation of an initial terminal overdeepening with a subsequent up-valley thinning of the glacier along its centreline (McKinnon et al., 2012; Purdie et al., 2016). Lateral moraine morphology, as inferred from the lake bathymetry and moraine topography, is akin to the classic $U$ shaped glacial valley. The ice-bed contact itself has been interpreted as wet (McKinnon et al., 2012), and also inferred to have an erosion rate of about $10 \mathrm{~mm} \mathrm{yr}^{-1}$, sufficient to achieve a steady-state with the surrounding rock uplift (Adams, 1980). Relative-gravity-based glacier modeling has failed to provide reliable thicknesses for subglacial till, if it is present at all (Hart, 2014).

\subsection{Thesis Structure}

The remainder of this thesis is presented in five chapters: Background Theory, Methods, Results, Discussion, and Conclusion. Chapter 2, Background Theory, presents the theory and literature relevant to this thesis. Chapter 3, Methods, begins with an overview of the design and deployment of the combined seismic and geodetic instrument network before detailing the data processing used to generate results. Chapter 4, Results, presents the categorisation of recorded seismic events, their relation to glacial processes, and seismic event locations and timeseries plots of those categories and auxiliary data considered relevant to accelerated sliding at Haupapa/Tasman Glacier. Chapter 5, Discussion, focuses on the trends seen in the results, aiming to describe them through combinations of glacial processes. This analysis culminates in 
a conceptual model for accelerated sliding at Haupapa/Tasman Glacier and discussion of the likely triggers for the modes of crevasse opening observed over the study period. These outcomes are then presented in Chapter 6, Conclusions, a summary of the findings of this study including commentary on potential future research. 


\section{Chapter 2}

\section{Background Theory}

\subsection{Glacier Hydrology}

In the absence of fractures and channels, water flow in a glacier is restricted to trickling through snow and firn in the surface layers or through subglacial materials (sediments, till, bedrock) and any gaps at the ice margins and bed (Benn and Evans, 2010). Often surficial water flow occurs in channels and is directed towards moulins - large, deep vertical shafts exposed at the glacier surface - or crevasses: elongate scars in the glacier surface (Benn and Evans, 2010). Figures 2.1 and 2.2 shows these drainage pathways schematically.

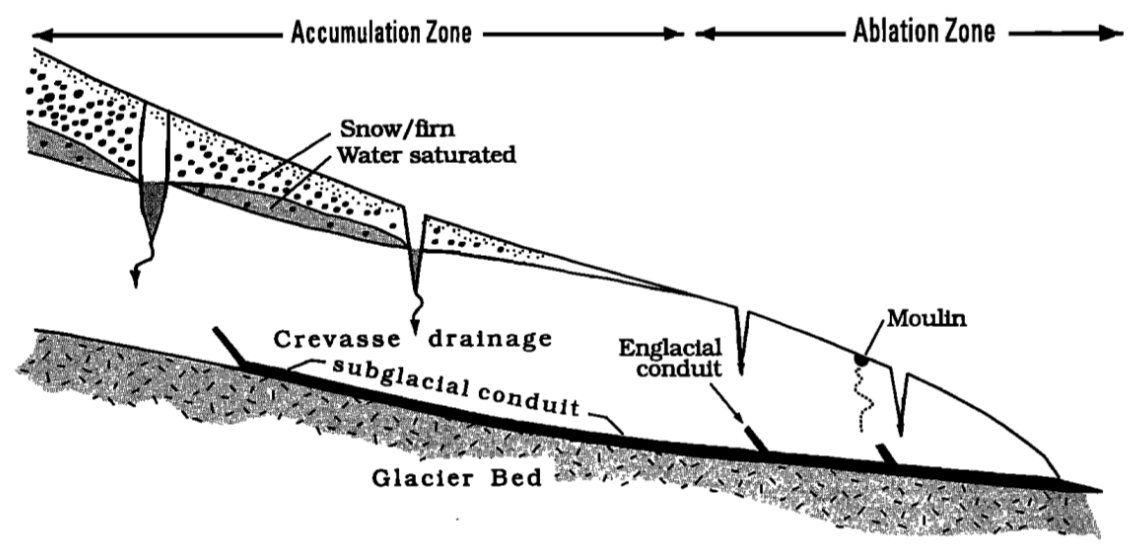

Figure 2.1: Simplified longitudinal cross section of a temperate alpine glacier showing key aspects of the hydrological system. Here snow and firn are shown in one layer and distinguished by the size of dot. In the accumulation zone water pools in snow/firn before being delivered to crevasses. In the ablation zone there is no delay in drainage with water being routed effectively instantaneously into and through crevasses/moulins. These crevasses and moulins then drain into the englacial or subglacial drainage system, which itself routes toward/through the terminus region. Figure from Fountain and Walder (1998). 


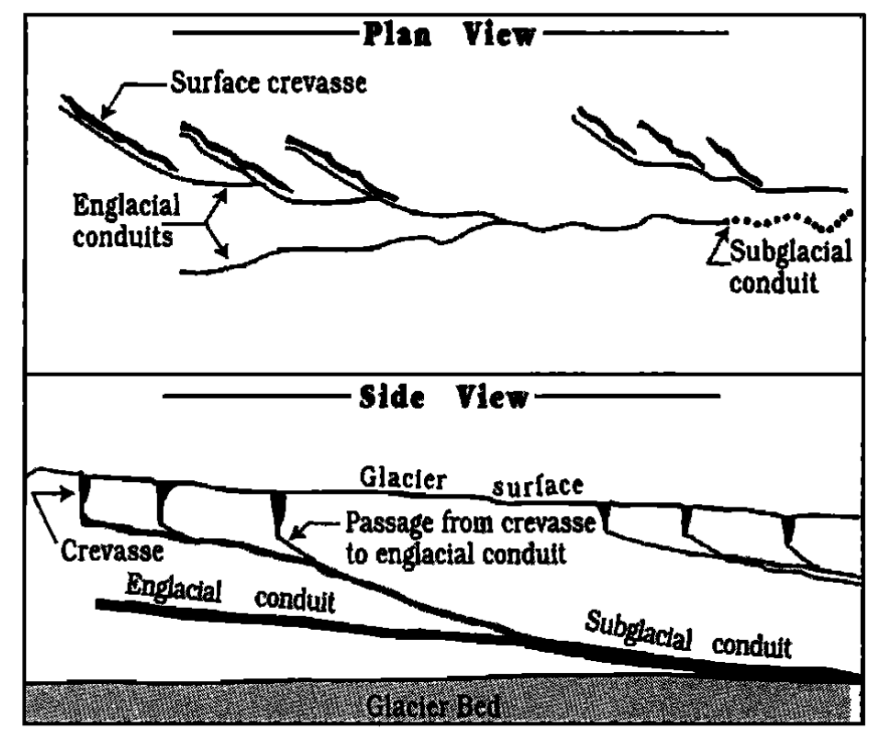

Figure 2.2: Plan view and side view of hypothetical crevasse drainage systems and their connection to the glacial drainage system. Figure from Fountain and Walder (1998).

Crevasses are thought to drain through intergranular passages and microfractures into the englacial drainage system as illustrated in Figure 2.2 (Fountain and Walder, 1998). If a crevasse is well-oriented in the glacier stress field then crack tip propagation can occur by brittle failure (Nye, 1952). A crevasse containing standing water can expand rapidly in this case: outward pressure from water in the crack tip opposes the local lithostatic stress and forces the crevasse to open (Van der Veen, 2007). This water-induced crack-tip propagation, termed hydrofracture, occurs laterally and vertically (Van der Veen, 1998) and sustained hydrofracturing, driven by continued water input, can deepen a crevasse to intersect with englacial channels in matter of hours (Benn and Evans, 2010). Sustained hydrofracture therefore forms one mechanism by which a glacier rapidly delivers surface water to its bed (Das et al., 2008; Stevens et al., 2015).

Water flow through a fracture, fissure, or other kind of englacial passage can cause its expansion through frictional melting of the surrounding ice. With continued expansion, a passage evolves into a channel, a circular artery of water drainage in which water pressure is inversely proportional to channel size (Rothlisberger, 1972; Fountain and Walder, 1998). Ice deformation acts to close such englacial pathways (Nye, 1953). If the ice overburden pressure, the driving force of ice deformation, exceeds the water pressure within a pathway, creep closure will overcome wall melting and the channel will shrink (Nye, 1953).

Subglacial drainage forms a complicated system, both spatially and temporally, as it can occur in a system with multiple arrangements. The two dominant forms are dis- 
tributed and channelised drainage systems (Fountain and Walder, 1998), e.g. Figure 2.3. The principal difference between these systems is their efficiency: channelised drainage systems are efficient at draining the glacier bed while distributed systems are not (Benn and Evans, 2010). Water pressure in subglacial channels varies inversely with channel size (Rothlisberger, 1972) while in distributed drainage systems water pressure increases with flux (Hubbard and Nienow, 1997).
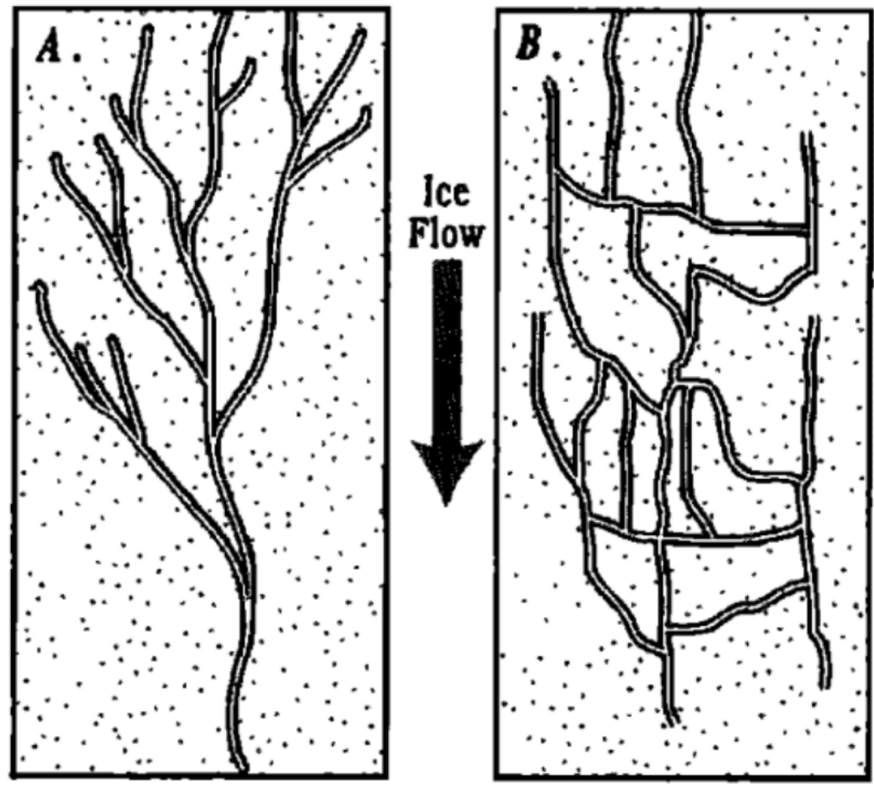

Figure 2.3: Idealised plan view of subglacial drainage systems: $\mathbf{a}$ channelised and $\mathbf{b}$ distributed. Figure from Fountain and Walder (1998).

Distributed drainage systems exist over all of the glacier bed, but flow within them occurs slowly and at high pressures (Hubbard and Nienow, 1997). There are many different forms of distributed drainage systems, each of which may act independently, in combination, or not at all. The dependency of water pressure on flux in distributed drainage systems inhibits their development into channelised drainage systems, though sustained water inputs above the drainage capacity of these systems can trigger channelisation (Kamb, 1987; Hubbard and Nienow, 1997; Schoof, 2010).

The sliding of a glacier over large undulations in its bed, known as bedrock bumps, forms basal cavities or voids in the lee of the bumps (Kamb, 1987). Cavities fill when subglacial water input exceeds the drainage capacity (Figure 2.4). While cavities are filling, they form a localised zone of high water pressure between the glacier sole and bed. Small channels or orifices connect disparate cavities across the glacier bed to form a linked cavity network, as shown in Figure 2.5 (Hubbard and Nienow, 1997). When drainage-induced ice melting opens a cavity beyond its entrained water volume, a pressure drop occurs within the cavity (Kamb, 1987). Drainage from higher pressure cavities then migrates toward the low-pressure cavity, triggering the 
initiation of cavity collapse and channelised drainage system development (Kamb, 1987; Schoof, 2010).
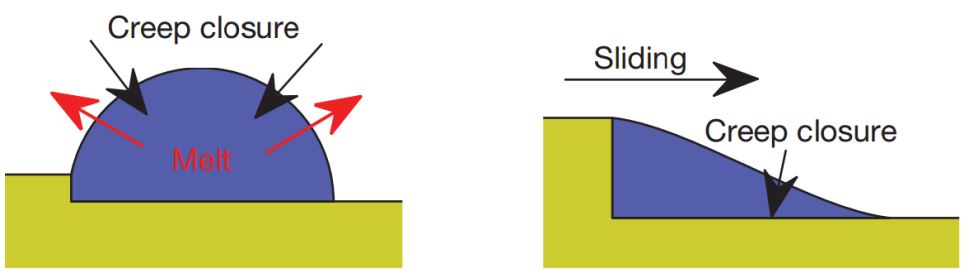

Figure 2.4: Schematic diagram of channels (left) and cavities (right) showing their shape and growth/collapse processes. Channels are typical of a channelised drainage system while cavities form one part of a distributed drainage system. Figure adapted from Fountain and Walder (1998).
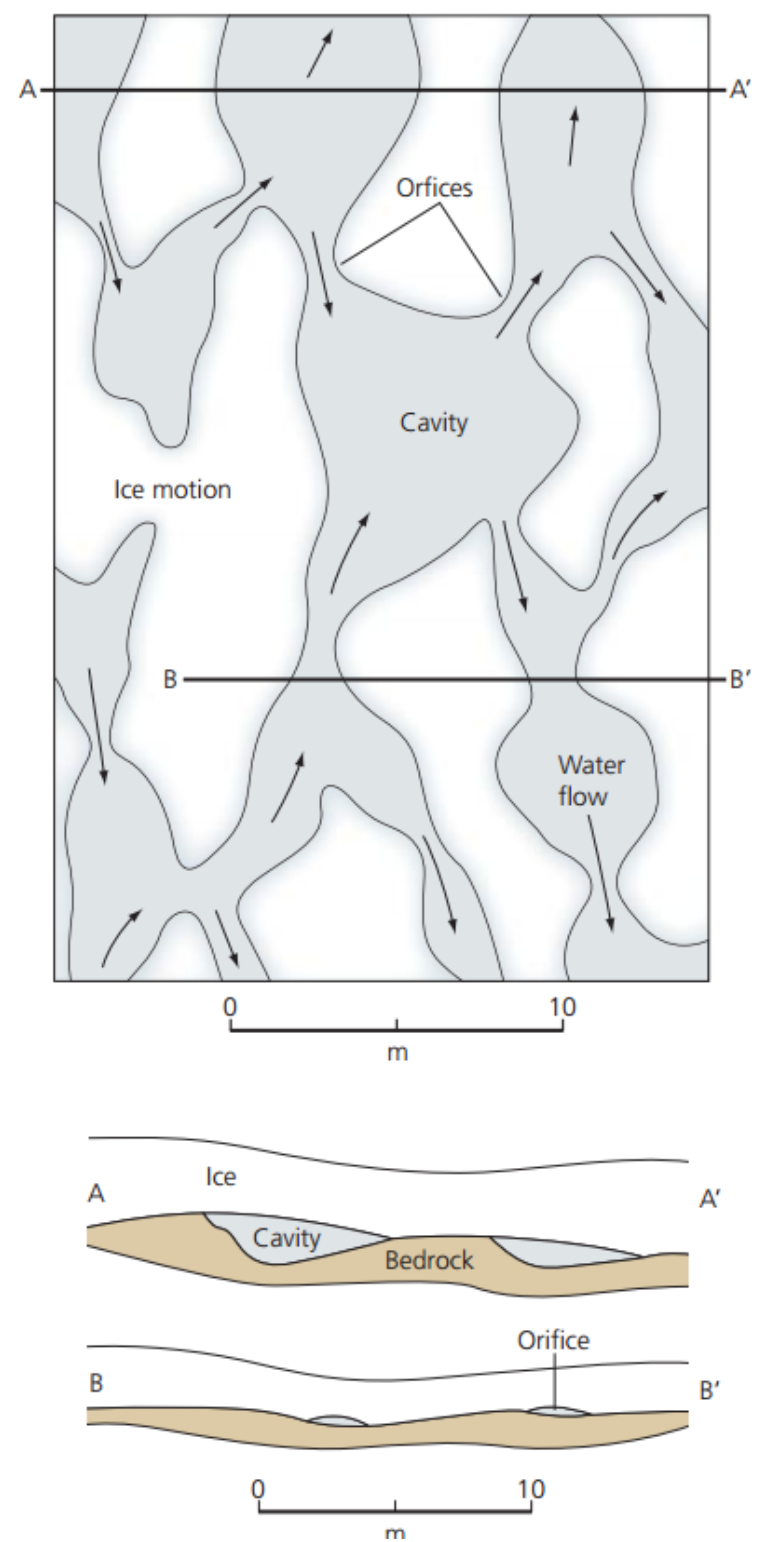

Figure 2.5: Plan view and cross sections of a linked cavity network. Figure from Benn and Evans (2010). 
Channelised drainage systems consist of an arborescent network of large, efficient channels (Figure 2.4) that are fed by many smaller, slower flowing channels. These smaller channels migrate outward and up-glacier from the larger channels they feed into, thus acting to connect large parts of the glacier bed to the subglacial drainage system (Rothlisberger, 1972; Hubbard and Nienow, 1997; Schoof, 2010). The simplest subglacial channel is a semi-circular form of an englacial channel that is incised upwards from the glacier bed by the flow of water (Rothlisberger, 1972). In all forms of subglacial channels, water pressure drops with increasing water flux, thus allowing the development of arborescent drainage systems (Rothlisberger, 1972). The types of drainage pathways that can exist at the glacier bed are summarised schematically in Figure 2.6.
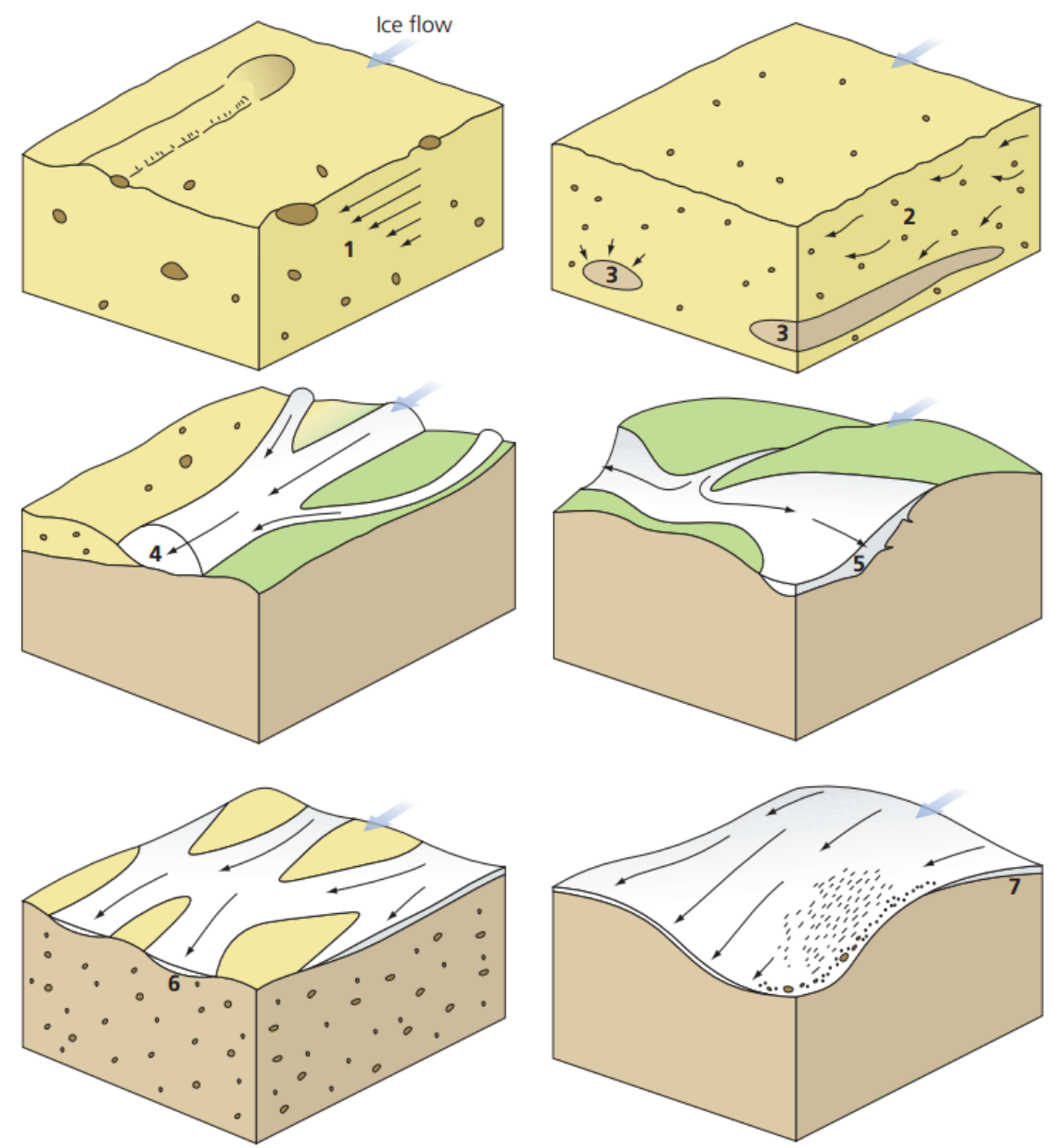

Figure 2.6: Schematic diagrams of subglacial drainage pathways. A deformable bed is shown as a yellow porous material while a hard bed is shown as a green surface. Glacier and water flow are denoted by blue and black arrows respectively. The drainage pathways shown are: 1 - flow in till due to shear dislocations, $2 / 3$ - flow through a subglacial aquifer/permeable pathway, 4 - flow in an arborescent channel system, 5 - flow in a linked cavity network, 6 - flow in a canal system, 7 - flow within a thin basal water film. Figure from Fountain and Walder (1998). 
Storage of water occurs in a glacier when melt water, rain, or flood water inputs increase at a rate greater than the glacier drainage system can transmit. Englacial and subglacial storage takes the form of filled crevasses and cavities, backlogged conduits and channels, water films, and water in the pore space of the glacier bed or subglacial aquifers (Jansson et al., 2003). Given a large enough input of water supraglacial and subglacial lakes can form in zones of poor hydraulic connectivity (Jansson et al., 2003).

\subsection{Glacier Dynamics}

Glacier motion can be partitioned into three parts: deformation of the ice, deformation of the bed, and sliding of the ice over the bed (Patterson, 1994), the bed being the material subjacent to the glacier. These flow components are presented schematically in Figure 2.7. The dominant mechanism of glacier flow over hard and soft beds is via ice deformation and bed deformation, respectively, while glacier sliding can occur over either type of bed (Patterson, 1994).
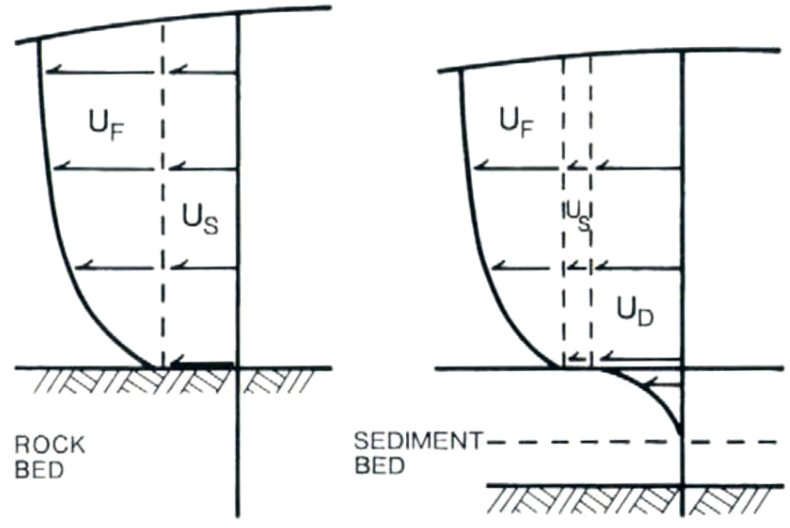

Figure 2.7: Components of glacier motion in a temperate glacier with a rock (hard) bed and a sediment (soft) bed. $U_{F}$ and $U_{D}$ are the glacier motion from ice and bed deformation, respectively. $U_{S}$ is the glacier motion from sliding. This diagram assumes a constant rate of ice supply causing the soft bedded glacier to be thinner due to its higher net motion. Figure from Boulton (1996).

The surface slope and weight of glacial ice is the driving force of basal glacier motion. This driving force is often referred to as basal shear stress when considering the force balance at the glacier bed. The basal shear stress is heterogeneous due to variations in bed strength and glacier sole composition. It is opposed by basal drag which can be enhanced by locally or globally resistive regions of the glacier margins and reduced by basal lubrication or decoupling of the glacier sole from its bed (Patterson, 
1994).

Two mechanisms of hard bed sliding are regelation and enhanced creep. Regelation follows from the migration and subsequent refreezing of melt water produced on the stoss side of small bedrock bumps as it rounds the bump and enters its lee (Patterson, 1994). Enhanced creep results from high basal shear stresses on the stoss face of large bedrock bumps promoting ductile ice flow (Patterson, 1994).

Deformation of the bed occurs by the top-down shearing of subglacial till by glacier motion. Major displacement results only above the yield stress of the till, this being reduced by high water pressures in the sediment pores (Patterson, 1994). Subglacial flooding can cause large swaths of the glacier bed to yield. However, when water volumes are sufficient to drown the bed, basal shear stresses become focused to bedrock bumps and hard-bed sliding forms the basis of basal glacier motion (Patterson, 1994).

The sliding of a glacier over its bed is governed by stress, friction, and contact area. These dependencies are captured in the simple sliding law describing basal slip:

$$
U_{S}=k \frac{\tau_{b}^{p}}{N^{q}}
$$

Here $U_{S}$ is the basal sliding velocity of the glacier, $\tau_{b}$ is the basal shear stress, $N$ is the effective pressure at the ice-bed interface $\left(N=\rho_{i}-\rho_{w}\right.$, i.e. the difference between ice overburden pressure and subglacial water pressure), and $k, p$, and $q$ are all empirical parameters (Patterson, 1994).

Increased basal shear stress and greater basal lubrication, represented by $\tau_{b}$ and $k$ in Equation 2.1 respectively, can both cause rapid basal sliding. However, it is often the effective pressure that controls transient glacier velocity changes, especially when the average basal water pressure sits near the ice overburden pressure in a hydraulically well-connected subglacial environment (Sugiyama, 2011). Here the basal water pressure acts to effectively decouple the glacier from its bed when it approaches the ice overburden pressure across the full glacier sole. The result is an unbounded velocity, i.e. $\mathrm{U}_{S} \rightarrow \infty$ when $N=0$ in Equation 2.1. However such unbounded velocities have not been observed (Table 2.1).

Accelerated sliding from increased basal shear stresses, greater basal lubrication, and near-zero effective pressures can result from the flooding of a subglacial drainage system. When large volumes of water enter a subglacial system the water film, a thin 
and widespread layer of water at the ice-bed interface, and cavities expand (Patterson, 1994). Thickening of the water film promotes basal lubrication and ice-bed decoupling by submerging small bed protrusions and focusing basal shear stresses onto bedrock bumps (Patterson, 1994). The resulting high pressure exerted on the stoss side of the bedrock bumps promotes rapid enhanced creep over the bumps and water migration into the cavities in the lee of the bumps (Patterson, 1994). As the cavities fill the effective pressure at the glacier sole reaches its minimum (Benn and Evans, 2010), thus allowing accelerated basal motion by the combination of these three factors. However, for the bed to be truly decoupled and a runaway glacier acceleration to occur the effective pressure would need to be zero or below at every point on the bed. Some parts of the bed may not be available for cavitation or bedrock bumps may be too large to inundate, meaning that parts of the bed are always either hydraulically isolated or in such a state that they act as sticky spots (Iken, 1981). Similarly stress coupling between fast and slow ice will also retard glacier motion, effectively spreading glacier velocities spatially and limiting them overall (Patterson, 1994).

Above a certain rate of drainage the water film and linked cavity system that allows the accelerated sliding will develop into an arborescent, channelised drainage system (Iken 1985; Schoof, 2010). The higher the rate of subglacial discharge, the more dramatic this shift will be (Schoof, 2010). Channels do not cause uplift of the glacier sole or lubrication of the bed due to their sparse distribution and low water pressures and as such the development of a channelised drainage system will inhibit accelerated sliding (Schoof, 2010; Sundal et al., 2011). After channelisation, transient high magnitude water inputs can cause passing episodes of accelerated sliding, if their input is sufficient to overwhelm the subglacial drainage system (Bartholomew et al., 2010).

\section{Accelerated Sliding}

A synthesis of the theory and observations of accelerated sliding is presented in Table 2.1. To summarise, accelerated sliding is initiated by the flooding of the subglacial drainage system (Iken and Bindschadler, 1986). Subsequently subglacial film expansion and cavitation lubricate the glacier sole and decouple it from the bed (Horgan et al., 2015). As the cavities expand the glacier lurches forward (Harper et al., 2007). Cavity expansion wanes as drainage systems become developed and glacier velocity drops steeply due to the subsequent increase in effective pressure at its sole (Bartholomew et al., 2010). Cavities then collapse as their entrained water is routed towards nearby channels (Kamb, 1987; Schoof, 2010). Water that is unable to be drained efficiently can spread across the glacier bed, maintaining the flooded 
nature of small protrusions, and raising glacier velocities for days to weeks after the subglacial flooding (Harper et al., 2007). If channelised drainage systems become entrenched following flooding (due to continued high water flux) glacier velocities can be reduced for weeks to months (Zwally et al., 2002, Bartholomew et al., 2010; Sundal et al., 2011).

In ice streams accelerated sliding occurs during cavitation (Bartholomew, 2010; Sole et al, 2011; Doyle et al., 2015; Das et al., 2008) but in these systems cavitation can be a relatively minor influence compared to the gross lubrication of the glacier bed (Sundal et al., 2011; Siegfried et al., 2016). In ice streams it is the resultant increase in basal water pressure, often over a soft and saturated bed (Engelhardt et al., 1990), that promotes the triggering of accelerated sliding episodes. 


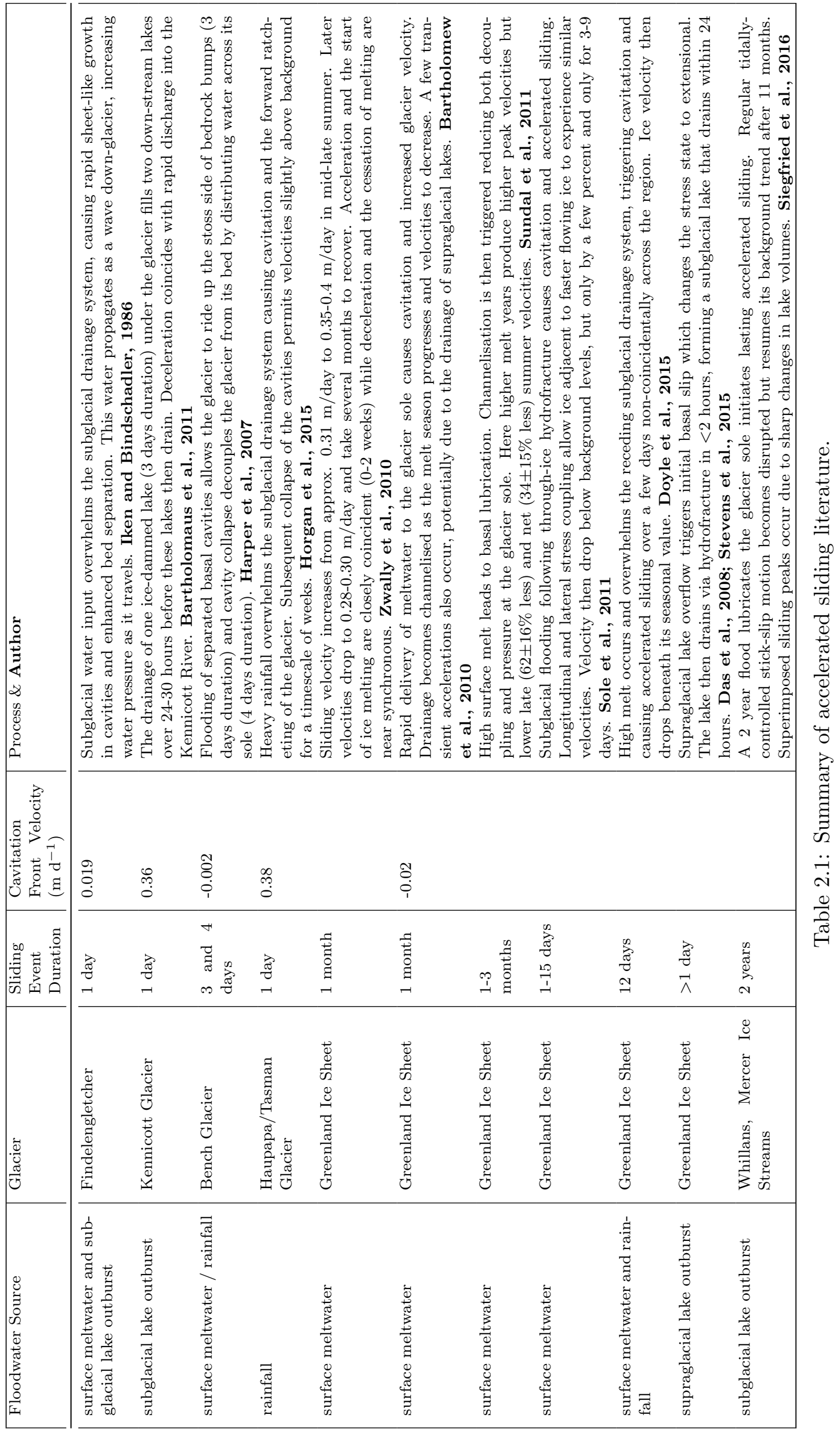




\subsection{Glacial Seismicity}

In the following section I summarise relevant glacial seismicity literature to describe typical waveform characteristics and sources. Prior to this I provide a summary of the general seismic structure of a temperate glacier, including the effects of temperature and pressure changes.

The theoretical compressional $(\mathrm{P})$ and shear $(\mathrm{S})$ wave velocites in a temperate glacier are $3795 \mathrm{~m} \mathrm{~s}^{-1}$ and $1915 \mathrm{~m} \mathrm{~s}^{-1}$, respectively (Kohnen, 1974), and $\mathrm{P}$ wave velocities discerned from explosive shots are between $3600 \mathrm{~m} \mathrm{~s}^{-1}$ and $3800 \mathrm{~m} \mathrm{~s}^{-1}$ (Deichmann et al., 2000; Walter et al., 2009; Dalban Canassy et al., 2013). Rayleigh waves are generated by sources within one wavelength of the glacier surface (Deichmann et al., 2000), suggesting that glaciers have a velocity structure akin to a homogeneous halfspace (Stein and Wysession, 2002). As the quality factor of ice is very low (Podolskiy and Walter, 2016) the high frequency content of waves propagating through glaciers is rapidly attenuated (Stein and Wysession, 2002). A simple seismic model of a temperate glacier is a homogeneous halfspace of ice that is isotropic, has no porosity, and is at a constant temperature throughout.

\section{Crevassing Seismicity}

Crevasses are elongate fissures exposed at the surface of a glacier. A condition of their formation is extensional stress between adjacent sections of a glacier (Van der Veen, 1998). When the extensional stress at a point in the glacier exceeds the ice fracture toughness a crevasse is formed (Van der Veen, 1998). The mechanism of crevasse formation is crack tip propagation: an existing crack is broken initially and then repeatedly propagates downwards until the stress intensity at its tip is balanced by the lithostatic stress of the ice (Van der Veen, 1998). For extensional stresses typical of a glacier, the required initial crack size for crevasse formation is only a few centimetres (Van der Veen, 1998). Van der Veen (1998) suggests that crevasse width increases as the square of the stress intensity, meaning that crevasses will grow rapidly laterally as they penetrate downward under increasing stress intensities.

Seismic observations of crevasse opening, or crevassing, were among the first studies of glacial seismicity (Neave and Savage, 1970). The vertical-component waveform observed due to crevassing is often dominated by a Rayleigh wave with a weak (potentially unobservable) body wave arrival preceding it (Figure 2.8), especially at great distances from the source or when the source is shallow (Neave and Savage, 
1970). Later studies revealed that the Rayleigh wave is not generated by sources deeper than one wavelength (Deichmann et al., 2000).

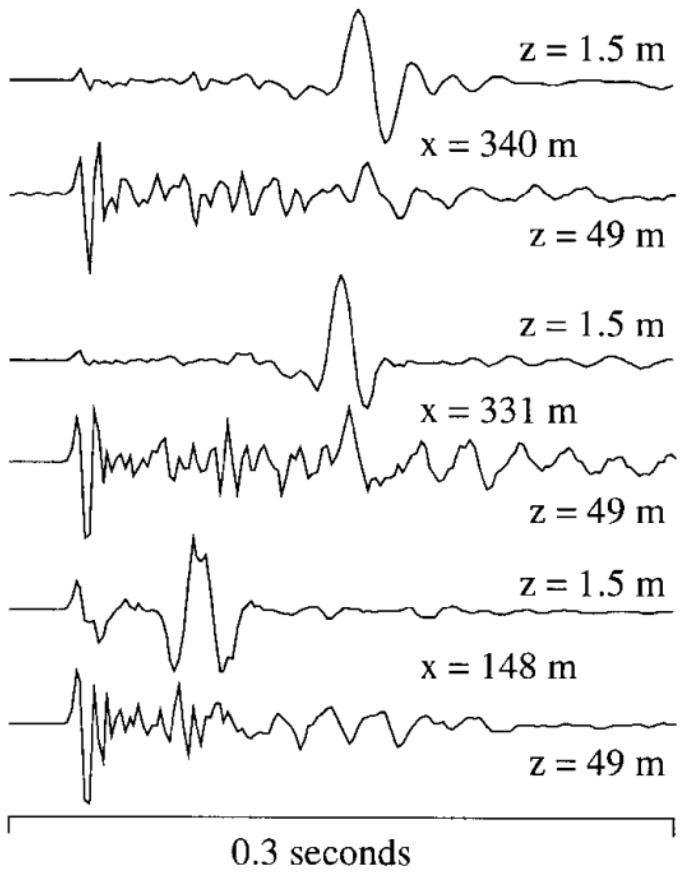

Figure 2.8: Vertical component seismograms from shallow and deep events for distant (top, middle) and nearby (bottom) seismic sensors. Here $\mathrm{z}$ is the source depth and $\mathrm{x}$ is the epicentral distance. The shallow event is inferred to be from crevasse opening with the dominant phase being the Rayleigh wave. The deep event is an icequake signal from failure near the glacier bed. Note the reduction in $\mathrm{P}$ wave to Rayleigh wave amplitude with increasing epicentral distance. Figure from Deichmann et al. (2000).

The work of Neave and Savage (1970) demonstrated crevassing exhibiting swarm-like seismicity: similar-magnitude events migrating along a linear path closely spaced in time. Those authors attributed this to the opening of a new crevasse. Roux et al. (2010) and Mikesell et al. (2012) observed similar trends in crevasse opening and noted elevated rates of seismic event detection associated with increases in surface strain rate following basal water inputs.

\section{Calving Seismicity}

Calving is the loss of ice due to fracture at the glacier terminus and margins. This fracturing is enhanced in glaciers with a strong terminal velocity gradient, and in glaciers with a proglacial water body (Benn and Evans, 2010). Each of these features promotes the forces required for fracture propagation and hence calving, though the form of calving can vary between small subaerial collapse and total detachment of the terminal front (Benn and Evans, 2010). 


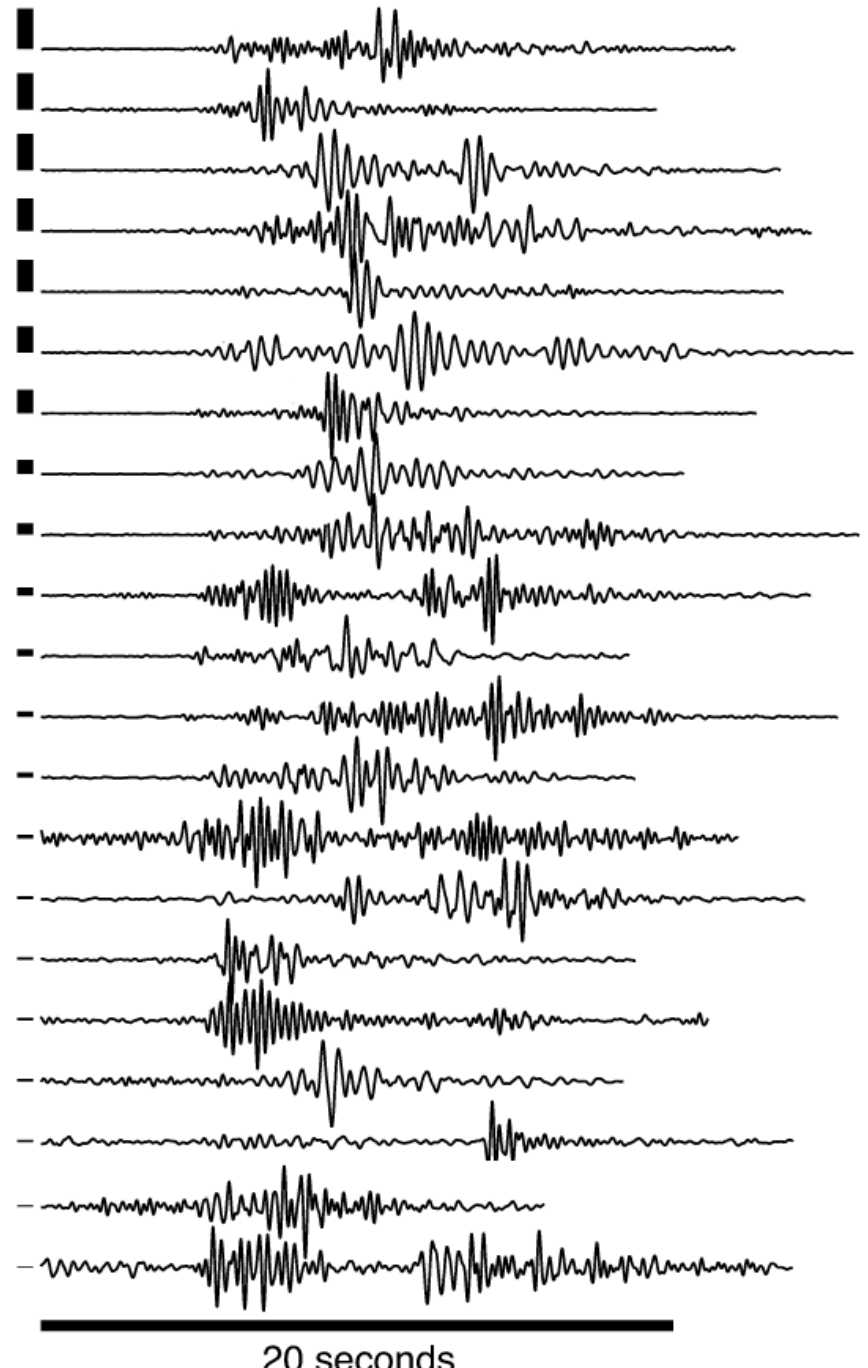

Figure 2.9: Vertical component seismograms from subaerial calving events in the $1-5 \mathrm{~Hz}$ frequency band. Seismograms are normalised with relative amplitude represented by the size of the corresponding black bar. Figure adapted from Bartholomaus et al. (2012).

The seismic signature of calving is typically that of an emergent, long-duration, and predominantly low-frequency waveform, as observed for a number of subaerial calving events in Figure 2.9 (Wolf and Davies, 1986; Qamar, 1988). O'Neel et al. (2007) found crevassing events at Columbia Glacier to be emergent, of several minutes duration, monochromatic within the 1-3 Hz frequency band, and distributed near the glacier terminus in a predominantly along-flow trend. They also observed terminal crevassing in the $10-20 \mathrm{~Hz}$ frequency band occurring mainly transverse to flow, which they suggest is a precursor process to iceberg generation via calving. Bartholomaus et al. (2012) also observed calving waveforms in the 1-3 Hz frequency band. These authors interpret the source of this seismicity as interactions between calved icebergs and the water surface. Compared to this ice-water interaction the iceberg calving itself produces relatively weak waveforms in the $5-20 \mathrm{~Hz}$ frequency band (Bartholomaus et al., 2012). 
Dry calving (also known as serac collapse) produces a similar waveform to waterbased calving. Roux et al. (2008) observed serac collapse producing high-amplitude waveforms with durations longer than 10 seconds and frequencies of 1-4 Hz at Glacier d'Argentière. They suggested that these waveforms are either composites of small events (formed from ice falling on the glacier or rock after serac collapse) or are from the opening and widening of crevasses that split the glacier into seracs. Jónsdóttir et al. (2009) observed similar waveforms emanating from the dry calving of a steep outlet glacier in Iceland where an unclear onset is followed by a $0.3-8$ second long low-amplitude coda in which a $\mathrm{P}$ phase arrives.

\section{Icequakes}

Icequakes are the seismicity that is distinct from crevassing and calving. Typically such seismicity is associated with englacial and subglacial crack opening and closing as well as basal stick-slip. The concept of cracking in a glacier follows from the earlier description of crevassing: local stresses become greater than the ice fracture toughness and opening (or closing) occurs (Van der Veen, 1998). Basal stick-slip results from the rapid release of progressively loaded basal shear stresses at an asperity, a scenario that arises from the continuous slip of ice surrounding the asperity but the relative stagnation of ice over the asperity (Fisher and Clarke, 1997; Winberry et al., 2011).

\section{Basal Stick-Slip}

The general case of basal stick-slip is that which occurs without an external forcing such as increased basal water pressures or tides. The study of Roux et al. (2008) presents the seismicity of basal stick-slip events beneath a temperate alpine glacier as measured by a seismic array in bedrock near the ice-bed interface. At these basal depths the $\mathrm{P}$ and $\mathrm{S}$ wave were indistinguishable and the authors assumed their recorded waveforms to be dominantly $\mathrm{S}$ waves, these having durations of $\sim 0.1$ seconds and frequency content in the 10-40 Hz band. Clusters of stick-slip events were located and consisted of icequake multiplets, a result that lead the authors to conclude that a repeating source process at similar locations was required, and that the distribution of these clusters could represent frictional inhomogeneities at the glacier bed. Smith (2006) found families of basal-slip events occurring beneath Rutford Ice Stream with consistent interevent times within each family. Frequencies of the observed waveforms were upward of $50 \mathrm{~Hz}$ and sources were assumed to be low porosity zones on the bed where ice-bed friction was sufficient to accumulate basal shear stresses. 
Basal stick-slip is often triggered or modulated by external forcings such as increased basal water pressures and tidal cycles (Fisher and Clarke, 1997; Ekström et al., 2006; Wiens et al., 2008; Winberry et al., 2011; Zoet et al., 2012; Winberry et al., 2013). These external forcings promote stick-slip glacier motion by either lubricating the glacier sole (increased basal water pressure) or reducing the backpressure at the glacier terminus (tidal cycles). Wiens et al. (2008) found repeated rupture of Whillans Ice Stream over a basal asperity was tidally modulated with rupture velocity, slip velocity, and seismic wave amplitude correlating with tidal amplitude (Wiens et al., 2008; Winberry et al. 2011). Winberry et al. (2013) found families of waveforms from these stick-slip events on Whillans Ice Stream (Figure 2.10) with the occurrence rate of events in these families being correlated with the local ice stream velocity. Typical frequency content of these stick-slip event families is from $1 \mathrm{~Hz}$ to upwards of $40 \mathrm{~Hz}$ (Winberry et al., 2013). Zoet et al. (2012) identified a similar process at an Antarctic outlet glacier where repeated rupture of a basal asperity was formed by debris-laden ice moving over a rough bed. Here they found falling tides reduced interevent times and greater event magnitudes occurred when interevent times were longer, this suggesting the reaccumulation of basal shear stresses between slip episodes. However when interevent times were long event magnitude did not increase beyond a certain value. The authors interpret this as the result of aseismic slip caused by debris-free ice sliding over the asperity. If interevent times are sufficiently small the resultant waveform can be harmonic (Figure 2.10) as is observed by Winberry et al. (2013). Here the fundamental frequency of the waveform is the event repeat rate and the higher frequency content is integer overtones of this frequency. Gliding spectra may result from changes in the interevent time, a property that is controlled by the overriding glacier velocity (Figure 2.10). 

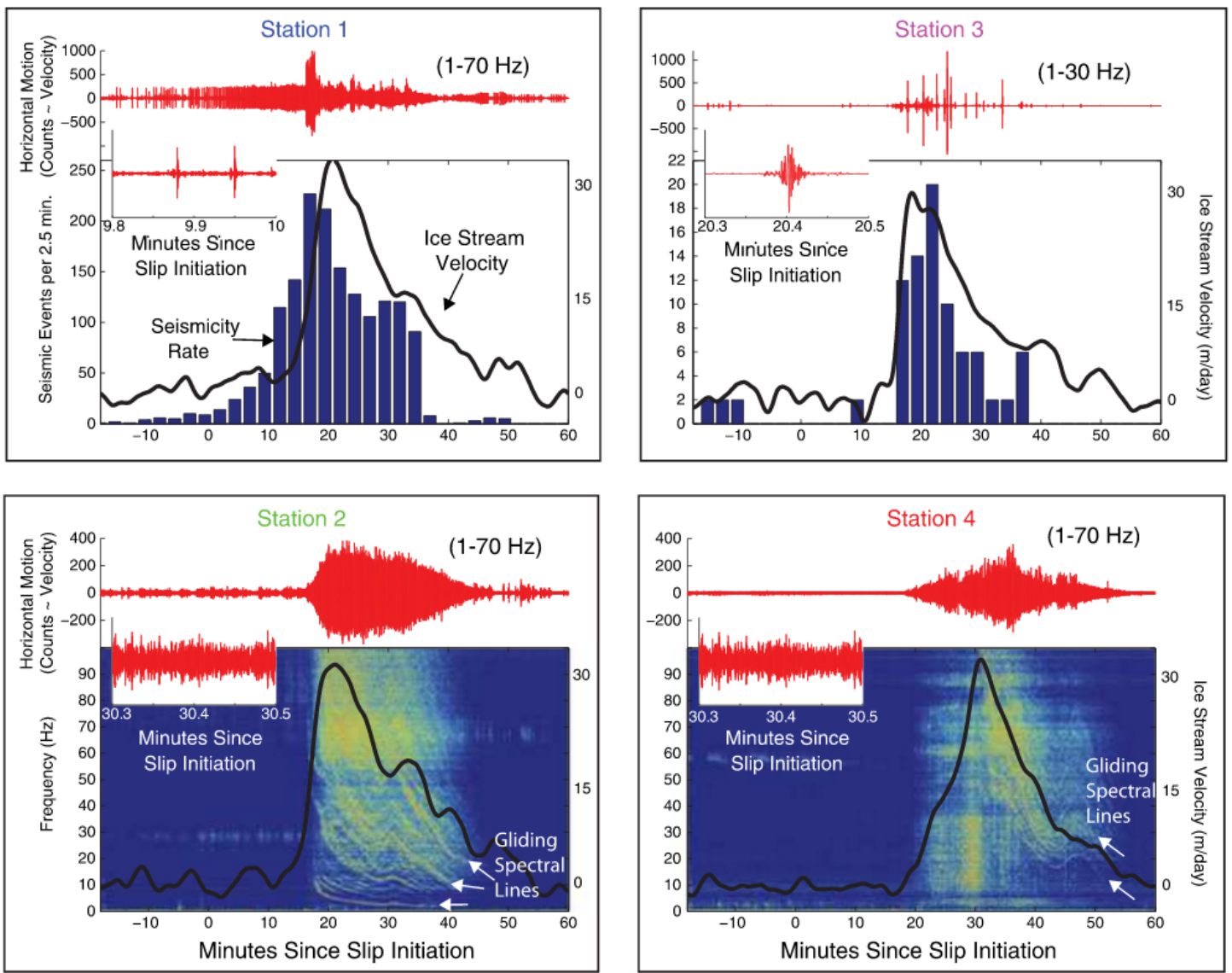

Figure 2.10: Seismic signal observed due to repeated rupture of four separate basal asperities. Insets show 0.2 minutes of data. Top and bottom subplot lower panels have seismicity rate and spectrograms overlain with glacier velocity, respectively. White arrows point to the termination of gliding spectral lines in the spectrograms. Figure from Winberry et al. (2013).

\section{Deep Cracking}

Deep cracking, the opening and closing of cracks below the surface crevassing zone, is often observed as one of three types of waveform: 1) high frequency impulsive waveforms with $\mathrm{P}$ and $\mathrm{S}$ waves resembling those of tectonic seismicity, 2) initially impulsive waveforms with low frequency tails (hybrid events), and 3) purely resonant waveforms (Figure 2.11). Resonant waveforms are often associated with fluid resonance in cracks in the glacier while hybrid events are a combination of crack opening and subsequent resonance following the rush of fluid into the crack (Metaxian et al., 2003; Stuart et al., 2005; West et al., 2010). The peaked spectral nature of the resonant waveforms is their distinguishing factor (Figure 2.11). The results of West et al. (2010) suggest a continuum exists between purely resonant waveforms and purely impulsive waveforms formed by the relative importance of crack opening to fluid-driven resonance in the waveform source (Metaxian et al., 2003; Stuart et al. 2005; West et al., 2010). The position of a waveform on this continuum is described 
by its dominant frequency as seen in Figure 2.11 (West et al., 2010). While these waveforms can be caused by a source anywhere in a glacier they are most often observed as coming from the ice-bed interface (Metaxian et al., 2003; Stuart et al., 2005; West et al., 2010; Hammer et al., 2015). Here the stresses or water pressures can reach states sufficient to force cracks open or direct water into existing cracks (Hammer et al., 2015).

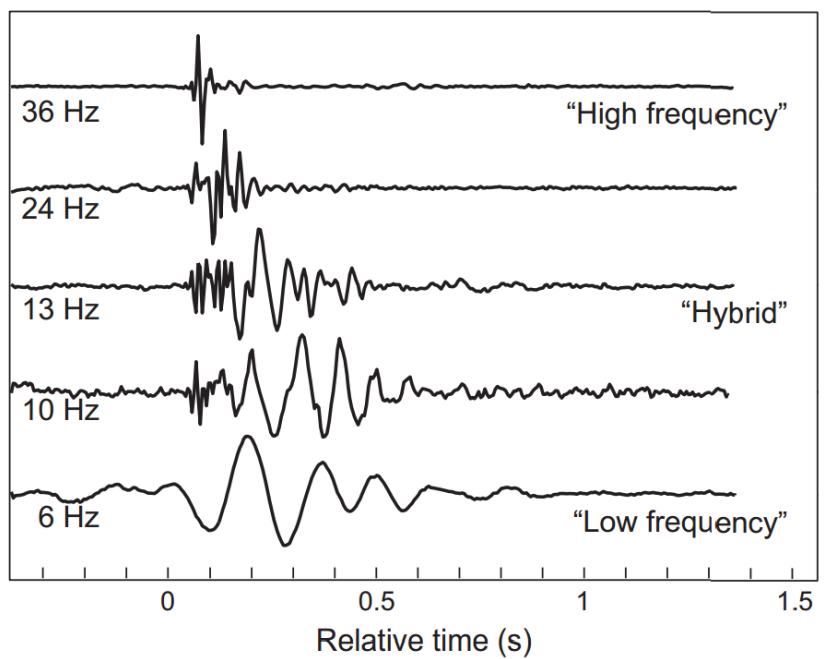

Figure 2.11: Deep seismic event classes with dominant frequency shown to the left of each waveform. Figure from West et al. (2010).

Impulsive seismicity resembling tectonic earthquakes (Figure 2.12) is a challenge of glacial seismicity characterisation due to the often indistinguishable nature of basal slick-slip and deep cracking waveforms, something that makes the interpretation of seismic sources questionable when focal spheres are not well resolved (Walter et al., 2013). Walter et al. (2008) and Dalban Canassy et al. (2013) both find basal cracking events occurring near the glacier sole at localities of a steep ice-bed interface. Here the seismic source is assumed to be extensional cracking due to the single polarity nature of the icequake first motions. This follows increased deformation rates after accelerated sliding and cavitation. Walter et al. (2013) suggest the source of basal extensional crack opening and closing is from the recoupling of the glacier sole to its bed following cavitation. Here crack opening follows the drop in water pressure during cavity drainage, a process that induces suction on the overlying ice and increases its vertical strain to the point of failure, while crack closing occurs when the glacier sole effectively collapses, rapidly sealing a cavity off from the subglacial drainage system. This rapid collapse creates a pocket of high pressure water that can force open fractures in the overlying ice shut as the glacier sole continues to recouple to the bed. This theory requires an existing damage zone at the glacier sole consisting of cracks well-oriented for opening and closing. Hence clusters of 
basal cracking form in zones of high deformation rate, these being steep slopes of the glacier bed or zones of high water pressure variation such as in the lee of cavities (Walter et al., 2008; Walter et al., 2013).

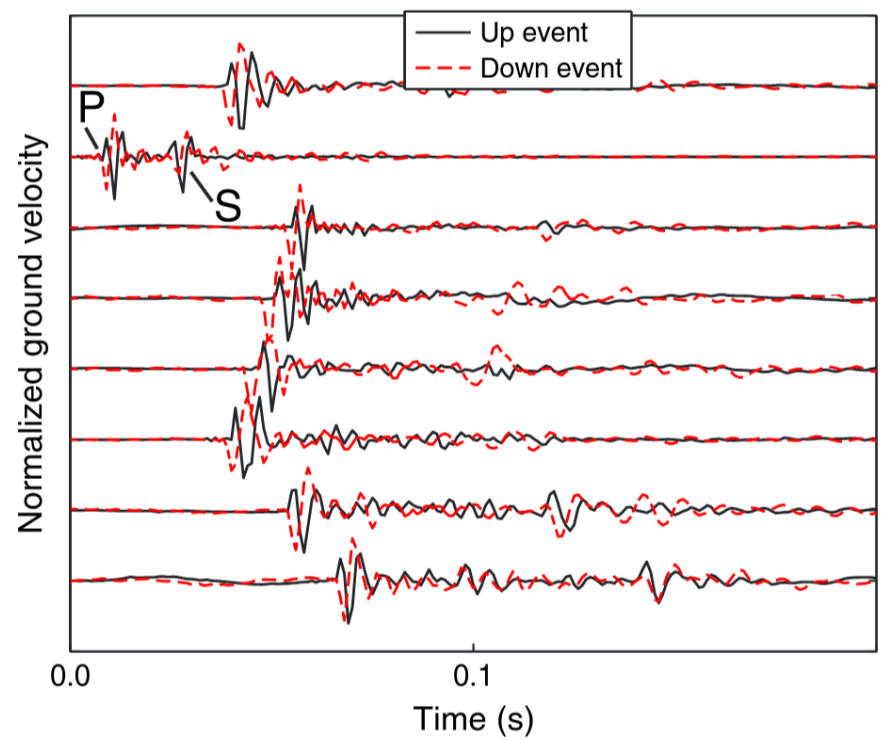

Figure 2.12: Vertical component seismograms of two basal cracking events. The "Up event" has compressional first arrivals indicative of extensional crack opening while the opposite is true for the "Down event". P and S phases are labelled for the first arriving station. Both events are located within the same cluster, but likely originate from different cracks seen in the small differences in their waveforms. Figure from Walter et al. (2013).

\section{Water Flow}

Water flow in a glacier, as well as increasing the noise floor in seismogram recordings (Metaxian et al., 2003), can cause observable tremor. Winberry et al. (2009) record tremor episodes on MacAyeal Ice Stream with durations of approximately 10 minutes and waveform frequency content of $3 \mathrm{~Hz}$. Their inferred tremor source is the drainage of a subglacial lake. The drainage is interpreted as occurring through a 10 $m$ wide basal crack parallel to ice flow that, following excitation by repeated crack tip propagation, exhibits flow-transverse resonance. Bartholomaus et al. (2015) observe something similar, although much simpler: a correlation between subglacial discharge and 1.5-10 Hz tremor amplitude at Mendenhall Glacier. Here the tremor source is inferred as the drag of turbulent water against a rough bed during flow. Yet another tremor source, that of Heeszel et al. (2015), is from water resonance in an englacial crack (Figure 2.13). These authors found that this tremor appeared as both stepped gliding harmonic tremor and continuously increasing high frequency tremor. In the former case stepped decreases in tremor frequency are associated with the sudden expansion of a water-filled basal crack via hydrofracture, while gliding spectral decay is though to be due to slow crack growth from frictional melt- 
ing. The continuously increasing high frequency tremor is formed by repeated basal crack closure. The short time between discrete closure events gives this the appearance of continuous resonance as each successive event shrinks the crack further, thus increasing the resonance frequency.
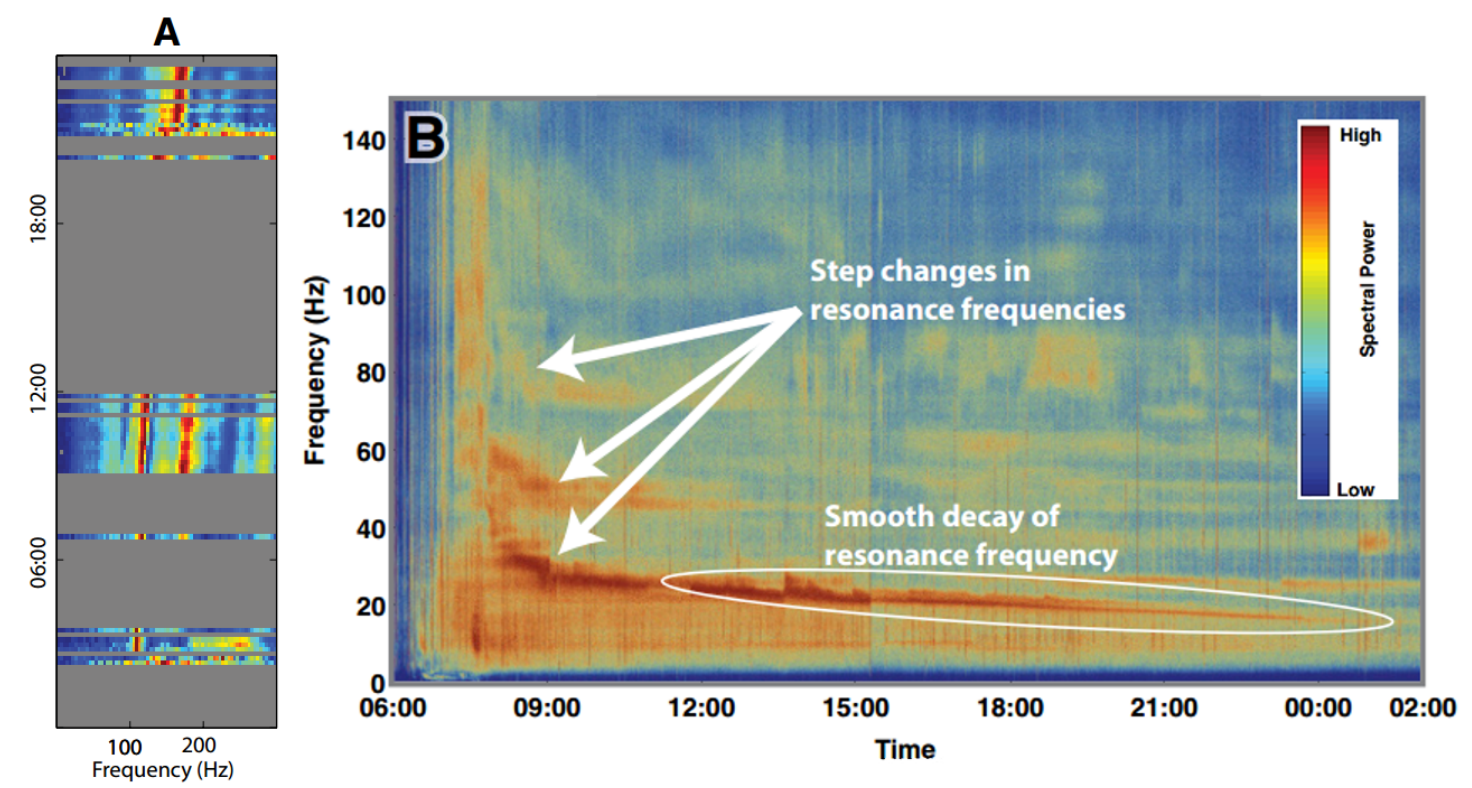

Figure 2.13: Tremor formed by crack closing, A, and crack opening, B. Crack closing occurs via discrete events in a cluster of icequakes (punctuated record) while crack opening is a continuous signal. Spectra in $\mathbf{A}$ are averaged over 10 minute bins with grey areas showing quiet periods. Spectra both $\mathbf{A}$ and $\mathbf{B}$ are from a sliding Fourier transform of 30 s time windows with $50 \%$ overlap. Figure from Heeszel et al. (2015).

A similar signal to gliding harmonic tremor associated with water flow or rapid repeated basal slip is that of helicopters (Eibl et al., 2015). Eibl et al. (2015) studied the seismic signature of a moving helicopter to distinguish it from volcano-related tremor (Figure 2.14). These authors found that the observed harmonic frequencies were overtones of the fundamental frequency of the helicopter's main blade rotation; this being the product of the rotation frequency and the number of blades. Eibl et al. (2015) also noted that the gliding nature of this signal follows from the Doppler effect: an advancing (retreating) source will exhibit an increasingly higher (lower) frequency signal with an inflection in its frequency as it passes the seismic sensor, here showing its fundamental frequency without distortion. Observed waveforms from this source consist of Rayleigh waves formed from sonic waves transmitted into the ground via atmospheric coupling (Eibl et al., 2015). The amplitude of these waves is not peaked when the source is closest to the receiver, but rather at the geometries for which atmospheric coupling is greatest (Eibl et al., 2015). 

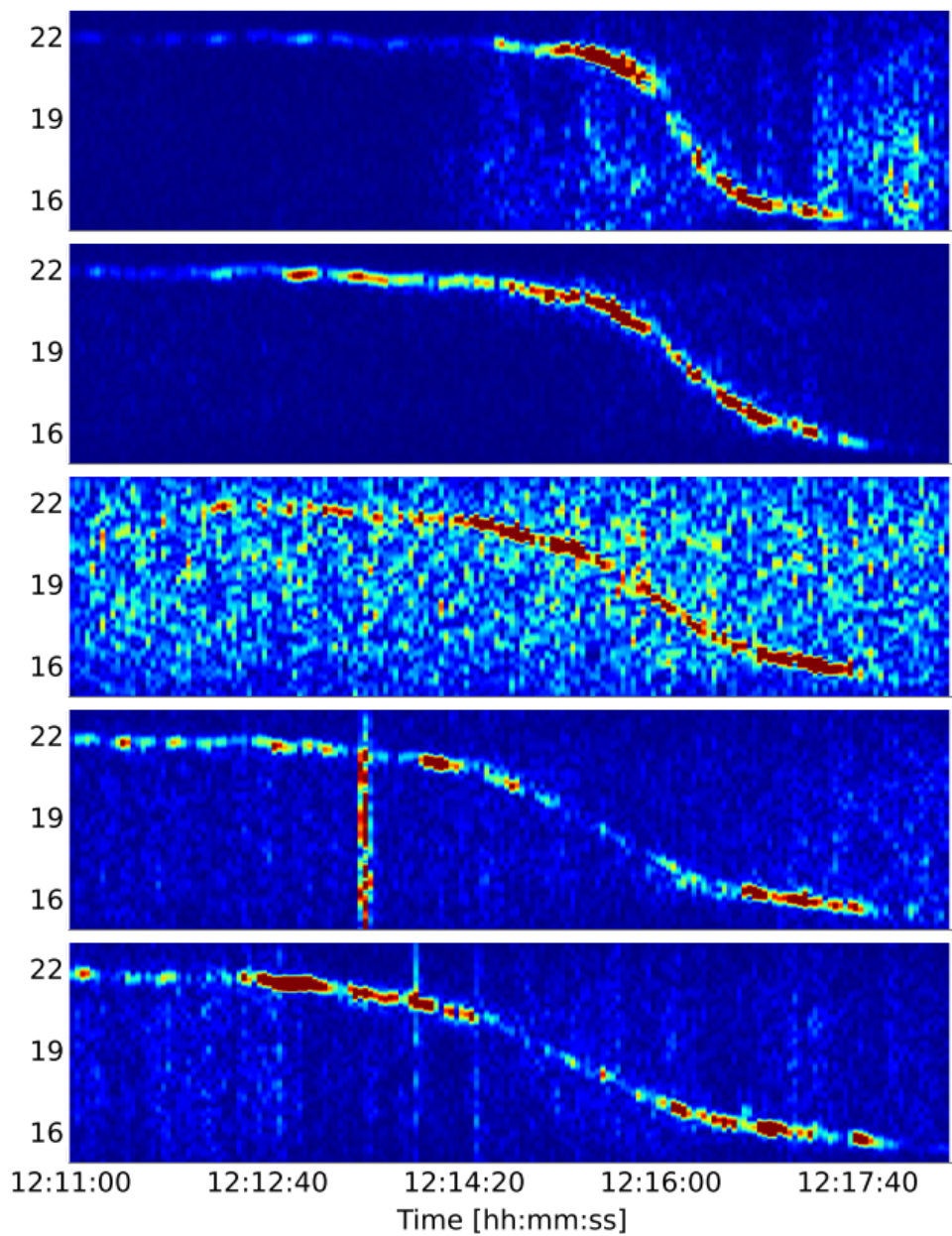

Figure 2.14: Vertical component spectrogram of five stations filtered between $15-23 \mathrm{~Hz}$ showing gliding harmonic tremor caused by the advance and retreat of a helicopter. Colour denotes relative power: blue is low and red is high. $\mathrm{Y}$-axis is seismogram frequency content in Hz. Figure from Eibl et al., 2015.

\section{Summary}

Glacial seismicity exhibits a broad range of waveforms resulting from similar processes in many different settings. The present phases, frequency range, dominant frequency, arrival impulsivity, and waveform length are all characteristics that define categories of this seismicity. As such it is possible to discern one glaciogenic waveform from another, thus allowing glacial process to be identified and studied directly from observable seismicity. 


\section{Chapter 3}

\section{Methods}

\subsection{Instrument Network (RISSIN)}

The Rain-Induced Seismogenic Sliding of Ice Network (RISSIN: summary data available in Table 3.2) was designed to complement an existing deployment of Global Navigation Satellite System (GNSS) sensors (Figure 3.1). Technical details of seismic sensors used are presented in Table 3.1. The GNSS sensor network used in this study was an expansion of that used by Horgan et al. (2015) to study the velocity variability of Haupapa/Tasman Glacier.

The naming convention of RISSIN is in two parts. For on-glacier stations the letter describes the position of the station relative to the flow-direction: $\mathrm{L}$ (true left), $\mathrm{C}$ (centre), $\mathrm{R}$ (true right), and the number describes the relative position of the station up-glacier from those of the same letter. For moraine (M) stations the number describes the relative position of the station clockwise from the flow direction of the glacier.

Five L-28 3-component geophones were collocated with the existing GNSS network and one L-28 3-component geophone was located in the planned position of a sixth GNSS sensor (TSNC1, TSNC3, TSNL2, TSNL3, TSNR2, TSNR3). Subarrays were later derived from these seismic sensors: the upper subarray (TSNL3, TSNR3, TSNC3) and the lower subarray (TSNL2, TSNR2, TSNC1). To enhance the low frequency sensitivity of the on-glacier network a T-120 seismometer was established near the network centre (TSNC2). Two planned near-terminus seismic stations were not deployed due to their proximity to the calving front, which had retreated by $>200 \mathrm{~m}$ in a recent calving event (Horgan, pers comms 2015). 
To increase the accuracy of the network for detecting and locating seismicity occurring near the margins of the glacier three seismic sensors were positioned on the adjacent lateral moraine (TSNM1, TSNM2, TSNM3). Here T-120 Compact seismometers were chosen over geophones due to their order-of-magnitude greater sensitivity. A final L-28 3-component geophone (TSNC4) was established near the Ball Glacier and Tasman Glacier confluence to improve location accuracy at the upper extent of the network and to study the seismicity of Ball Glacier, Hochstetter Icefall, and the upper Tasman Glacier. Overall L-28 geophones operated better than T-120 seismometers due to their passive power supply. 


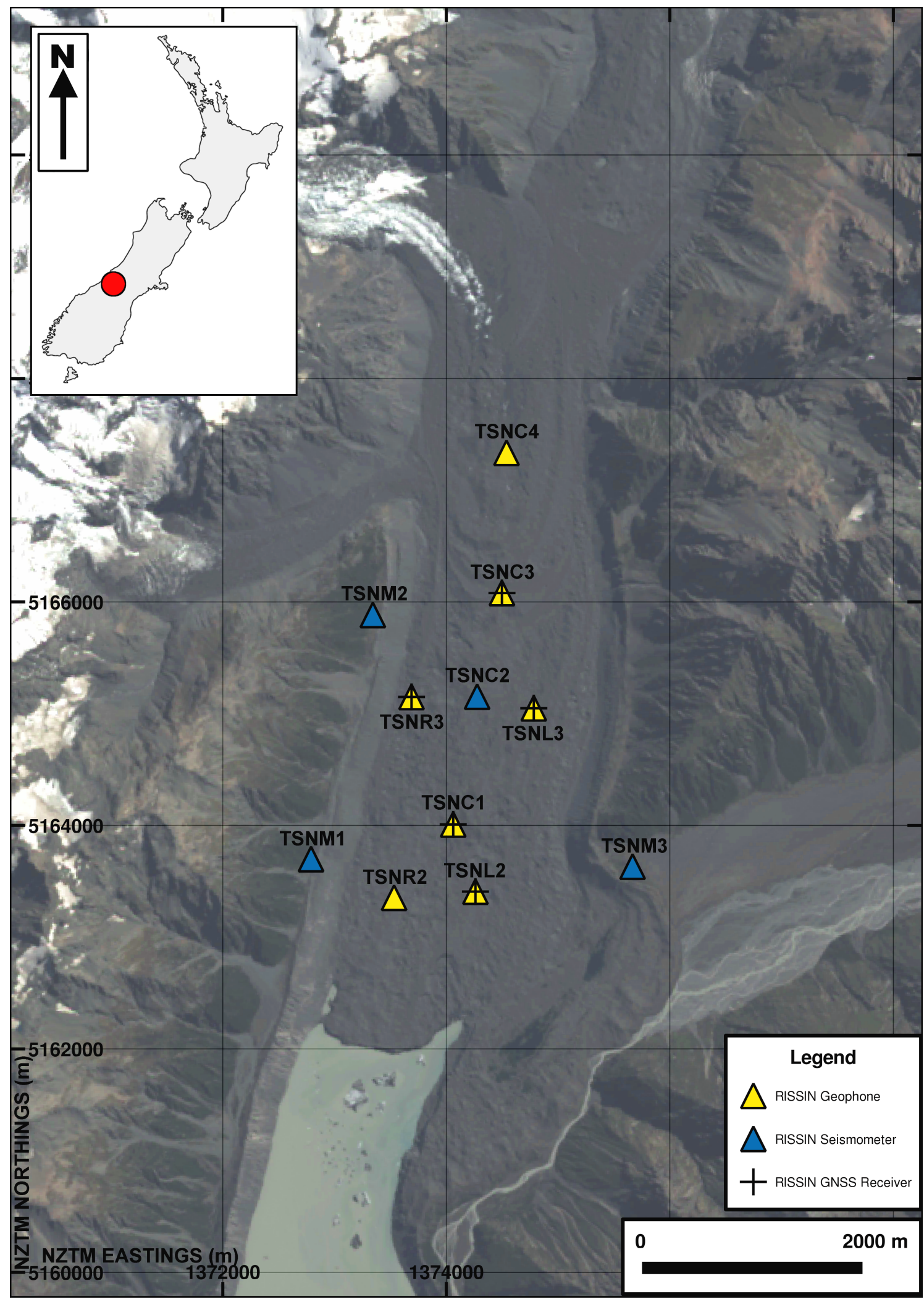

Figure 3.1: Map of all RISSIN seismic and GNSS sensor positions. For geographic feature names and locations see Figure 1.2.

Each RISSIN seismic station was equipped with a seismic sensor, solar panel, data acquisition system (DAS), GPS clock, and $12 \mathrm{~V}$ battery. At those sites where seismic sensors could not be adequately buried, rocks were used to shelter the sensor from 


\begin{tabular}{lll}
\hline & $\mathrm{L}-28$ & T-120 Compact \\
\hline Components & ZNE & ZNE \\
Natural Frequency & $4.5 \mathrm{~Hz}$ & \\
Damping & Critical at 0.7 & \\
Frequency Response & Flat above $10 \mathrm{~Hz}$ & Flat between $0.01 \mathrm{~Hz}$ and $100 \mathrm{~Hz}$ \\
Sensitivity & $30 \mathrm{~V} \mathrm{~m}^{-1} \mathrm{~s}^{-1}$ & $750 \mathrm{~V} \mathrm{~m}^{-1} \mathrm{~s}^{-1}$ \\
\hline
\end{tabular}

Table 3.1: Summary of sensor features for L-28 geophones and T-120 seismometers.

surface exposure. Seismic station sampling interval was set at $250 \mathrm{~Hz}$ and timing accuracy was maintained by GPS clocks. Geodetic stations consist of a GNSS receiver on a tripod $>1 \mathrm{~m}$ above the glacier surface, a solar panel, a DAS, and a $12 \mathrm{~V}$ battery. The sampling interval for these stations is $15 \mathrm{~s}$. No infrastructure is shared between the two stations. All sensor timing is in Universal Coordinated Time, a convention adopted for all data processing and results presented in this thesis.

RISSIN data collection began on 18 and 19 April 2016 (day of year 109 and 110) and ended on 23 and 24 August 2016 (day of year 235 and 236). Due to glacier flow all on-glacier stations experienced some displacement over the deployment. This displacement was crudely captured by hourly location measurements made by the GPS clocks of each station. To find a representative location of each on-glacier station the mode of the station positions was taken, this being favoured over other measurements due to its independence of outliers. As on-glacier stations moved around 20 $\mathrm{m}$ over the deployment the approximate location uncertainty is $10 \mathrm{~m}$ for these station positions. Elevations for the on-glacier stations were taken from handheld GPS measurements as these had lower elevation measurement uncertainties than the GPS clock positions. Moraine (off-glacier) station positions and elevations were discerned from high-resolution satellite imagery and digital elevation models using landmarks, photographs, and approximate positions from handheld GPS measurements.

All stations recorded until day 159 when TSNC2 lost power. Data for this station were corrupted, preventing their use in later processing. Further station loss for periods longer than a few days did not occur until after day 201. As seismic and GNSS stations had separate power supplies their periods of downtime are not always synchronous during these punctuated periods of power loss. Power loss results from: low sun angle and topographic obstructions, solar panel snow cover, and low light during heavy rainfall.

The non-uniform glacier flow and surface ablation beneath on-glacier stations caused rotation and inclination of seismic stations TSNC1, TSNL3, and TSNR3. As orien- 


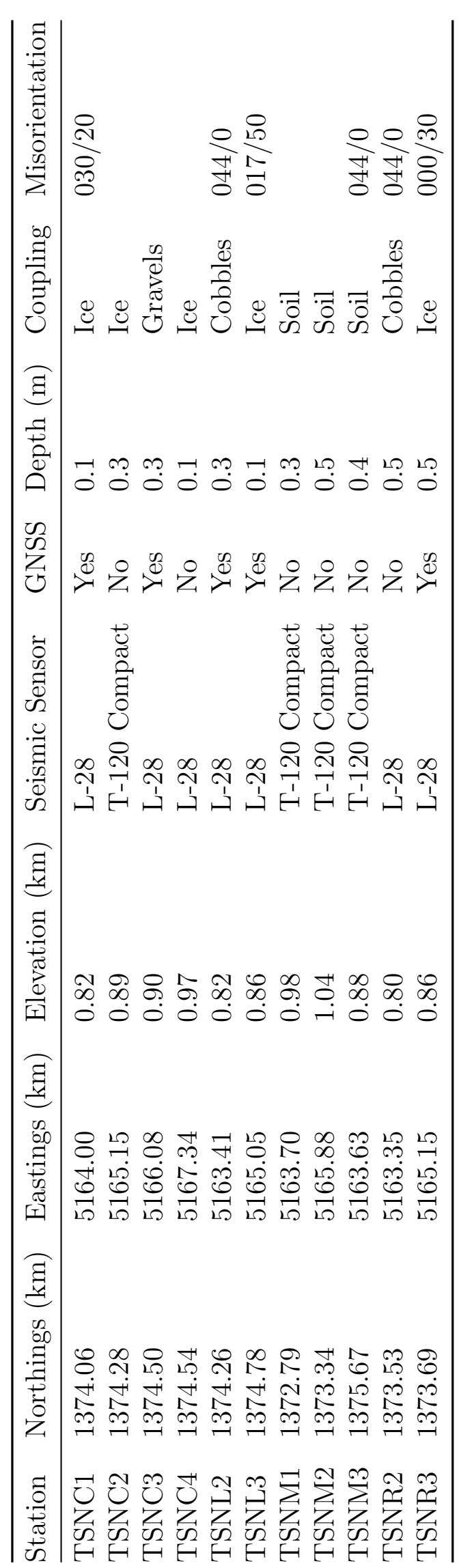


tation measurements were made only at the start and end of the deployment the rate of rotation and inclination for these stations is not known. Thus the misorientation of these sensors cannot be corrected for and introduces an unknown uncertainty to the observations made from their data. The use of vertical component seismograms mitigates the uncertainties stemming from sensor rotation.

Seismic stations TSNL2, TSNR2, TSNM3 were also misoriented (stemming from deployment error and not glacier flow), but retained this orientation over the course of the deployment. The orientation of these stations was corrected during data conversion.

The start and end days of RISSIN data were chosen as day 112 and 201, respectively. Data between these days is far enough from the deployment/collections periods for any anthropogenic noise to be minimal and is before the period of intermittent data loss during the peak of winter. Thus the RISSIN data presented in this thesis consists of 90 days of $250 \mathrm{~Hz}$ three component seismograms.

\subsection{Data Processing}

\section{Seismic Data}

RISSIN seismic station data were converted from 15 minute DAS format data (RefTek binary data with STEIM2 compression) to day-long miniSEED files for each component of each seismic sensor. Data were converted between day 112 and 234. During data acquisition a low-pass filter was applied at the Nyquist frequency $(125 \mathrm{~Hz})$ to avoid aliasing. Following initial data conversion horizontal components of TSNL2, TSNR2, and TSNM3 were rotated counterclockwise by 44 degrees to correct their initial misorientation. Seismic processing of the continuous data is detailed in Sections 3.3-3.6.

\section{GNSS Data}

GNSS data, also referenced to as geodetic data, were processed using combined code and carrier phase location. This technique uses the cross-correlation lag time (phase) between both the code and carrier wave emitted by a satellite of a known position and the same code and waveforms generated internally by the GNSS receiver. The product of the code phase and the speed of light gives the distance between the GNSS 
receiver and the satellite to a few hundred metres accuracy (Subirana et al., 2013). With four or more receiver-satellite distances a linearised inverse problem can be solved iteratively for the receiver position (Subirana et al., 2013). By constraining the non-unique carrier wave lag time with the code phase position uncertainties can be reduced to less than a metre (Subirana et al., 2013). Carrying out the receiver location inversion with lag times relative to those of a GNSS receiver with a known position reduces position uncertainty further (Subirana et al., 2013). The combination of differential receiver location and combined code and carrier phase locations can produce receiver positions with millimetre accuracy. It is this combined approach that is used for processing the geodetic data over the RISSIN deployment.

Position and velocity data were processed for TSNC1 and TSNC3 by Huw Horgan. These stations represent the upper glacier tongue velocity (called upper glacier velocity) and the lower glacier tongue velocity (called lower glacier velocity), respectively. A summary of RISSIN geodetic data processing, as used by Horgan et al. (2015), is:

1. Measurements of phase lags for code and carrier signals were acquired at each receiver. Some data loss occurred during periods of surface snow or sustained rainfall.

2. Reference receiver data were acquired from a GNSS station located on a fixedrock site approximately $11-14 \mathrm{~km}$ from the RISSIN receivers at $30 \mathrm{~s}$ intervals.

3. Receiver location was calculated every $30 \mathrm{~s}$ by differential code phase positioning relative to the reference receiver.

4. Refined receiver positions were calculated every $30 \mathrm{~s}$ by differential carrier phase positioning relative to the base station using loose position constrains from the initial receiver locations.

5. Receiver velocities were calculated using weighted linear regressions of the two-dimensional receiver positions within a number of sampling intervals, each centered on successive times defined by a time step. Positions weights were derived from processing uncertainty estimates, these being representative of satellite coverage at the time of measurement.

Calculating velocities over longer sampling intervals results in timeseries representative of long term trends in glacier velocity, while shorter sampling intervals yield velocities of a higher fidelity. Changes in the time step used during calculation adjusts the smoothness of the data with the smallest possible time step providing the most continuous timeseries. 


\section{Meteoric Data}

Rain rate data was acquired from Mt. Cook Village as a continuous record of hourly rainfall. Though observed over $10 \mathrm{~km}$ from Haupapa/Tasman Glacier, these data are assumed to represent the magnitude and timing of rainfall at the glacier (Henderson and Thompson, 1999). Rainfall observation is made at the end of each hour, a convention that is used in all other hourly data binning.

\section{Lake Level Data}

Lake level data was taken from an atmospherically-coupled pressure transducer located at the southern end of Tasman Lake (Horgan et al., 2015). This instrument sampled the lake level once per minute. Data from this sensor were averaged over hourly bins.

\subsection{Event Detection Algorithm}

To automate the detection of seismicity occurring at Tasman Glacier a short-termaverage (STA):long-term-average (LTA) triggering algorithm was used (Allen, 1978). This algorithm uses the ratio of the average absolute waveform amplitude in two windows of continuous seismic data to discern seismic event onsets and durations. With RISSIN seismic data the parameters (Table 3.3) were set in a "catch-all" mode such that all impulsive seismic events strong enough to be observed across a number of stations (and hence be locatable) were detected and extracted from the continuous data.

The event detection time from the algorithm is used as a proxy for the origin time of the detected event. Timing uncertainty resulting from this assumption is on the order of a few seconds due to the proximity of event sources to the network sensors. As analysis is not carried out on comparable timescales any uncertainty arising from this assumption does not affect the results or conclusions presented in this thesis.

\section{Algorithm Description}

The STA:LTA triggering algorithm (Figure 3.2) uses a continuous calculation of the STA:LTA ratio over data windows of different lengths. The STA window length is 
less than the LTA window length such that each describes the average amplitude of data recorded between the current time and a short (STA) or long (LTA) time before it. Because of this the STA:LTA ratio captures the signal:noise ratio but - as the STA and LTA sample more than just instantaneous seismic amplitudes - it is a more robust and reliable measurement than an instantaneous signal:noise measurement.

When the STA:LTA ratio exceeds a chosen threshold triggering begins (trigger active in Figure 3.2). This triggering continues until the STA:LTA ratio drops below a defined value. Trigger onset times and lengths are analogous to seismic event arrival times and durations at a single station. An expansion of the STA:LTA algorithm was made so that network event detection could be performed by combining these independent station triggers.
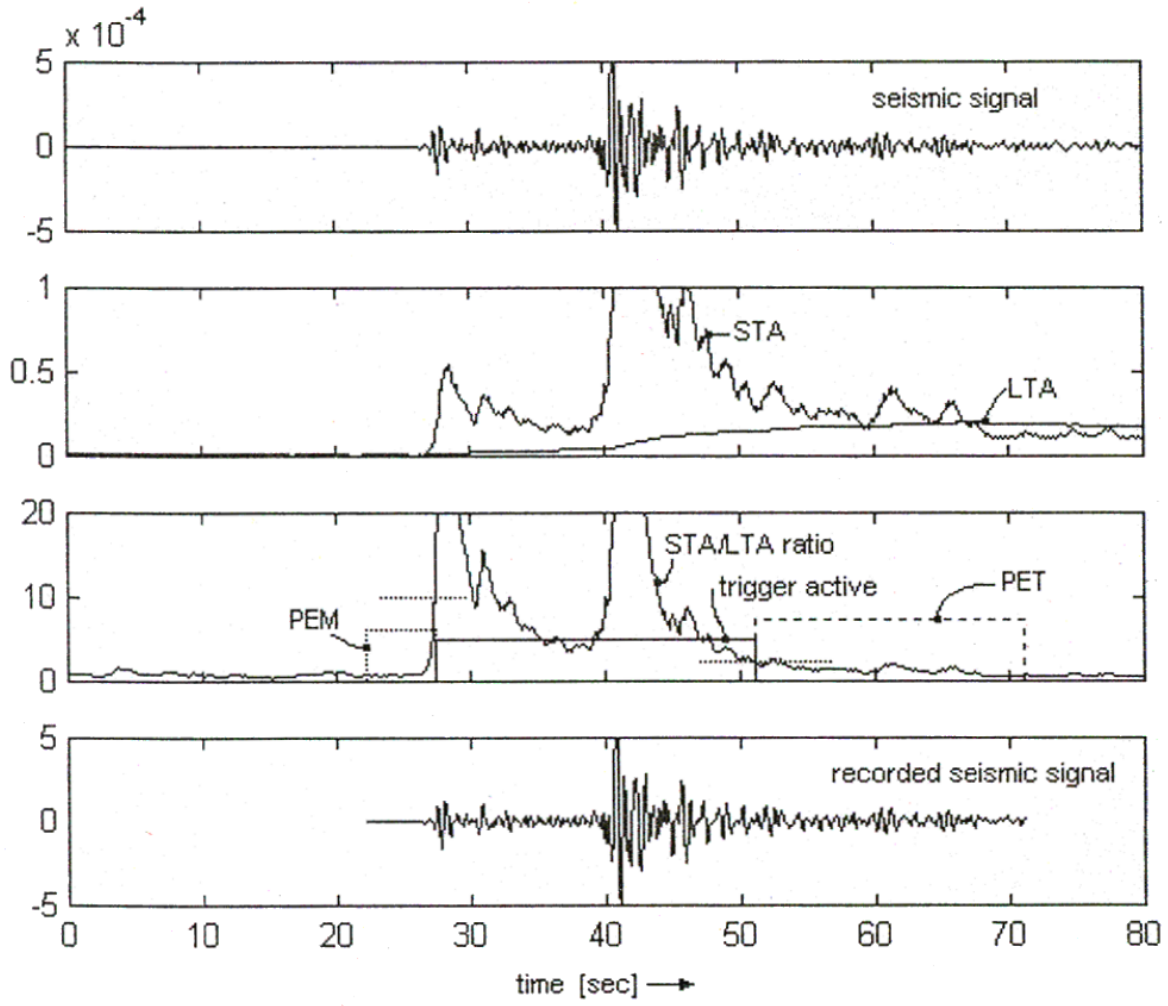

Figure 3.2: Example of STA:LTA algorithm triggering on a seismic event. From top to bottom the plots show: the inbound waveform; the STA and LTA values calculated for each subsequent data point; the STA:LTA ratio with trigger threshold and detrigger thresholds shown as horizontal dotted lines, the trigger duration represented by the trigger active box, and pre- and post- event times (PEM and PET, respectively) shown as the dotted boxes adjacent to the trigger active box; the seismic signal that is saved as an event file. Figure adapted from Trnkoczy (1999).

\section{Short Term Average Window Length}

The STA window length is chosen such that the STA of an expected waveform is 
representative of its average amplitude. For RISSIN seismic data, a challenge of this parameter is the balance between capturing short duration seismicity and avoiding noise triggering. This arises due to the presence of events local to sensors that have durations and amplitudes similar to the shortest duration network detectable seismicity. These nearby events cannot cause network detection in isolation, but when many such events occur across the network the likelihood of their detection increases. A short STA window length emphasises triggering on these events while a long STA window length fails to capture relevant short duration seismicity. Accordingly the STA window length was chosen as 0.1 seconds to ensure no loss of signal. This short STA window length, in combination with other parameters, lead to nearly $70 \%$ of network event detections being due to nearby event triggering.

\section{Long Term Average Window Length}

LTA window length is chosen such that the LTA represents the pre-signal noise amplitude and hence provides a baseline to reference STA values to. The LTA window length was chosen as 10 seconds to compliment the STA window length's focus on short-duration seismicity.

\section{STA:LTA Thresholds}

The threshold for triggering was set at a value of 3. This ensured that weak events were detected during periods of increased noise. To avoid writing long event files (and to accurately determine event lengths) the detrigger threshold was set at a value of 2 . Thus triggering was easy to initiate but difficult to sustain. The low trigger threshold used with RISSIN seismic data was likely a significant factor in the majority of detected events being nearby events, but a higher threshold was unrealistic given the noisy nature of the data.

\section{Signal Filtering}

In glacial seismic studies it is common to filter the continuous data in a narrow frequency band before applying the STA:LTA triggering algorithm (West et al., 2008). This targeted filtering aims to increase the amplitude of the expected waveforms in relation to noise and other waveforms. A key assumption to the use of such a filter is that the typical frequency of the expected waveform is known. With the RISSIN seismic data no such assumptions were made and as such no filtering was carried out on the data. This may have lead to higher amounts of noise triggering and potential loss of event detections due to high noise amplitude. 


\section{Network Event Detection and Event Registration}

Event detection and registration uses the temporal relationship between individual station triggers to discern arriving waves from noise. This process functions by finding triggers at different stations within a chosen length of time (the search window) following each successive trigger. Here each station can only have one trigger per event. The trigger that initiates the search process is the first trigger observed outside the search window following any prior trigger. Once enough coincident triggers are found (triggers occurring within the search window following each successive trigger) an event is registered.

The coincidence trigger threshold and search window length define the network sensitivity for event registration. The coincidence trigger threshold sets the required strength of an event for it to be registered while the search window length alters the tolerance of the event registration to ray paths and path effects. For the purpose of the RISSIN seismic data processing the coincidence trigger threshold was chosen as 4 , the minimum number of event detections required for event source location, and the search window length was chosen as 1.5 seconds, the maximum travel time of a $\mathrm{P}$ wave between the extremes of the network. Any event that satisfied these conditions was registered and saved in miniSEED format (with pre- and post-event data appended to it) with its initial trigger time as its title and its duration saved to a separate file.

\section{Pre- and Post-Event Times}

The pre- and post-event times are chosen to ensure that the output event file contains the full waveform and a sample of pre-event noise. Given that triggering sometimes initiates and terminates on a single phase - and not necessarily the $\mathrm{P}$ phase - sufficient data need be added to the front and end of a trigger window to ensure other phases and relevant signal is captured. Due to the nearby nature of sources to the RISSIN stations the pre- and post-event times could be short: both were chosen as 5 seconds.

\section{Station Sensitivity}

Sensitivity to seismicity varies between stations and instruments. Aspects of the station setup such as exposure, sensor coupling, component connections, and nearby environmental processes all act to increase or decrease the amount of triggering at a station. Several stations (TSNC3, TSNC4, TSNL3) showed signs of poor component connections at various times, with TSNC4 experiencing this consistently. The data 


\begin{tabular}{lll}
\hline & Run 1 & Run 2 \\
\hline STA Window Length & $0.1 \mathrm{~s}$ & $0.5 \mathrm{~s}$ \\
LTA Window Length & $10 \mathrm{~s}$ & $10 \mathrm{~s}$ \\
Trigger Threshold & 3 & 4 \\
Detrigger Threshold & 2 & 3 \\
Filter & None & $60-80 \mathrm{~Hz}$ Bandpass \\
Coincidence Trigger Threshold & 4 & 6 \\
Search Window Length & $1.5 \mathrm{~s}$ & $1 \mathrm{~s}$ \\
\hline
\end{tabular}

Table 3.3: STA:LTA algorithm parameters.

corruption observed from this effect appears as frequent spikes in the timeseries or as distorted waveforms. Noise triggering also occurs due to local glacial and mass wastage processes, phenomena also most common to TSNC4. Continuous noise such as wind, rain or water flow raise the noise floor at a sensor and can inhibit triggering, while sensor coupling may reduce the amount of energy that is partitioned into the sensor when a wave reaches the surface, thus enhancing sensitivity for some stations and reducing it at others. These aspects of station sensitivity can aid or mitigate signal and noise triggering and are time variant.

STA:LTA parameter adjustments were not made for individual RISSIN stations. Exceptionally noisy stations like TSNC4 produce triggers almost continuously, meaning that for any potential event there is always one trigger available regardless of whether it is signal or noise derived. Any noise detections caused by these effects were removed manually during categorisation (Section 4.1). Retaining noisy stations during STA:LTA event detection proved beneficial as these stations later provided necessary constraints for event location.

\section{Second STA:LTA Algorithm}

The first STA:LTA algorithm was designed to focus on short duration impulsive seismic events with no known frequency content. This was successful in capturing nearly 911 short duration and 69 long duration impulsive events. Manual inspection showed the latter detections to be only a subset of the full catalogue: the STA:LTA parameters had failed to capture this waveform type to a representative level. Thus a second STA:LTA algorithm was run on the continuous RISSIN seismic data to extract more of these events. The parameters used for this algorithm run are presented in Table 3.3 with the parameters of the first STA:LTA algorithm for comparison.

After manual discrimination and removal of noise detections the results were merged with the long duration impulsive seismicity found in the first STA:LTA algorithm 
run. This raised the total event registrations of this type to 221 .

\section{STA:LTA Algorithm Performance}

This subsection makes reference to the results of the seismic event characterisation by comparing the occurrence of seismicity from sources discerned in Section 4.1.

Manual inspection of the continuous data showed neither STA:LTA algorithm run detected all seismicity of the targeted style. The lack of icequake detection during rainfall episodes, periods where basal shear stresses and basal water pressure fluctuations are expected to be high (Walter et al., 2013), suggests that the STA:LTA algorithm failed during these periods. Similarly the crevasse opening event count during some periods of heavy rainfall is similar to the background rate while in others it is clearly peaked (Figure 4.1). These opposing trends may also result from a failure of the STA:LTA algorithm.

To quantify the extent to which the STA:LTA algorithm missed events of interest manual inspection of two rainfall episodes (those of day 123 and 125; the latter causing an accelerated sliding episode and crevasse opening rate peak) was carried out. These rainfall episodes were chosen due to their temporal proximity, similarities in the rainfall over their duration, and differences in detected event style and quantity.

The general trend in seismicity over each rainfall episode, as discerned from the manual inspection of continuous seismograms, is summarised below. Examples of the seismicity observed during this inspection are presented in Appendix A.

- Pre-rainfall seismicity consists mostly of nearby events and helicopter noise. The nearby events are impulsive with a very short duration and variable frequency content. The helicopter noise is emergent and tremor-like in appearance, but exhibits the characteristic fundamental frequency and overtones of a three blade helicopter, as well as clear Doppler shifts in its frequencies as the source moves up or down the network (Eibl et al., 2015).

- When rainfall begins both the noise floor and the rate of nearby event occurrence increase. Crevassing rate remains near the background rate with individual events having high variability in the appearance of their waveforms.

- Increasing rain rate results in greater numbers of nearby events with waveforms of two types: impulsive with a short duration and emergent with a longer duration (on the order of a few seconds). 
- The rate of nearby event occurrence drops as the rain rate decreases. Helicopter noise returns as rainfall terminates and nearby events resume their regular short duration and impulsive style.

The second rainfall episode diverges from the above trend after the rain rate peak. Here the crevasse opening rate increases and impulsive style nearby events occur much more consistently and regularly with a substantially higher amplitude. Over time these impulsive nearby events get bigger than their emergent counterpart and appear similar to near-station crevasse opening events, potentially being of the same origin. These events remain local to the station that detects them, but larger events do not. In the falling limb of the rainfall episode the frequency of strong, network detectable crevasse opening events increases profoundly. This period of enhanced crevasse opening rate ends after three hours, returning the rainfall episode to the trend summarised above as it terminates.

Over each rainfall episode two icequakes were observed. This sparse occurrence is similar to the background distribution of these events, suggesting that rain water inputs to the glacier do not influence their generation.

It is likely that greater nearby event occurrence and higher rain rates raise the LTA over rainfall episodes. This high noise floor reduces the STA:LTA value and inhibits the trigger threshold from being reached, but also causes weak signals to become undetectable due to the continually high noise amplitude. This interpretation explains most of the data, but not the lack of a crevasse opening rate peak in the earlier rainfall episode. The reason for this is likely unrelated to the ability of the STA:LTA algorithm to trigger on such events and instead relates to the failed initiation of a glacial response to high water inputs (see Section ??). Thus the STA:LTA detection algorithm, though challenged by the noisy seismic environment of Tasman Glacier, produced a record of seismic events that is a fair representation of the true seismicity of the glacier. 


\subsection{Beamforming and Grid Search}

The wave propagation direction and location of each detected seismic event in the RISSIN catalogue were computed using beamforming and a 3D grid search routine. The code used for this processing was provided by Paul Winberry (Central Washington University, Ellensburg) and adjusted for use with RISSIN seismic data. The benefit of using both beamforming and a grid search technique arises from the nature of the arriving wavefront at the seismic network. To examine this point a brief overview of array methods in seismology is given as presented by Rost and Thomas (2002):

A wavefront sufficiently far from its source will be approximately planar as it arrives at a seismic network (Stein and Wysession, 2002). The propagation of this plane wave can be described by two parameters: horizontal apparent velocity, $v_{a p p}$, and back-azimuth, $\theta$, where $v_{a p p}$ is defined as:

$$
v_{a p p}=\frac{v_{0}}{\sin (i)}
$$

where $v_{0}$ is the velocity of the wave in the medium beneath the array and $i$ is the angle of incidence of the wavefront at the surface (Figure 3.3). The back-azimuth, $\theta$, is defined as the bearing of the seismic event epicentre (Figure 3.3). 
vertical plane

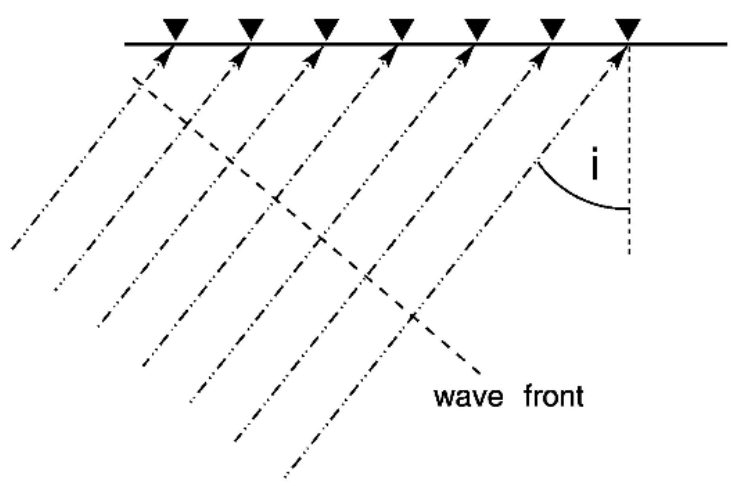

a)

b)

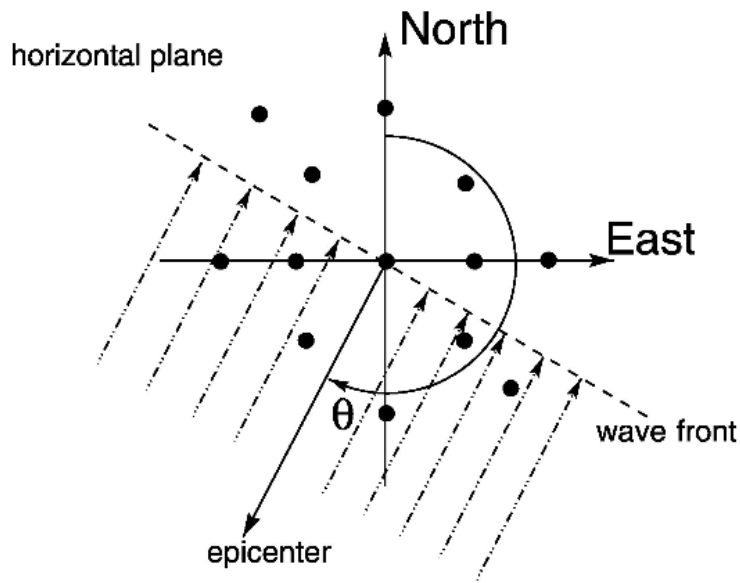

Figure 3.3: (a) Vertical plane diagram of a plane wave arriving at an array at angle of incidence i. (b) Horizontal plane sketch of a plane wave arriving at an array from an epicentre with bearing $\theta$. Figure from Rost and Thomas (2002).

Beamforming provides an estimate of the propagation direction of a plane wave by matching coherent signal across seismograms at different network stations. To match waveforms, temporal shifts are applied to the seismograms at each station. These temporal shifts correspond to the relative travel time of the planar wavefront to each station as it traverses the network, and are dependent on the angle of incidence and back-azimuth of the wavefront as well as the distance between the stations. Crosscorrelation of time-shifted waveforms provides a measure of how well the proposed waveform propagation direction fits the observed wave. Therefore the greatest crosscorrelation value provides the best fitting angle of incidence and back-azimuth for the case of an observed planar wavefront.

An example of the beamforming result of cross-correlation values for a range of wavefront propagation directions is shown in Figure ??. Here results are plotted in terms of slowness, the inverse of horizontal apparent velocity, as a 2D projection of a 3D lower hemisphere plot of cross-correlation values. In these plots, loci of high 
cross-correlation values near the outer edge represent wavefronts traveling nearly parallel with the surface while those that are central to the plot show vertically incident wavefronts. The azimuthal position of the loci represents the back-azimuth of the wavefront.

In the beamforming routine, a horizontal apparent velocity range from $2-8 \mathrm{~km} \mathrm{~s}^{-1}$ in $0.2 \mathrm{~km} \mathrm{~s}^{-1}$ increments and a back-azimuth range of $1-360^{\circ}$ in $1^{\circ}$ increments was used. The medium velocity was set at $3.8 \mathrm{~km} \mathrm{~s}^{-1}$, the upper limit of $\mathrm{P}$ wave velocity in ice (Section 2.3).

In the theory of beamforming, the minimum horizontal apparent velocity is the medium velocity, this representing a wavefront with horizontal incidence. Optimal horizontal apparent velocities below this value suggest the arriving wave is not a $\mathrm{P}$ phase, but rather a slower traveling phase. Sources within the network also raise issues with back-azimuth resolution: a circular expanding wavefront can be matched by many back-azimuths, thus producing a limitation on the resolution of the wavefront propagation direction.

The 3D grid search does not suffer from the same issues as the beamforming. This method calculates the temporal shift for each station as the travel time of the ray between a grid cell and the receiver, thus removing any assumption of the nature of the wavefront. Subsequent cross-correlation of shifted waveforms produces a plot of cross-correlation values similar to that of the beamforming (Figure ??). Initial grid search parameters were set at $1 \mathrm{~km}$ cell spacing over the full Tasman Glacier glacier extent (Figure 1.2). However locations from this grid search showed a dominant locus of epicentres over the lower Tasman Glacier. A focused grid search was run over this region (Eastings 1369.1-1379.1 (km), Northings 5156.8-5172.8 (km), and depth $-3-0(\mathrm{~km}))$ with a $500 \mathrm{~m}$ cell spacing to better resolve the nature of these locations. Note the poor alignment of waveforms in the grid search result in Figure ??, this results from the coarse grid size resolution used. The principal limitation of the grid search is its computational intensity. Grid cell sizes less than $500 \mathrm{~m}$ were not realistic due to this computational restriction. 


\subsection{NonLinLoc}

Those waveforms exhibiting clear $\mathrm{P}$ wave arrivals at four or more stations were located using a nonlinear probabilistic approach. The software package NonLinLoc (NLLoc) was used for this purpose (Lomax et al., 2000). The location algorithm of NLLoc follows the approach of Tarantola and Valette (1982).

NLLoc calculates the hypocentral probability density function (PDF), which is the complete, nonlinear probabilistic solution to the inverse location problem. The PDF can be irregular in shape with many optimal hypocentres (these being the maximum likelihood value(s) of the PDF). This irregular shape arises from the non-linearity of the hypocentre location and travel time relationship and is representative of the uncertainty from wave arrival time picking errors, calculation error, and the network geometry. Further discussion of the location uncertainty in NLLoc results is given in Section 5.5.

Phase picking prior to event location was performed in SEISAN (Havskov and Ottemoller, 1999). All resolvable $\mathrm{P}$ wave arrivals, $\mathrm{P}$ wave first motions, and $\mathrm{S}$ wave arrivals were picked from events in the second STA:LTA algorithm catalogue. Wave arrival picks were weighted from 1-3 to represent their accuracy, with 1 being poor and 3 being near-perfect. Overall 211 seismic events were processed with 160 producing reliable hypocentres in NLLoc.

An Oct-Tree importance sampling algorithm (Curtis and Lomax, 2001) using an equal differential time (EDT) likelihood function (Zhou, 1994) was used to compute the PDF for each seismic event. The EDT likelihood function is robust in the presence of outliers and, when combined with the Oct-Tree method of grid search, can produce a good representation of a PDF with a complicated and irregular topology.

Parameters used for NNLoc with arrival picks for events in the second STA:LTA catalogue are as follows:

- Homogeneous velocity model between Eastings 1369.1-1379.1 (km), Northings 5156.8-5172.8 (km), and depth -3-20 (km) with P wave velocity $3.8 \mathrm{~km} \mathrm{~s}^{-1}$ and $\mathrm{S}$ wave velocity $1.9 \mathrm{~km} \mathrm{~s}^{-1}$. Grid cell size is $1 \mathrm{~km}$.

- Model errors are zero and pick errors are 0.2, 0.1, $0.01 \mathrm{~s}$ for respective arrival time pick weights of $1,2,3$. 
- Moraine sites have Gaussian arrival time variances of 0.07 s, 0.07 s, and 0.035 s for TSNM1, TSNM2, TSNM3, respectively. These were estimated from the time delay a wave propagating up the lateral moraine from the lower Tasman Glacier would experience.

- Oct-Tree importance sampling algorithm initiating on the $1 \mathrm{~km}$ cell size velocity grid and sampling down to $10 \mathrm{~m}$ cell size for up to 2,000,000 samples. This is an iterative algorithm that breaks the cell with lower residual at the end of each iteration into subcells before repeating the process until either the cell size or number limit are met.

Further details on the theory and functionality of NonLinLoc can be found in Lomax et al. (2000). Results of NLLoc processing are presented in Section 5.5.

\subsection{Seismic Event Categorisation}

Inspection of vertical component seismograms, spectrograms, and the beamforming and grid search results for each event in the detection catalogue was used to define initial categories for seismic events. A first pass of the 4208 events registered in the first STA:LTA run identified general categories before a second pass assigned waveforms to these categories. Overall twelve categories were defined.

To choose the category for a seismic event event first the waveform coherence across the network and two subarrays is inspected via the distribution and amplitude of cross-correlation values in the beamforming and grid search result plots for the event. High waveform correlation at the optimal solution for at least one array suggests that the event is signal rather than noise. Spectral characteristics are then considered. Generally waveforms of an event have spectra in either $<5 \mathrm{~Hz},<20-30$ $\mathrm{Hz}$, or in broadband ranges up to and above $80 \mathrm{~Hz}$. The rapid attenuation of high frequencies as the wave propagates in the glacier and similarities between source processes can cause spectral crossover between different categories. Inspection of the waveform shape and duration aids in constraining event category in these cases. A waveform's features are decomposed into: impulsive or emergent arrivals, short $(<1$ $\mathrm{s})$ or long $(>5 \mathrm{~s})$ duration, and visible phases. This, combined with the prior identified characteristics, is often sufficient to delineate a waveform category. However, ambiguity may remain between categories even after waveform and spectral characteristics have been considered. Here the waveform variation across the network is used: interstation moveout, waveform shape change and frequency attenuation, and 
the development or loss of phases. Results from the beamforming and grid search can supplement this by allowing a wave with a low apparent velocity and a glacial depth to be distinguished from one with great depth and a high apparent velocity, this acting as a crude separator of source process and hence waveform nature. Once a category is chosen the seismic event file and beamforming and grid search result are registered to the category.

The results of this categorisation, including the features characteristic of each category, are covered in detail in Section 4.1. 


\section{Chapter 4}

\section{Results}

\subsection{Seismic Event Categories}

The twelve seismic event categories populated using the method in Section 3.6 are summarised in Table 4.1. Example spectra, waveforms, and beamforming and grid search result plots are shown in Figures 4.1-4.10 for nine of the categories. For each set of example waveforms and beamforming and grid search cross-correlation value plots: seismograms are normalised independently for each seismic sensor, beamforming and grid search results show values for waveform cross-correlation of temporal shifts applied for each position in the parameter search grids, the $99 \%$ peak value contour is shown for the grid search result when the peak value is sufficiently above the mean, the optimal arrival direction (from beamforming) is plotted as a white line on the grid search plots, stations are labeled on the grid search result in order of: TSNC4, TSNM1, TSNM2, TSNC3, TSNL3, TSNR3, TSNC1, TSNL2, TSNR2, and upper and lower subarray results are shown in the second and third rows, respectively. Note that there is a special case for each category called repeating (Figure 4.11 ) in which the waveform either consists of many similar waveforms spaced closely in time or contains many such waveforms sufficiently spaced for them to be distinct. 


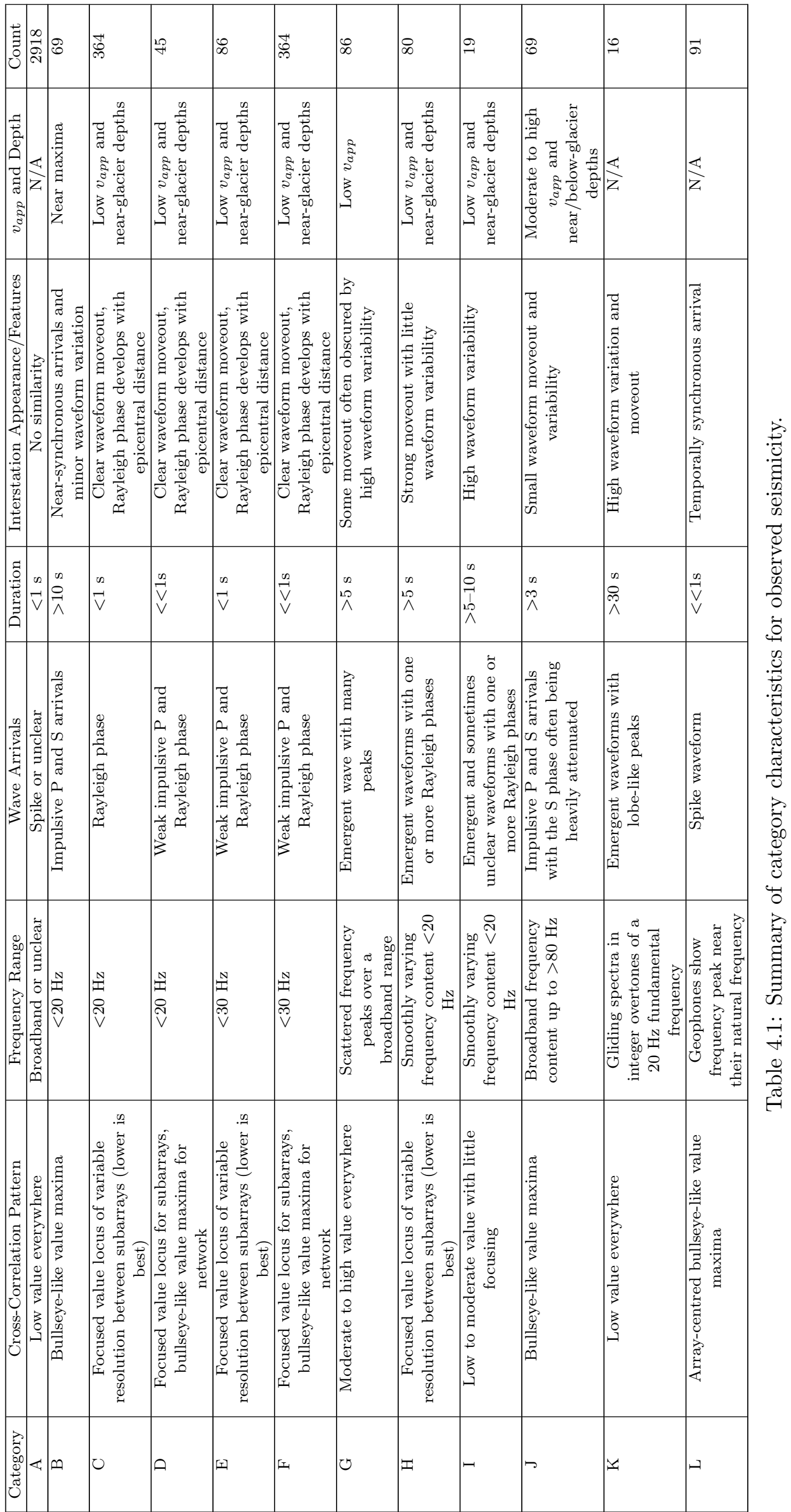



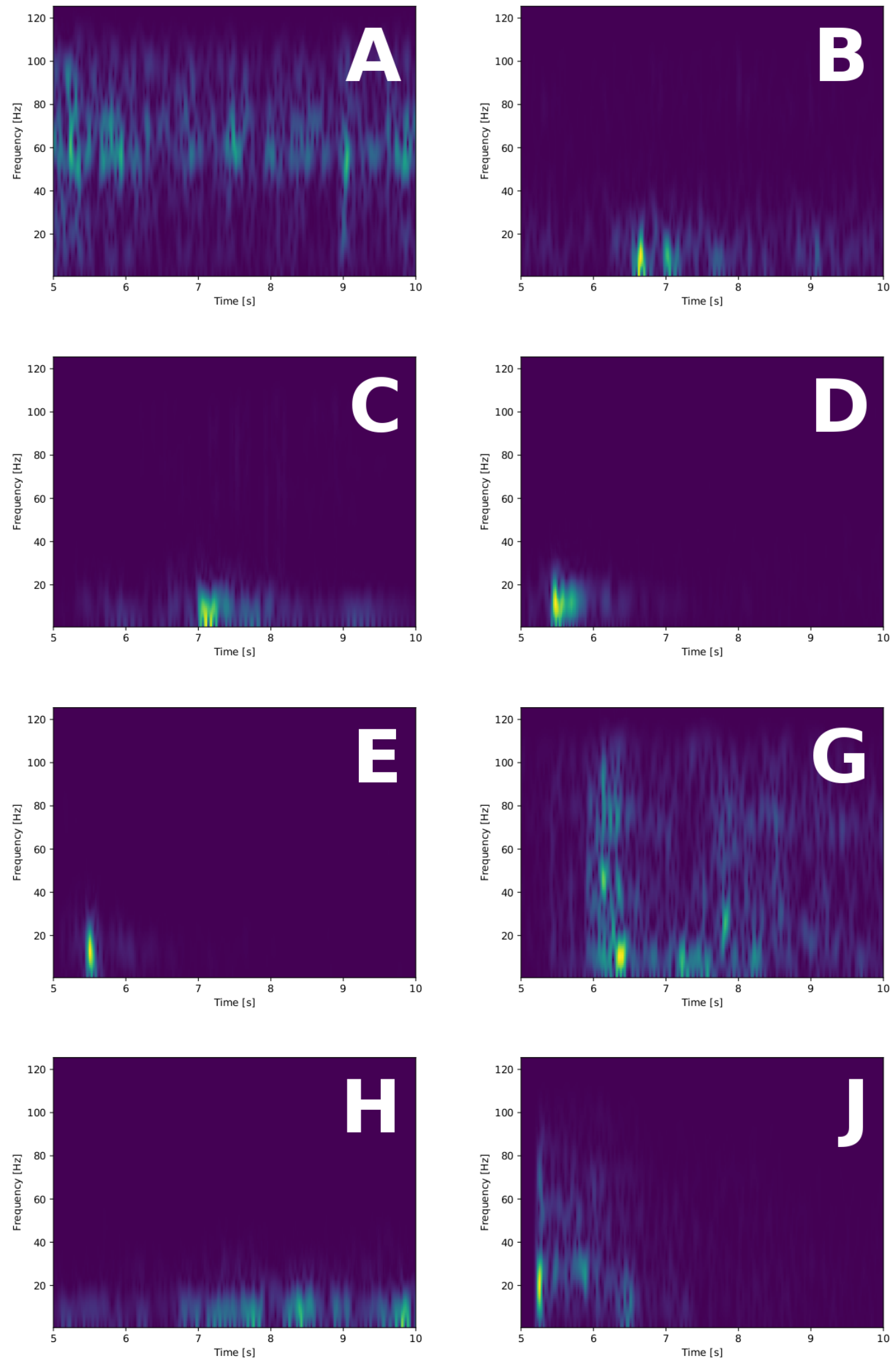

Figure 4.1: Vertical component spectrograms for all category example waveforms at TSNC1. Window length for frequency transform is $0.1 \mathrm{~s}$ and window overlap is $90 \%$. Total window size is cut to focus on the waveform energy. 

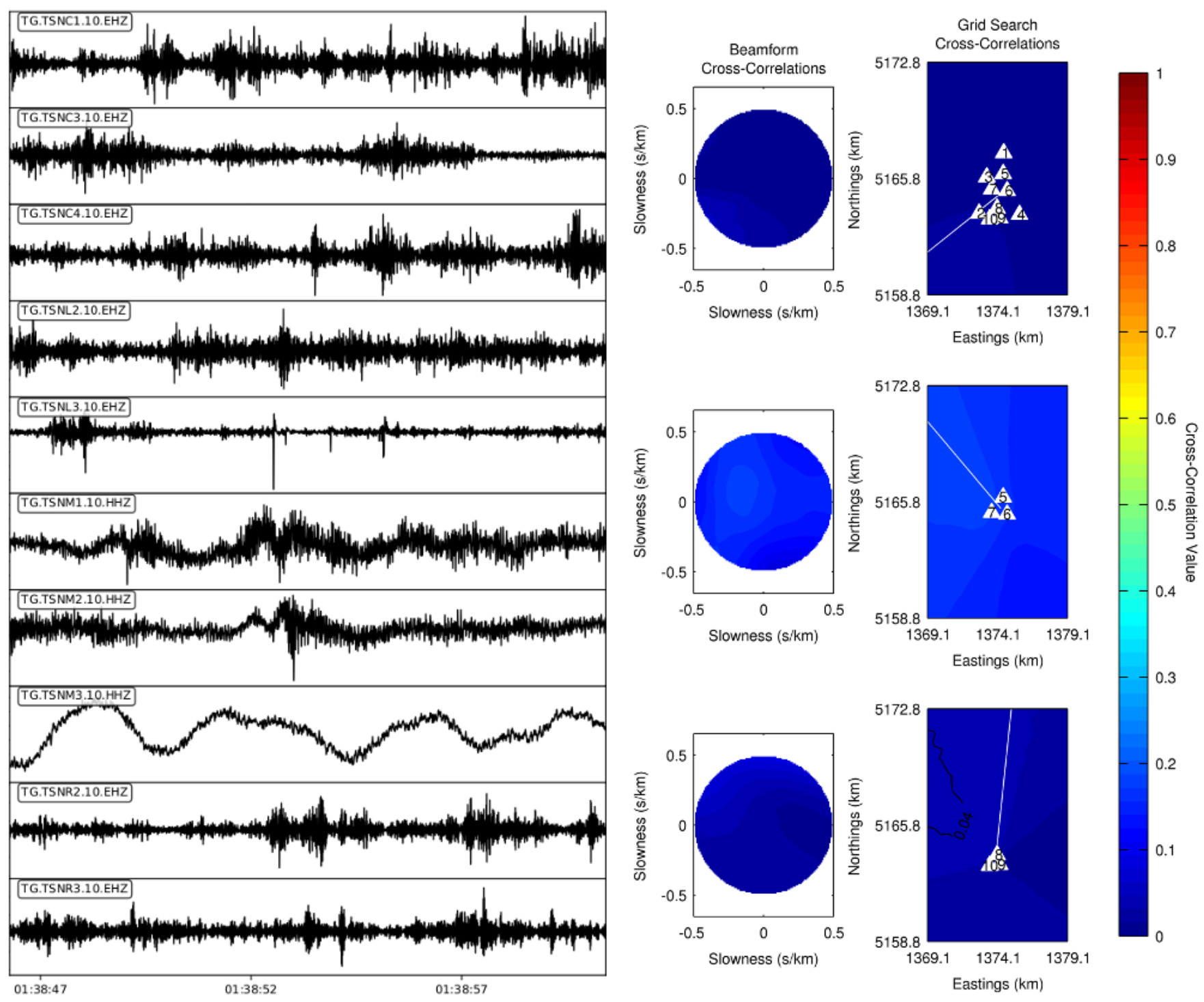

Figure 4.2: Waveforms and beamforming and grid search cross-correlation value plots for a typical category A seismic event. For spectra see Figure 4.1. 

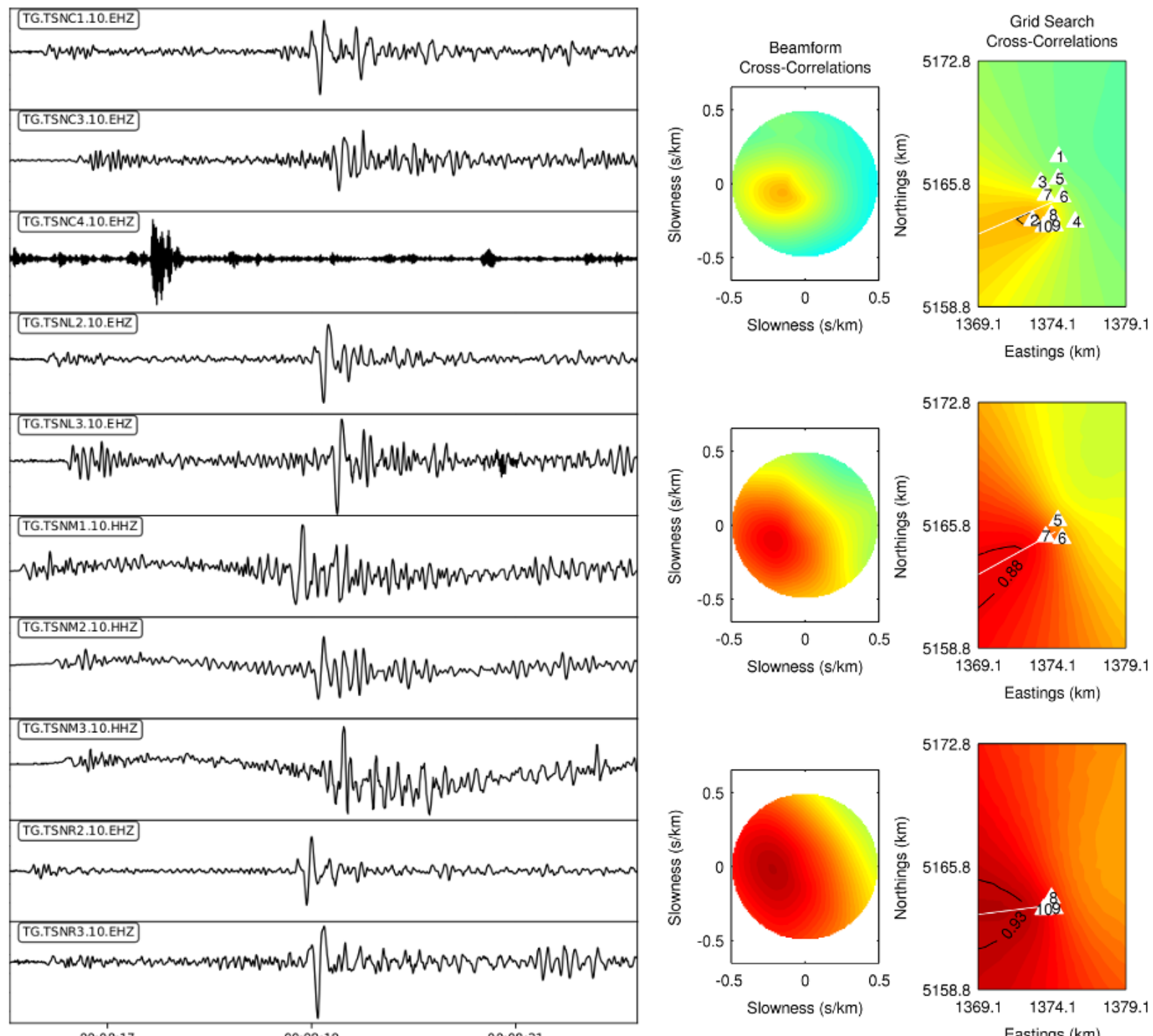

0.9
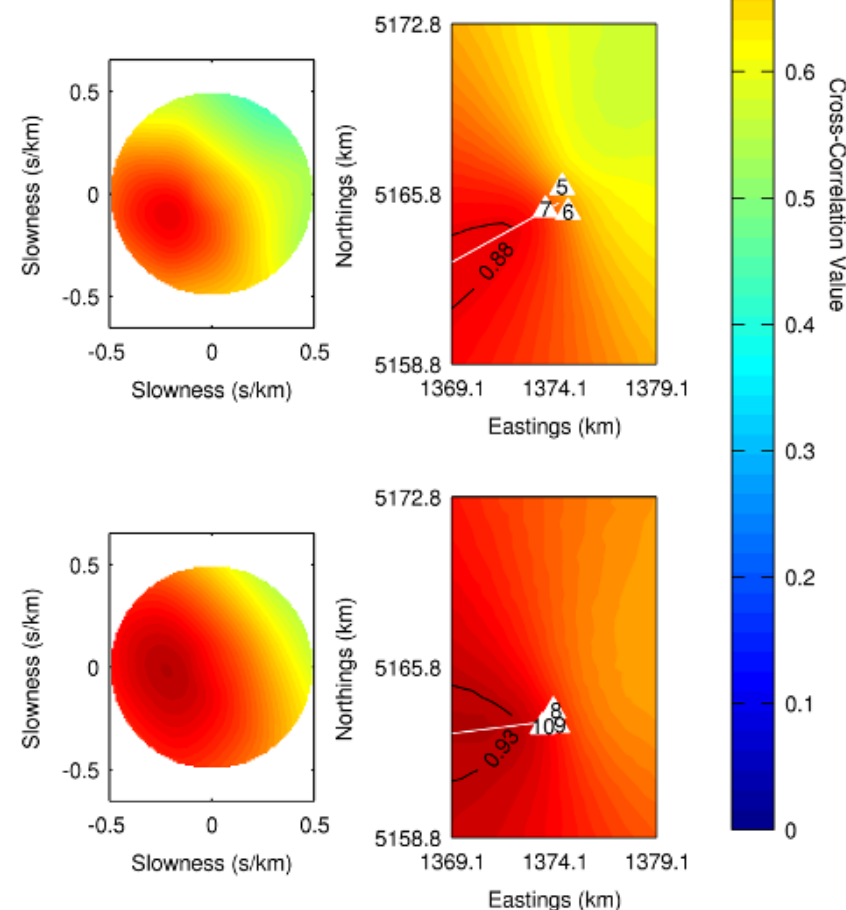

Figure 4.3: Waveforms and beamforming and grid search cross-correlation value plots for a typical category B seismic event. For spectra see Figure 4.1. 

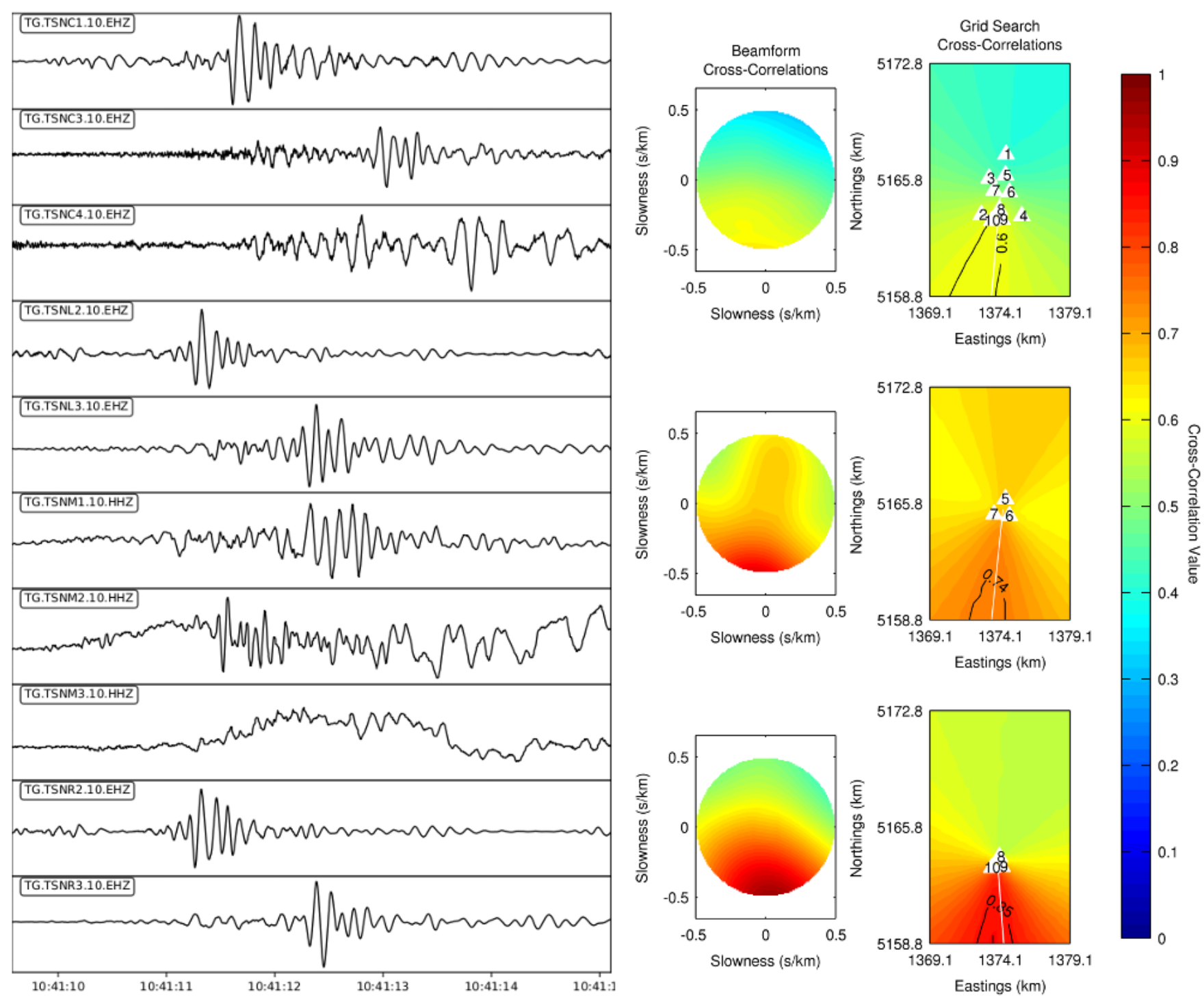

Figure 4.4: Waveforms and beamforming and grid search cross-correlation value plots for a typical category $\mathbf{C}$ seismic event. For spectra see Figure 4.1. 

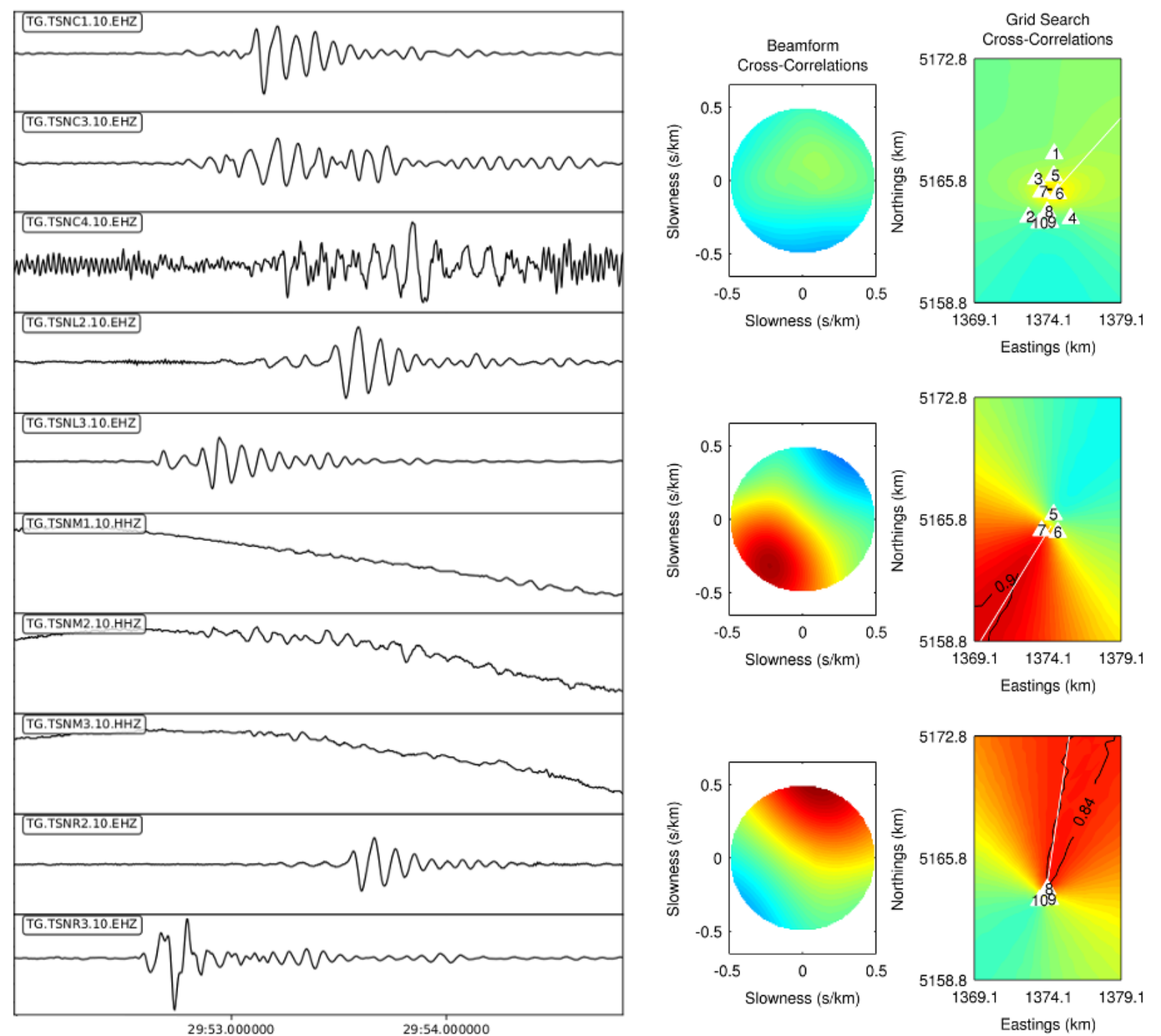

0.9
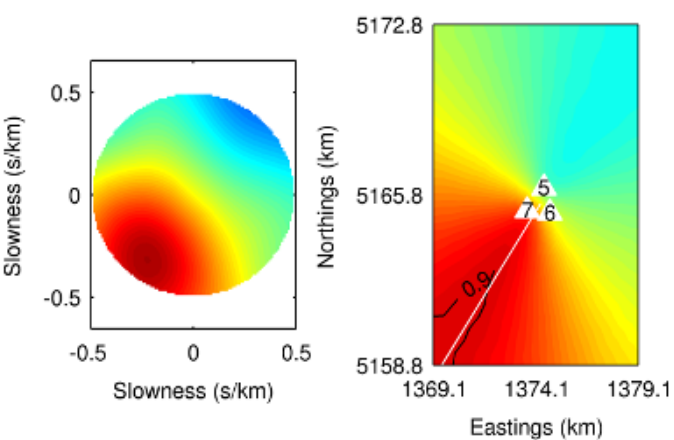

0.7
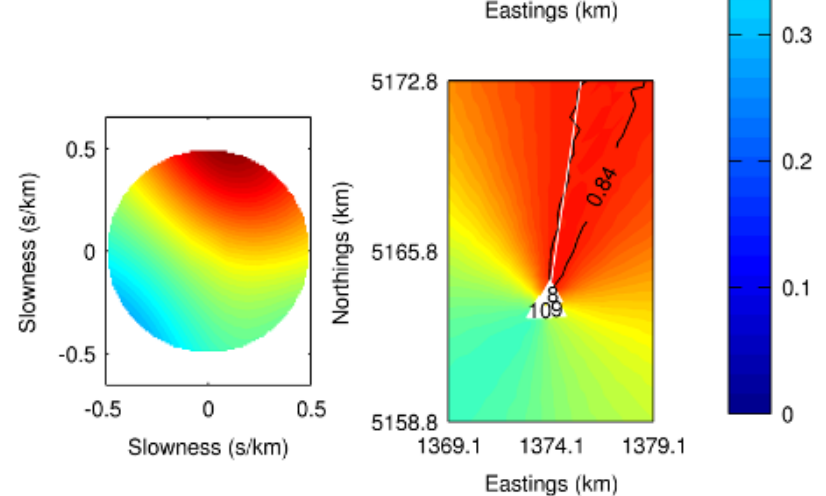

Figure 4.5: Waveforms and beamforming and grid search cross-correlation value plots for a typical category D seismic event. For spectra see Figure 4.1. 

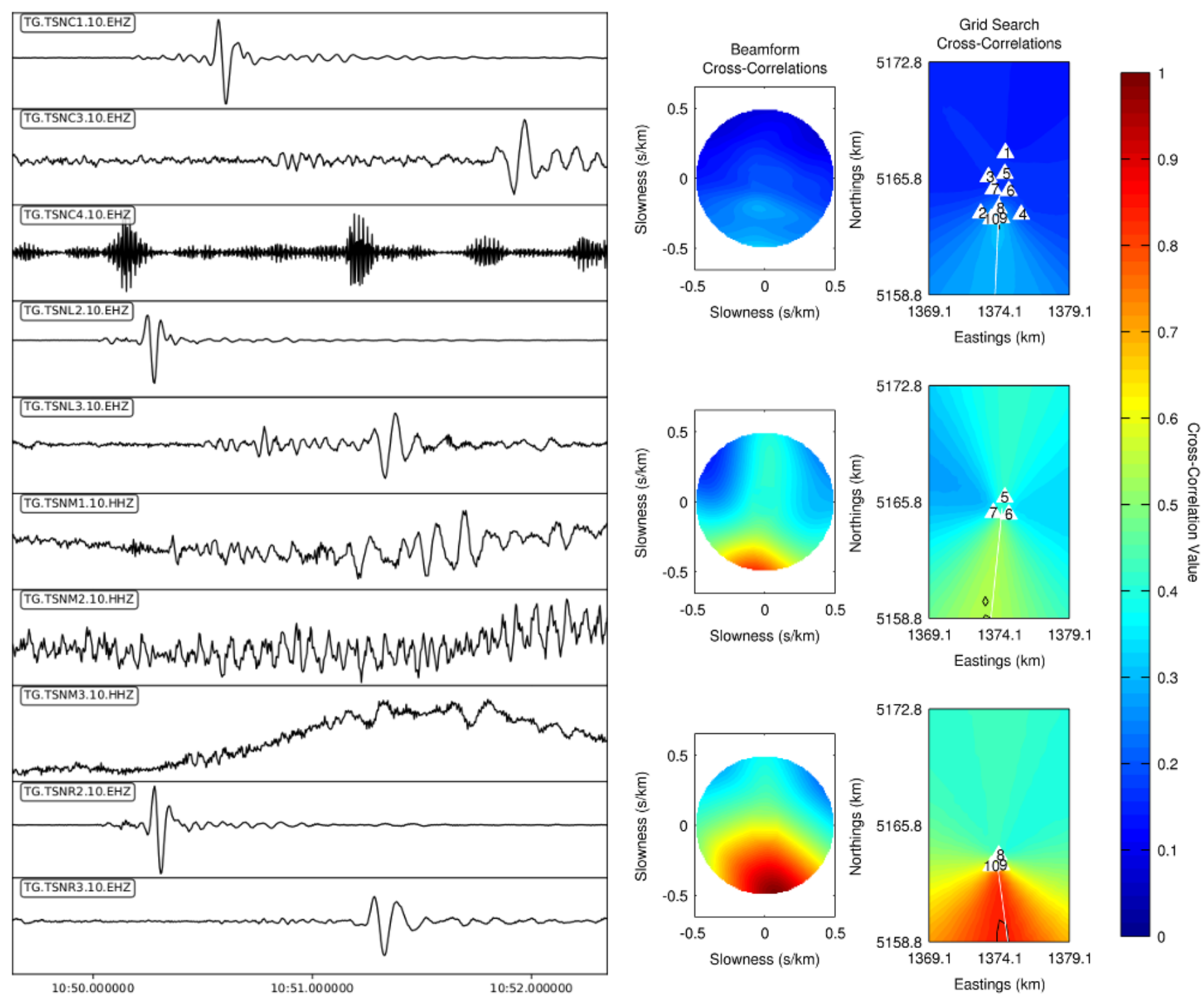

Figure 4.6: Waveforms and beamforming and grid search cross-correlation value plots for a typical category $\mathbf{E}$ seismic event. For spectra see Figure 4.1. 

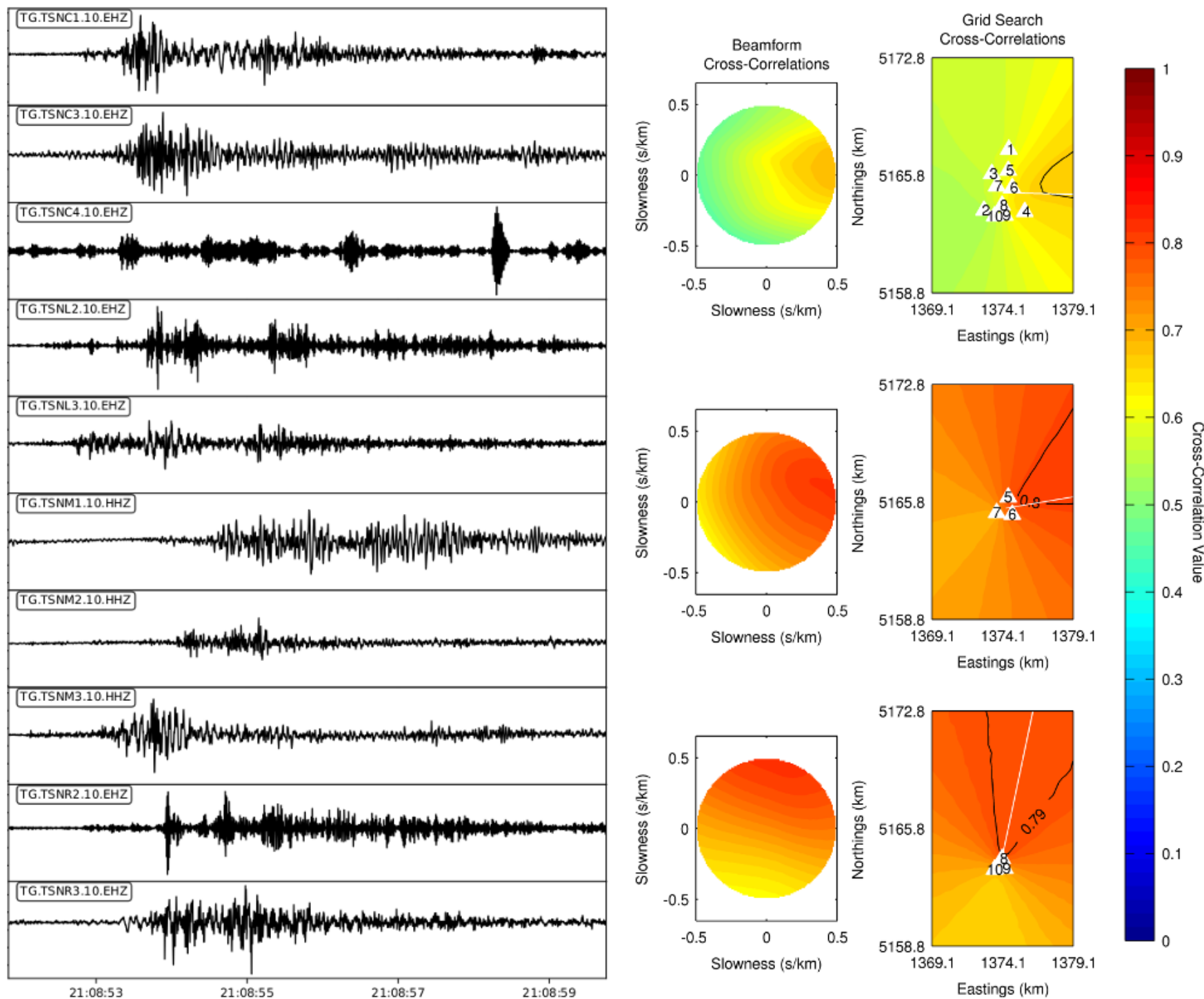

Figure 4.7: Waveforms and beamforming and grid search cross-correlation value plots for a typical category $\mathbf{G}$ seismic event. For spectra see Figure 4.1. 

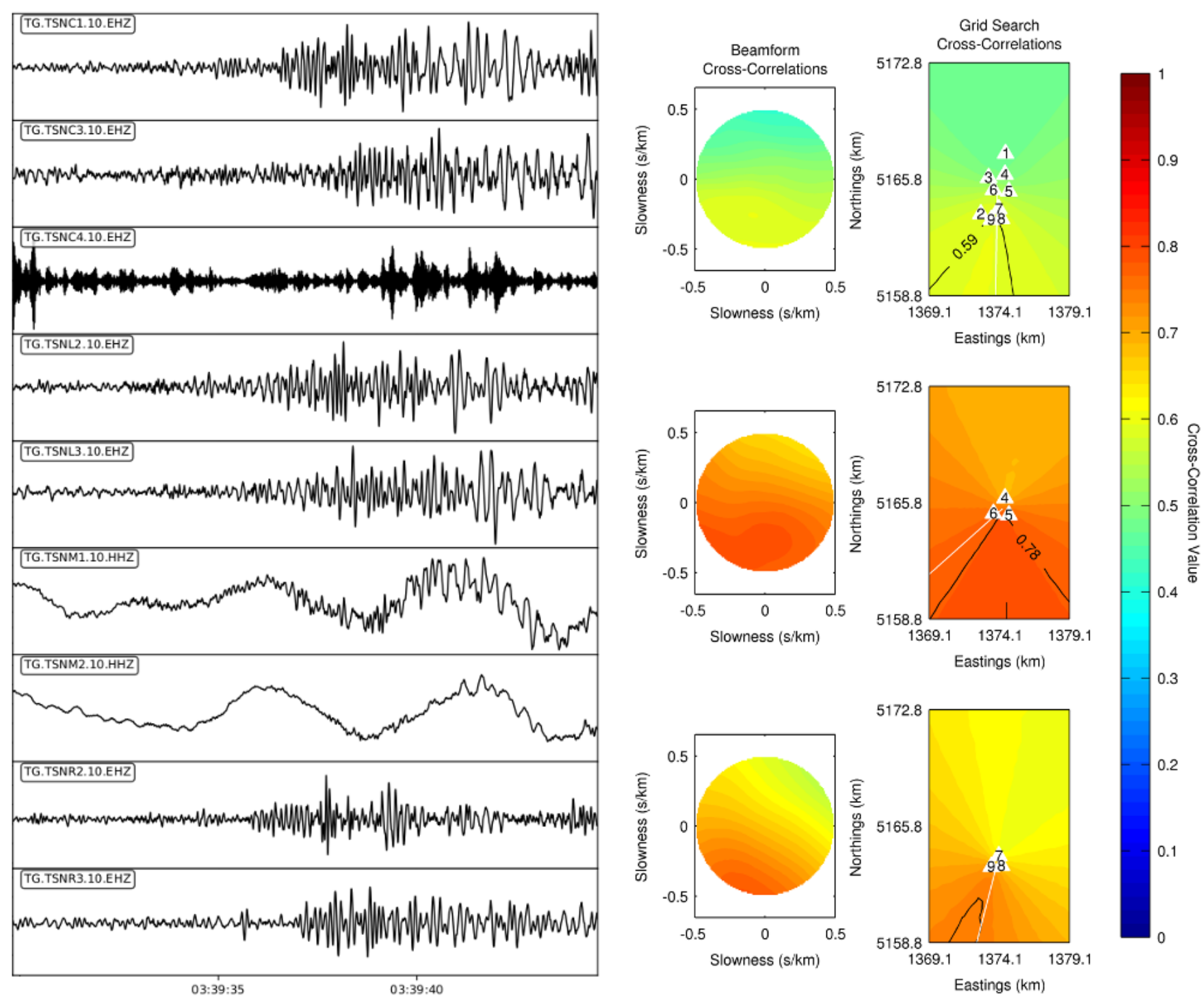

Figure 4.8: Waveforms and beamforming and grid search cross-correlation value plots for a typical category $\mathbf{H}$ seismic event. For spectra see Figure 4.1. 

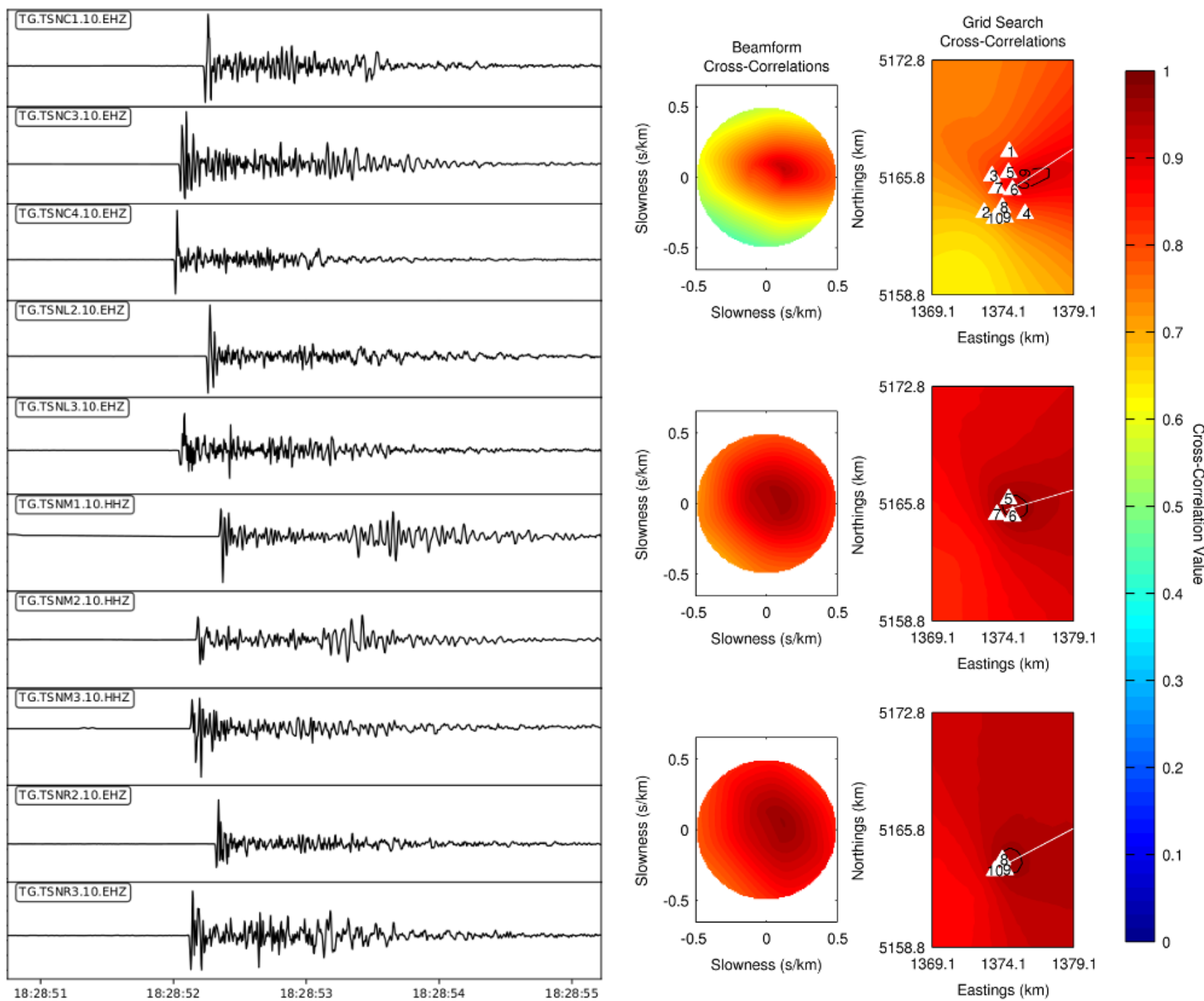

Figure 4.9: Waveforms and beamforming and grid search cross-correlation value plots for a typical category $\mathbf{J}$ seismic event. For spectra see Figure 4.1. 


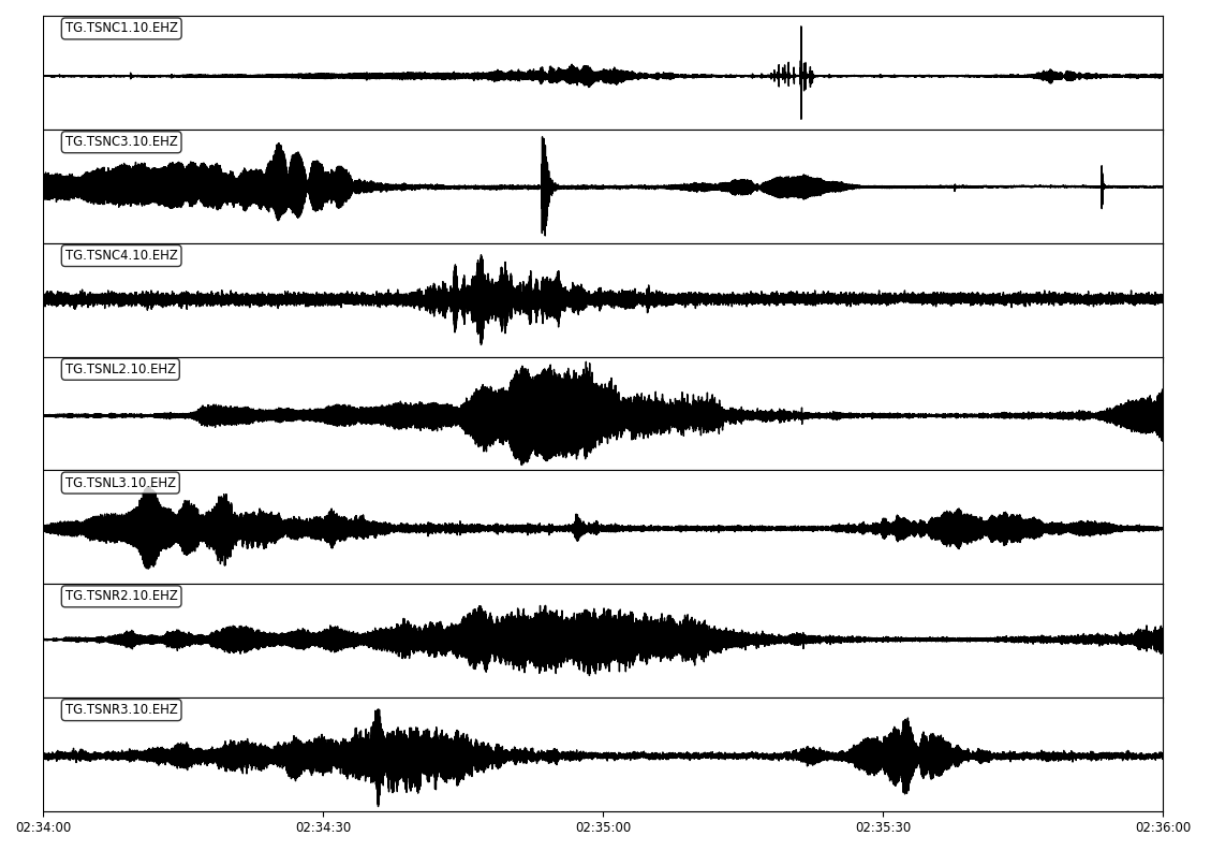

Figure 4.10: A typical category $\mathbf{K}$ seismic event seismogram and spectrogram observed at TSNR3. Spectrogram uses a $0.5 \mathrm{~s}$ window with $90 \%$ overlap between successive windows during calculation. Seismogram and spectrogram window lengths are $60 \mathrm{~s}$.

\subsection{Category Simplification}

A number of the categories exhibited overlapping characteristics making event characterisation uncertain for waveforms exhibiting characteristics of multiple categories. By redefining categories based on similarities in theorised waveform source processes category ambiguity is reduced and the number of categories drops significantly.

Following detailed inspection of categories C, D, E, F, and G (Table 4.1), these categories were all interpreted as manifestations of crevassing. The defining feature of a crevasse opening waveform is the strong Rayleigh phase on the vertical seismogram component (Neave and Savage, 1970; Deichmann et al., 2000). Opening crevasses closer to a seismic receiver will have a less attenuated waveform (stronger P phase) and a more developed Rayleigh phase (Stein and Wysession, 2002). A deep crevasse opening event will produce a waveform similar to near-receiver opening due to the effect of depth on the incidence angle of the $\mathrm{P}$ phase and the development of the Rayleigh phase (Deichmann et al., 2000; Stein and Wysession, 2002).

The combination of these factors explains the variability seen between categories $\mathbf{C}$, $\mathbf{D}, \mathbf{E}$, and $\mathbf{F}$ : category $\mathbf{C}$ and $\mathbf{D}$ waveforms are likely from shallow crevasse opening with category $\mathbf{D}$ events occurring closer to the seismic sensors than category $\mathbf{C}$ 
events; category $\mathbf{E}$ and $\mathbf{F}$ exhibit the same trend in their differences as that between categories $\mathbf{C}$ and $\mathbf{D}$ but have unique waveform characteristics, suggesting that these have similar relative source distances but originate from deeper crevasse opening due to their stronger $\mathrm{P}$ phase and weaker Rayleigh phase.

Category $\mathbf{G}$ represents short recurrence interval fracturing and crevasse opening near a single location. How a crevasse opening waveform might develop into a category G waveform, or any other kind of repeating crevasse opening waveform, is shown in Figure 4.11 using an example of repeated crevasse opening: at a short recurrence interval and large epicentral distances many Rayleigh waves superimpose to form a complex and obscure waveform that is difficult to shift into any particular origin using full waveform cross-correlation techniques. This latter point follows from the waveform being similar between stations but having inhomogeneities caused by varying seismic structures along the surficial ray path. The continuum observed in this category is likely caused by variations in epicentral distance and repetition interval as well as typical variability driving factors like the depth of the opening crevasse. 


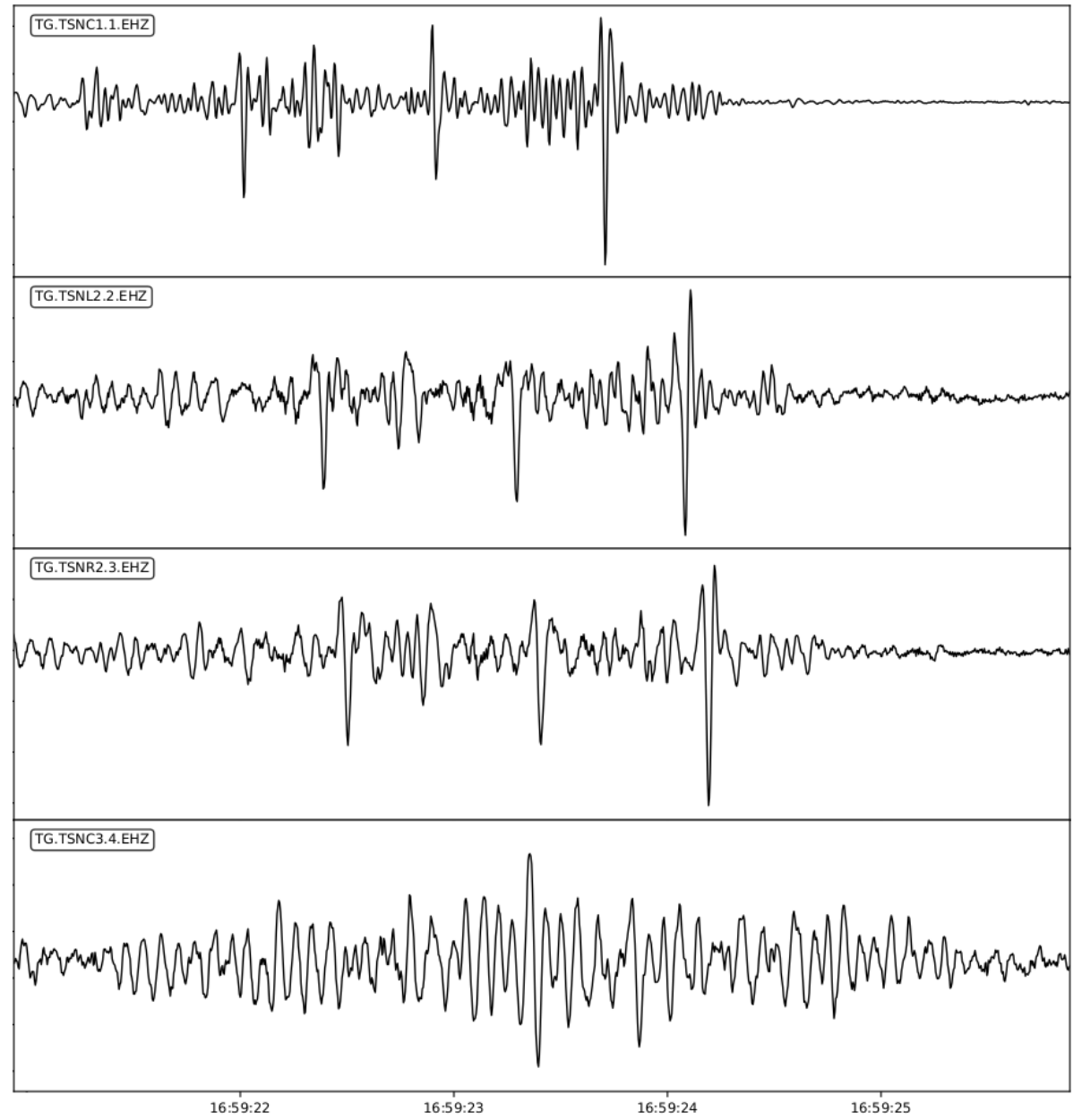

Figure 4.11: Seismograms of a repeating crevasse opening episode originating near the glacier terminus on day 201. The four seismograms are normalised independently and shown in order of increasing epicentral distance. As the waves travel their Rayleigh phase broadens and their body wave energy diminishes. When the wave arrives at the most distal station the observed waveform is a blended version of the originals, showing a lengthened waveform with no clear distinction between the composite waves.

Categories $\mathbf{H}$ and $\mathbf{I}$ appear to both be due to ice collapse, in particular calving and serac fall. These events fall in the spectrum of seismic signature of pre-calving fracture (Wolf and Davies, 1986; Qamar, 1988; O'Neel et al., 2007), ice-water interaction during calving (Bartholomaus et al., 2013), and ice-ice interaction following serac collapse (Roux et al. 2008; Jónsdóttir et al. (2009)).

Category $\mathbf{K}$ reproduces the characteristic seismic signature of helicopter flight observed by Eibl et al. (2015). This, combined with the observation of this seismic source exclusively during daylight hours on fine days (Figure 4.12), leads to the ascription of this category to helicopter-generated seismicity. During manual inspection of continuous data this signal was observed nearly continuously during daylight hours outside of rainfall episodes. Consideration of regular up- and downvalley helicopter flights seen (and heard) while deploying RISSIN sensors verifies 
this as a legitimate source for such seismicity.

Category $\mathbf{A}$ is the station-local (called nearby in Section 3.3) noise category formed by coherently timed but disparate brittle or resonant glacier processes.

Category B captures exclusively earthquake-style waveforms from both near and teleseismic sources (Stein and Wysession, 2002; Boese et al., 2012).

Category $\mathbf{J}$ is similar to category $\mathbf{B}$, though the higher frequency content, shorter phase and waveform length, and greater interstation moveout of category $\mathbf{J}$ delineates it from earthquake-generated waveforms. Rather the seismicity in category $\mathbf{J}$ falls in the realm of icequakes (Deichmann et al., 2000; Stuart et al., 2005; Roux et al., 2008 ; West et al., 2010; Zoet et al., 2012; Walter et al., 2013) and as such is considered to be generated by a source such as tensile crack opening/closing or basal stick-slip.

Category L occurs exclusively during heavy rainfall. The observation of temporally coincident spike seismicity requires an instantaneous source processes that produces a wave traveling at near-instant speed and experiences no attenuation or scattering along its ray path but somehow loses all frequency content outside the natural frequency of the recording sensor. It follows that such a spike likely results from the electrical response of a sensor to lightning.

Thus the initial catalogue of seismic events is simplified to the following sourcerelated categories presented as the original category $\rightarrow$ new category (total event count between days 112 and 201):

- Category A $\rightarrow$ Noise: station-local fracturing and resonance (1777)

- Category B $\rightarrow$ Earthquakes (60)

- Categories C, D, E, F, G $\rightarrow$ Crevassing (892)

- Categories H, I $\rightarrow$ Calving and serac collapse (78)

- Category $\mathbf{J} \rightarrow$ Icequakes (67)

- Category $\mathbf{K} \rightarrow$ Helicopter motion (10)

- Category $\mathbf{L} \rightarrow$ Lightning (91)

Previous studies at Haupapa/Tasman Glacier (Lui (2016)) conclude that calving 
events bear no relationship to accelerated sliding. As such events in the calving category are not considered further in this thesis. Station-local fracturing and resonance, earthquakes, serac collapse, helicopter motion and lightning are all also considered irrelevant to the process being studied (see Figure 4.12 and the lack of relationship shown between these categories and rainfall episodes). Note however that station-local fracturing and resonance event detections show a visual correlation with rain rate. This is strongest in the first month of the timeseries (Figure 4.12) but after this period the correlation is visually weaker and experiences variable delays between rain rate changes and event count changes. Hence the sources in this category are ascribed to a rain related process and a local fracture/resonance process, the latter likely being driven by stress changes in the glacier following high basal water pressures (Walter et al., 2008; West et al., 2010, Roux et al., 2010; Mikesell et al., 2012).

A re-categorisation of events in the discarded categories was carried out to ensure no loss of relevant events occurred. This added 19 further events to the crevasse opening catalogue. Detected seismic events of the second STA:LTA run were first manually trimmed of non-icequake detections and then combined with the refined icequake catalogue. Subsequently the total number of events in this catalogue increased to 211.

The seismic event categories used in the remainder of this thesis are crevasse opening and icequakes. Locations for crevasse opening events during periods of high hourly counts are shown in Section 4.5. Locations for icequakes are presented in Section 4.6 . 


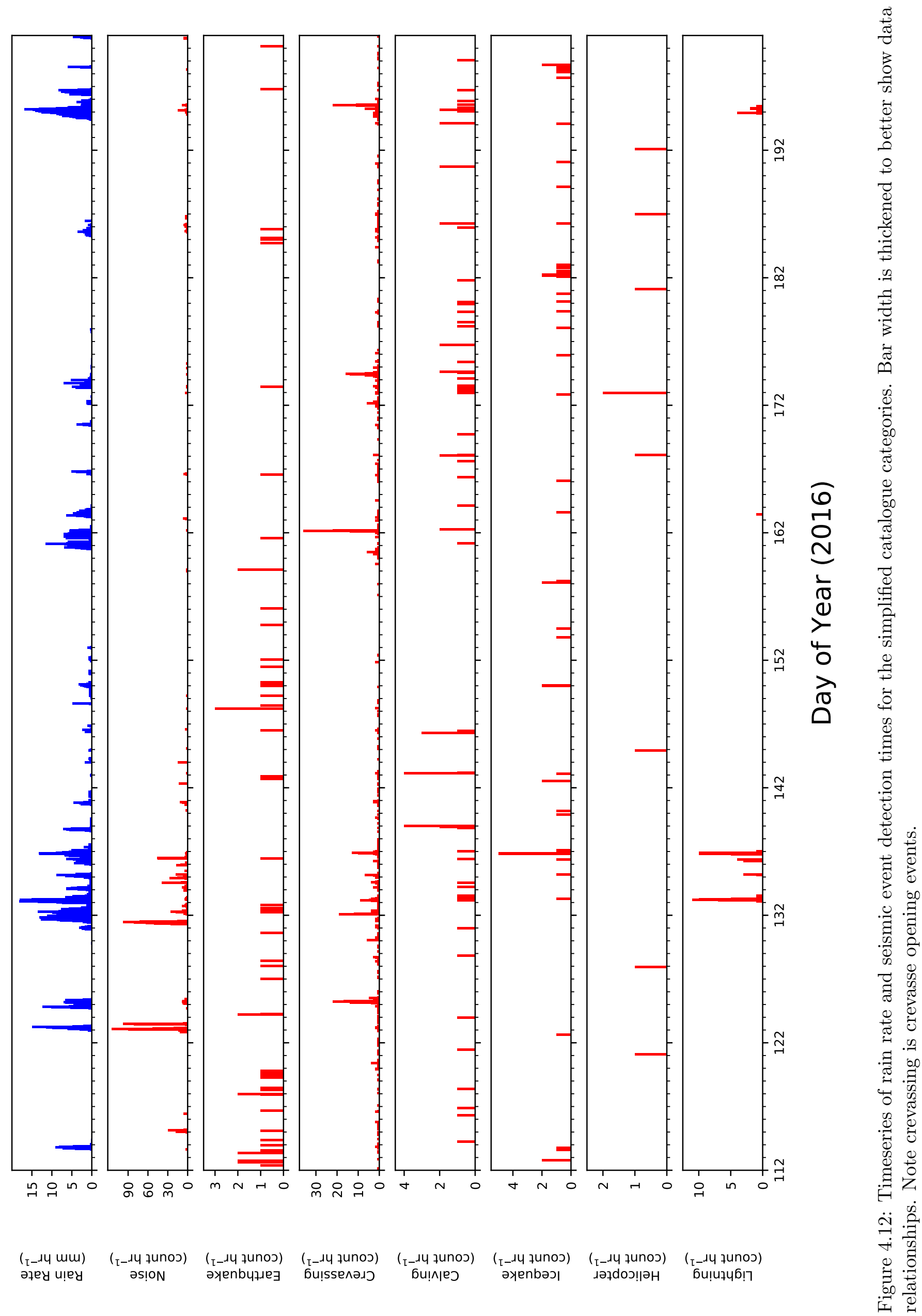




\subsection{Geodetic Timeseries}

All velocities at TSNC3 (upper glacier) and TSNC1 (lower glacier) show almost consistent timing of velocity maxima and minima (Figure 4.13). For trend identification the longest sampling interval was used (24 hours, see Appendix B) while for high fidelity measurements the shortest sampling interval was used (3 hours, see Figure 4.15). Geodetic data are complemented with meteoric and lake level data to clarify data relationships.

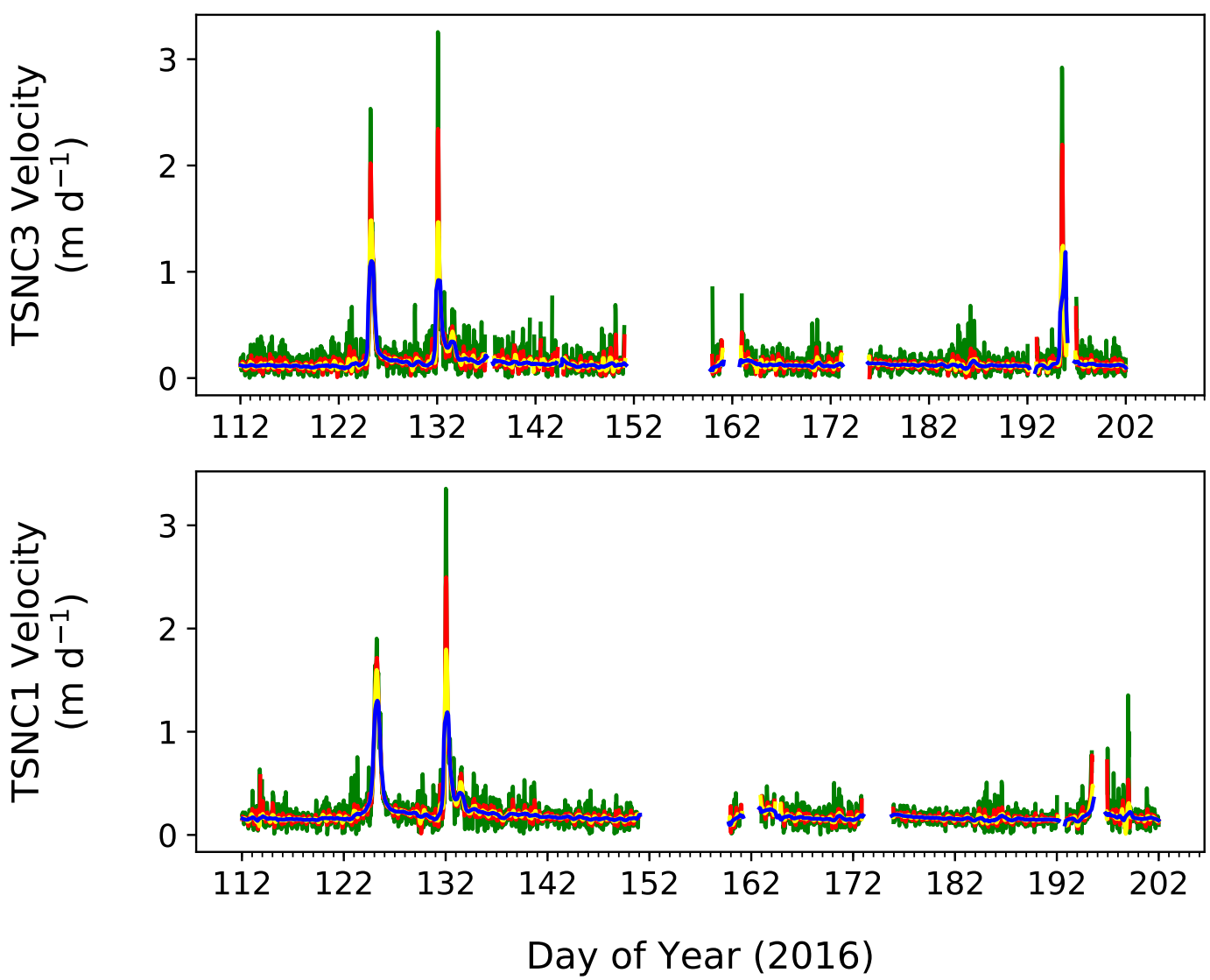

Figure 4.13: Velocity plots for TSNC3 (upper glacier) and TSNC1 (lower glacier) for various sampling intervals and time steps: blue line is 24 hour sampling interval, 60 minute time step; yellow line is 12 hour sampling interval, 15 minute time step; red line is 6 hour sampling interval, 15 minute time step; green line is 3 hour sampling interval, 15 minute time step.

The distribution of velocity uncertainties for 3 hour sampling intervals are shown in Figure 4.14. The mode of this distribution gives a representative velocity uncertainty for the data. Velocity uncertainties for upper (lower) glacier sensors using this method are $14 \%(12 \%), 6 \%(6 \%), 2 \%(2 \%)$, and $1 \%$ (1\%) for velocities from 3,6 , 12 , and 24 hour sampling intervals, respectively.

Due to the method of velocity calculation spikes are common at edge points of the 
data. Here short term trends dominate the sampling and become extrapolated to greater amplitudes with successive time steps. In all discussion of the geodetic data these spikes are considered processing artifacts.

For Figures 4.15-4.18 purple and green geodetic data are from the upper and lower GNSS sensors respectively, strain rate is positive during compression and negative during extension between the upper and lower GNSS sensors, velocities are calculated every 15 minutes from data in the surrounding 3 hours. In Figures 4.15 and 4.16 bar plot width is thickened to better show data relationships, and bounded sections $\mathbf{A}$ and $\mathbf{B}$ are shown with data relevant to accelerated sliding in Figures 4.17 and 4.18 , respectively.

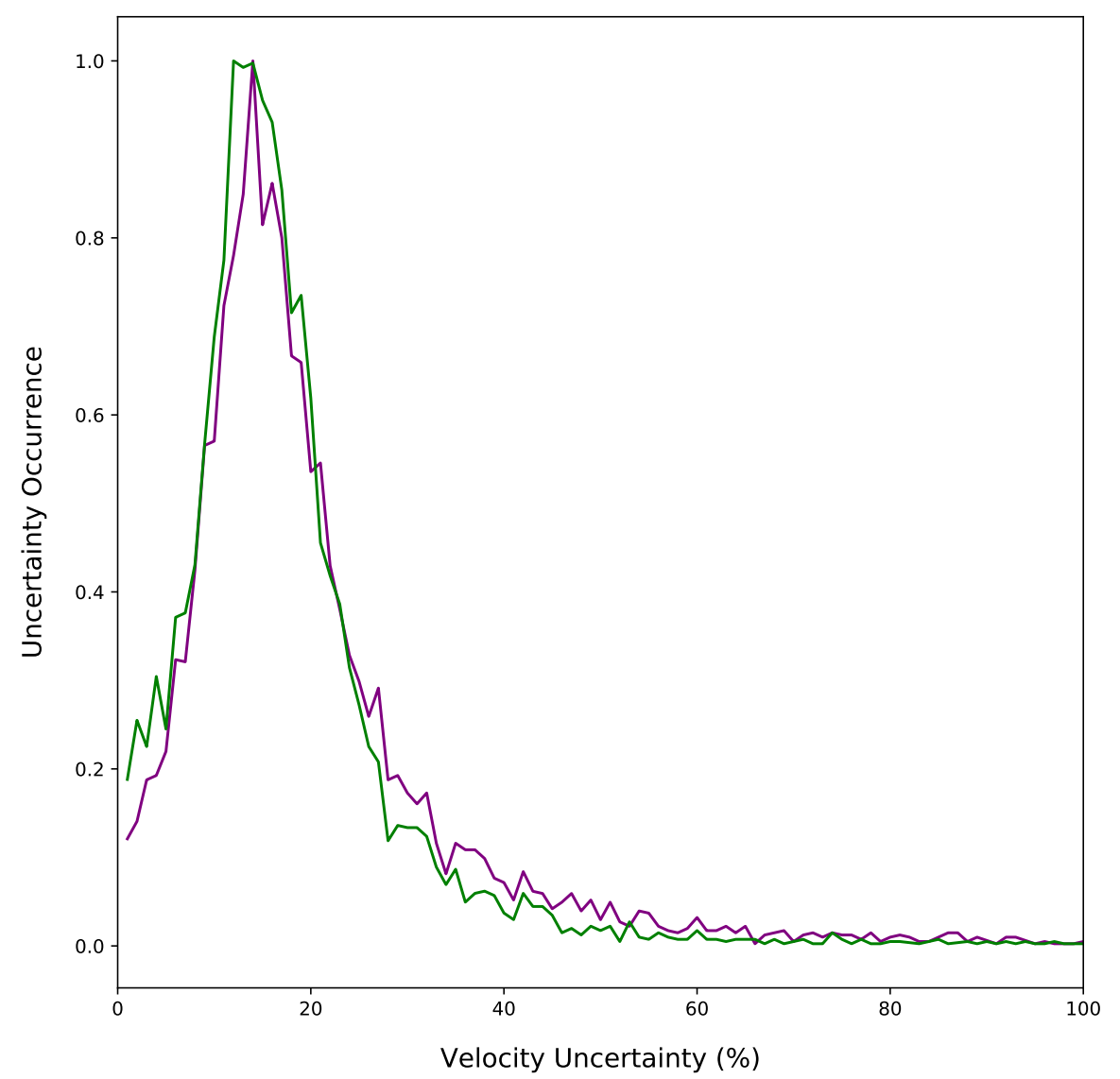

Figure 4.14: Velocity uncertainty distribution for upper (purple) and lower (green) glacier GNSS receivers for 3 hour sampling intervals and 15 minute time steps. 


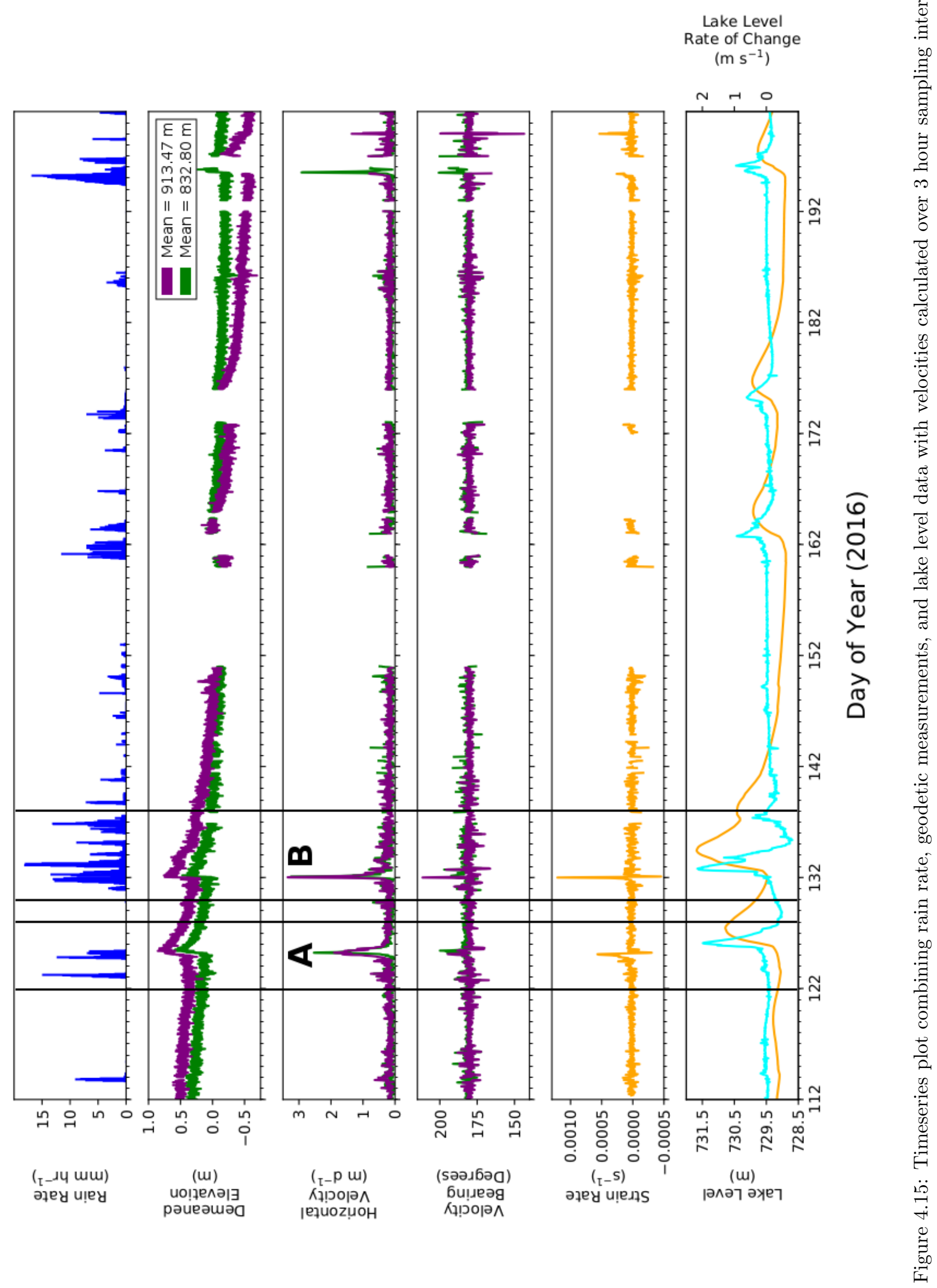




\subsection{Seismic-Geodetic Correlation}

Presented in this section are timeseries plots for the RISSIN data relevant to the discussion of accelerated sliding at Haupapa/Tasman Glacier (Figures 4.16-4.18). Correlations between timeseries are presented in Table 4.2. Here timeseries data are smoothed to 6 hours prior to the cross-correlation, this being the highest fidelity sampling interval for which data trends are more prominent than noise fluctuations. 


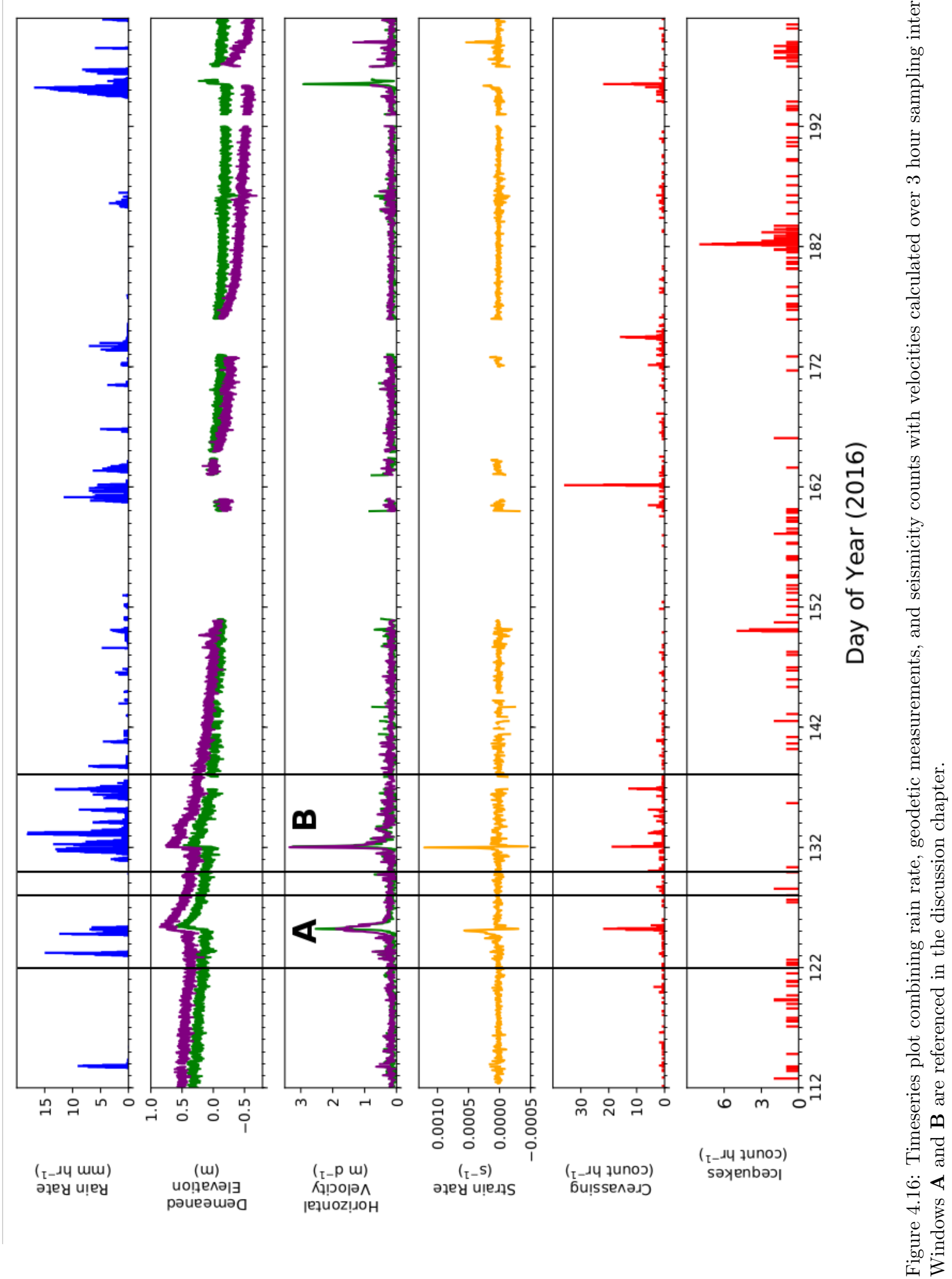




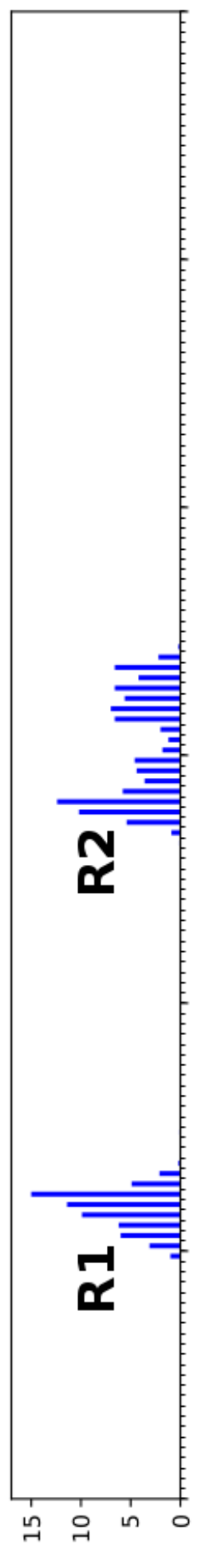

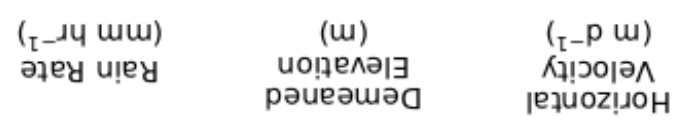
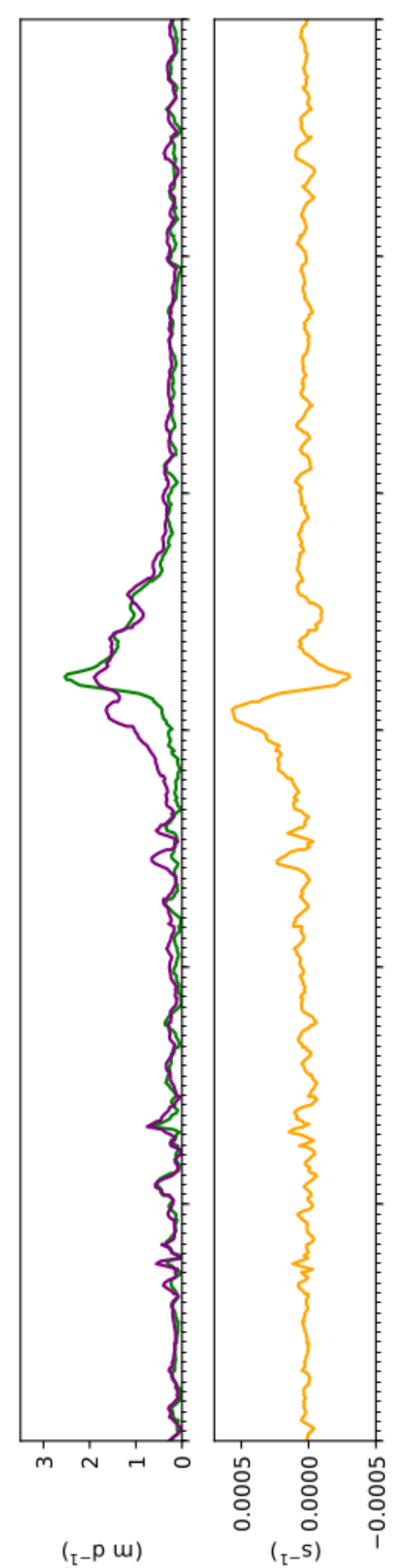

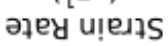

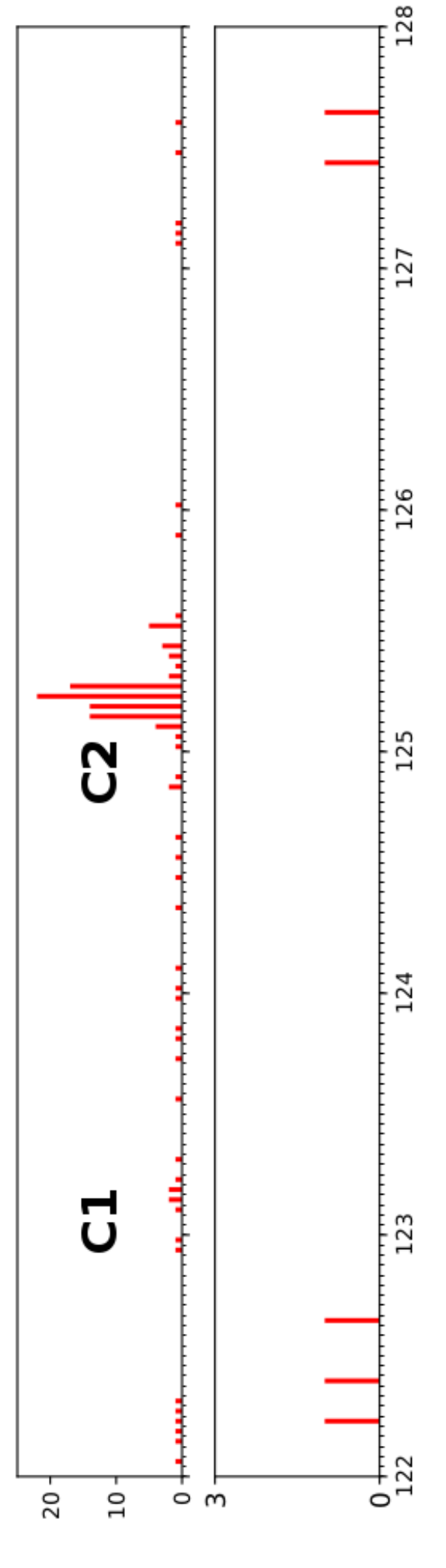

(I-dy zunoJ)

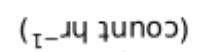

səx|enbəכ
:

.马

$\varangle$

总

$\mathbb{2}_{\infty}^{\infty}$

广

ㄱํำ

完.

-

屯ี

武

元:

ॠ

인

䎹

च

สี -

(ิ)

밍

ก

ก ธั

$>\quad-\frac{2}{0}$

प

จั

हี

巳

है

怘离

○

D.

范

.

bo

.$\exists$

है

0.

을

串

क

署

E

둔

구

$\stackrel{0}{3}$ 


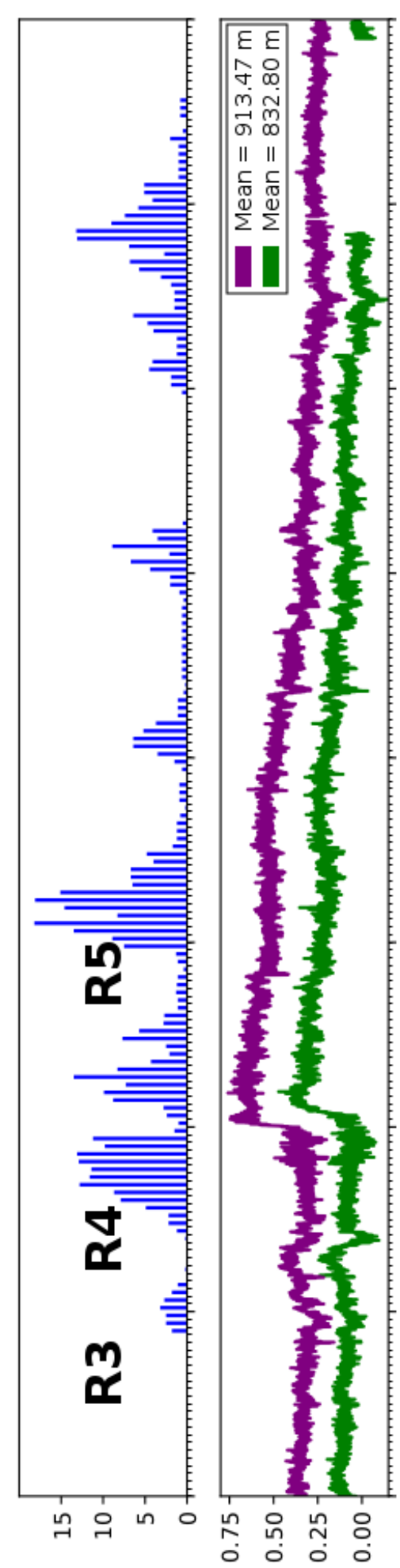

( әдеy uा̣ey

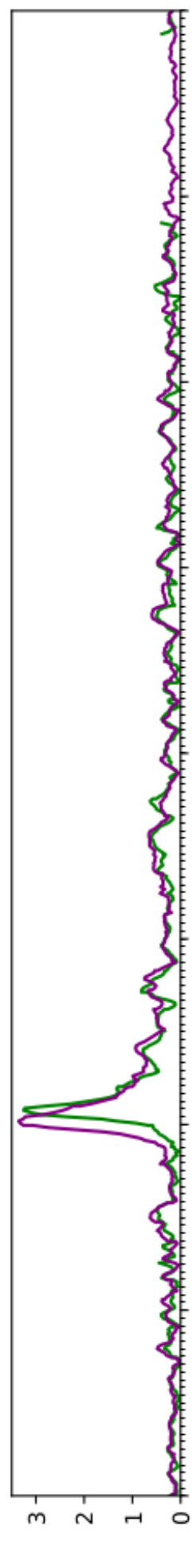

(

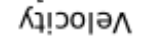
ןетuoz!joH
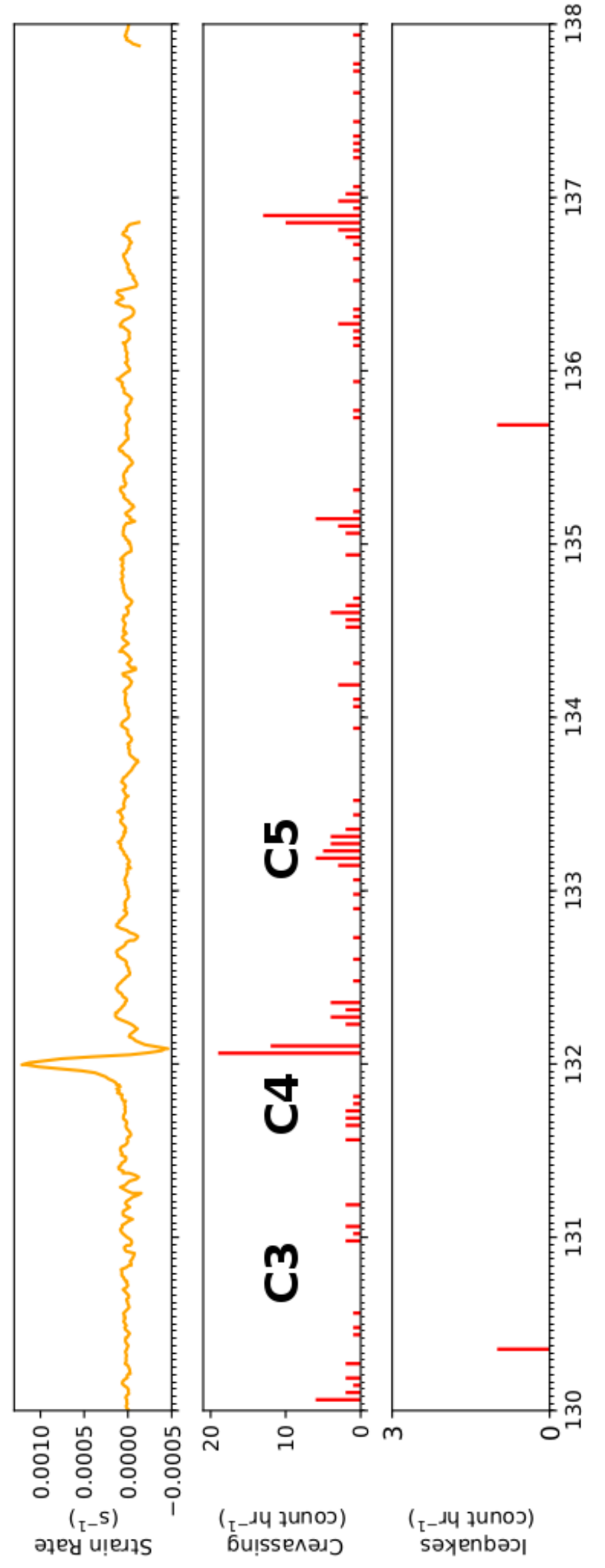

常



范

$\exists$

$\oplus$ เ

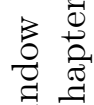

है

$\mathcal{E} . \exists$

m

ก

$\infty_{0}^{\infty}$

它 0

ब

ठิ

表

๑

అ

ㄴ. घ्व

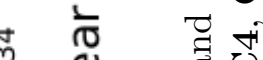

บ

บ 告

$>\quad$ 帛

बे

己્g.

.

可

so

$\infty_{0}^{\infty} \frac{\infty}{\pi}$

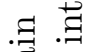

.7

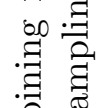

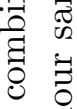

능

?

के

桴

$\ddot{\infty}$

고

○. స్.

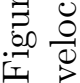




\begin{tabular}{|c|c|c|c|c|}
\hline 胥 号 & $\frac{\varangle}{z}$ & $\frac{\pi}{Z}$ & $\frac{\varangle}{z}$ & 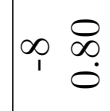 \\
\hline 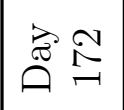 & 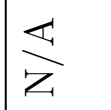 & $\frac{\varangle}{Z}$ & $\frac{\varangle}{Z}$ & $\stackrel{0}{\mathbb{2}}$ \\
\hline$\stackrel{R}{R}$ & $\frac{\varangle}{z}$ & $\frac{\varangle}{Z}$ & $\frac{\ll}{z}$ & $\sim \stackrel{\substack{\infty \\
0}}{0}$ \\
\hline ְु & $\frac{4}{z}$ & 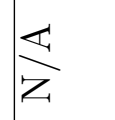 & $\stackrel{\circ}{\stackrel{\infty}{\circ}}$ & $\underset{\sim}{*}$ \\
\hline$\stackrel{8}{\bullet}$ & 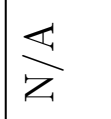 & 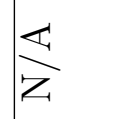 & $\frac{\ll}{Z}$ & or $\stackrel{12}{0}$ \\
\hline 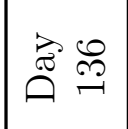 & $\frac{\varangle}{z}$ & $\infty \stackrel{\overrightarrow{0}}{0}$ & $\frac{\ll}{z}$ & $0 \begin{array}{l}0 \\
0 \\
0\end{array}$ \\
\hline$\stackrel{1}{\stackrel{2}{9}}$ & $0 \stackrel{0}{0}$ & 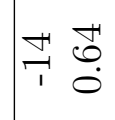 & $\underset{0}{\mathscr{P}}$ & o $\stackrel{\substack{0 \\
0}}{0}$ \\
\hline 号 & $\neg \stackrel{1}{0}$ & 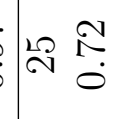 & $\stackrel{2}{2} \underset{2}{\stackrel{N}{0}}$ & o \\
\hline ๙ิ) & $\neg \stackrel{\infty}{\circ}$ & $0 \vec{g}$ & $\mid$\begin{tabular}{cc}
$\infty$ & \multicolumn{1}{c}{} \\
1 & $\stackrel{\infty}{0}$
\end{tabular} & $\infty \begin{array}{l}\infty \\
0 \\
0\end{array}$ \\
\hline$\stackrel{\circ}{\rightarrow}$ & $0 \stackrel{\infty}{0}$ & p & $\Re \stackrel{\vec{\rho}}{\ddot{\sigma}}$ & $\stackrel{\leftrightarrow}{\rightarrow} \stackrel{\mathscr{O}}{0}$ \\
\hline$\stackrel{10}{\sim}$ & T & $r_{1}^{\infty} \stackrel{\infty}{1}$ & 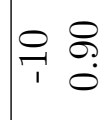 & is \\
\hline 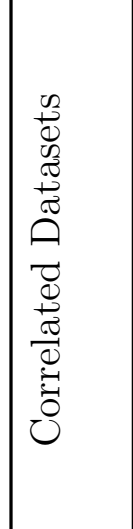 & 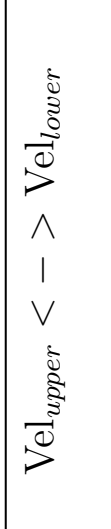 & 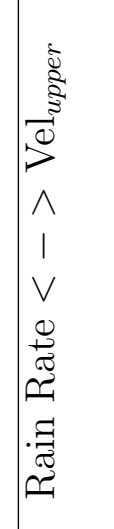 & 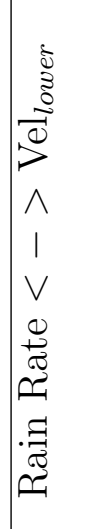 & 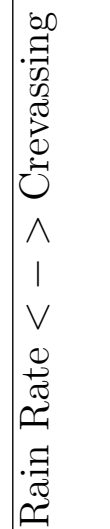 \\
\hline
\end{tabular}

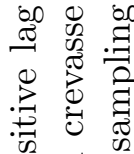

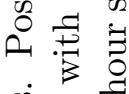

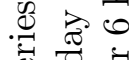

焉

50 离

औี

फे

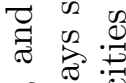

通事

$\therefore \rightarrow$

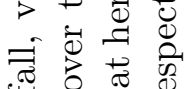

要

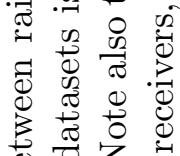

in

㟢

象

₹

苞

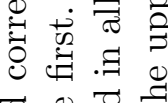

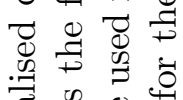

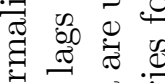

要

范苟记

可. 吾

o

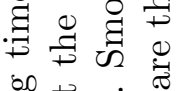

苞

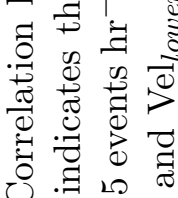

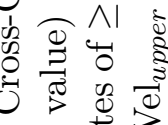

तi 各苋

+i 8

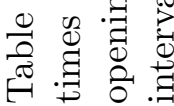




\subsection{Crevasse Opening}

Crevasse opening locations are determined by the optimal source location of the full network grid search for each crevassing event. Generally, crevasses open along the glacier margins and this opening is often temporally irregular with 1-2 events occurring in any given hour (Figure 4.12). To better quantify the magnitude and timing of peaks in crevassing rate (Figure 4.12) two conditions were defined such that crevassing event counts in a peak hour must: 1) be at or above one standard deviation from the mean hourly crevassing event count (Figure 4.19), 5 events hour ${ }^{-1}$, and 2) be greater than the crevassing event count in any of the surrounding 12 hours. These conditions ensured that crevassing rate peaks were outliers of the crevassing rate distribution and were not clustered unnecessarily during sustained periods of elevated crevassing rate.

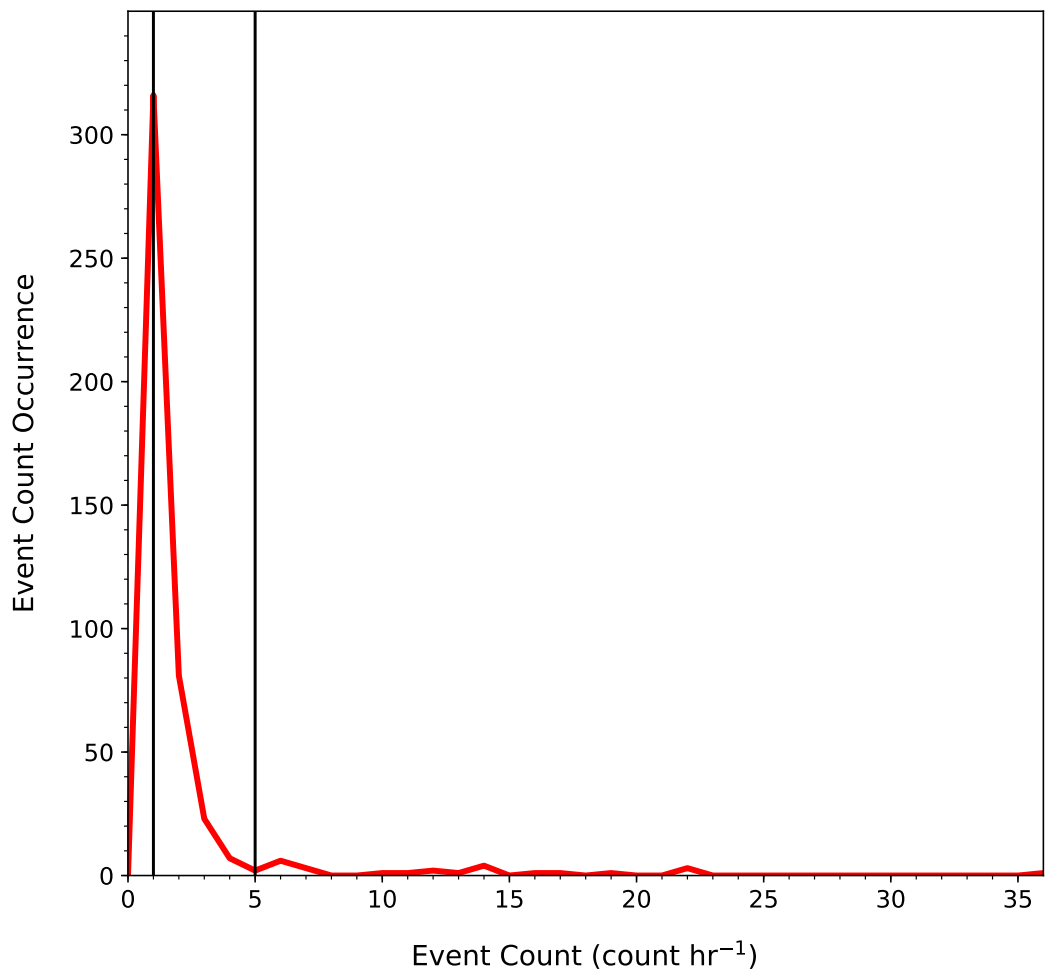

Figure 4.19: Distribution of non-zero crevassing event counts over the complete timeseries. The two bold lines show, in order from left to right, the value of the mode and one standard deviation above the mean.

Spatial trends in crevasse opening during crevassing rate peaks vary between very active hours of marginal and terminal crevasse opening and a down-glacier migration of crevassing locations. The terminal-distance of events in those crevassing rate peaks exhibiting a visible migration of events down-glacier are shown plotted against time in Figure 4.20. The locations and relative timing of crevassing events in these peaks are shown in Figures 4.21 and 4.22. Here linear regression curves are shown for 
those episodes whose event migration could be fit with a $\mathrm{p}$ value $<0.05$. The other episodes in Figure 4.20, though later interpreted to show down-valley crevassing migration, cannot be quantitatively described by such a linear fit. Further discussion on this topic is given in Section 5.2.

In Figures 4.21 and 4.22 3D crevassing positions are projected vertically onto a $2 \mathrm{D}$ plane and summed across the grid for each hour. In each sub-figure the $\mathrm{x}$ axis is Eastings $(\mathrm{km})$, the y axis is Northings $(\mathrm{km})$ and the grid cell size is $500 \mathrm{~m}$. Surface exposure of different materials is shown for reference as shades of grey; from darkest to lightest: proglacial lake, moraine and gravels, glacier, bedrock (white).

Off-glacier locations in Figures 4.21 and 4.22 result from limitations in the full waveform cross-correlation location method: greater waveform shifts can produce the same cross-correlation value by locating a source further from the network but with the same relative shift between waveforms. Additionally slower traveling waves can produce optimal cross-correlation values at greater distances from the network due to the erroneously high velocity model for these waves. These effects combine such that distal crevasse opening events, these being dominated by a slow moving Rayleigh phase, exhibit an optimal location locus that begins outside the network margins and stretches to the search grid maxima (Figure 4.4 shows this well). Optimal locations from these network-external events are therefore informative only of the back-azimuth of the event source.

For those crevassing events within the network another limitation arises due to the velocity model: waveforms observed at the moraine sites are assumed to travel through the moraine at the ice velocity. Though moraine sites encircle the network and generally provide improvements to location constraints (see the bullseye-like locus of $99 \%$ cross-correlation value in Figure 4.5) the lack of a travel time correction for these sites spreads the optimal location region. The result is that the location of crevasse opening may fall within one of the grid cells adjacent to the actual location. To reduce this uncertainty and improve location precision a heterogeneous velocity model (or station corrections) and a grid cell size substantially smaller than $500 \mathrm{~m}$ needs to be used. As this has not been done in the analysis of RISSIN data absolute locations are not considered: the relative distribution of crevasse opening locations is instead used as a proxy for the spatial distribution of surface strain. 


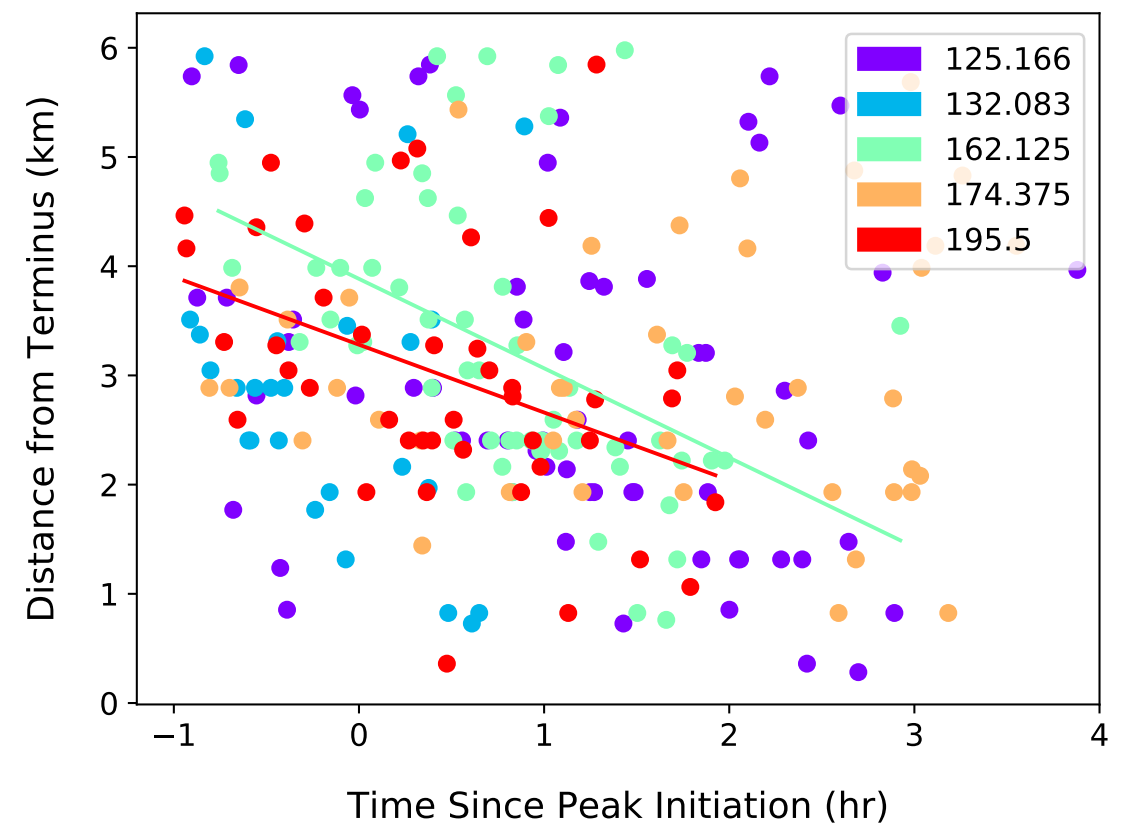

Figure 4.20: Five episodes of down-glacier migrating crevasse opening locations with crevasse opening distance from the terminus plotted against time. The scatter point colour denotes the day of year and hour of initiation of each peak. Negative hours are an artifact of binning times to the end of hours for timeseries display. Lines plotted are for linear regressions with $\mathrm{p}(\mathrm{r})$ values less than 0.05: $0.0002(0.46)$ and 0.009 (0.40) for the day 162 and day 195 lines, respectively. 

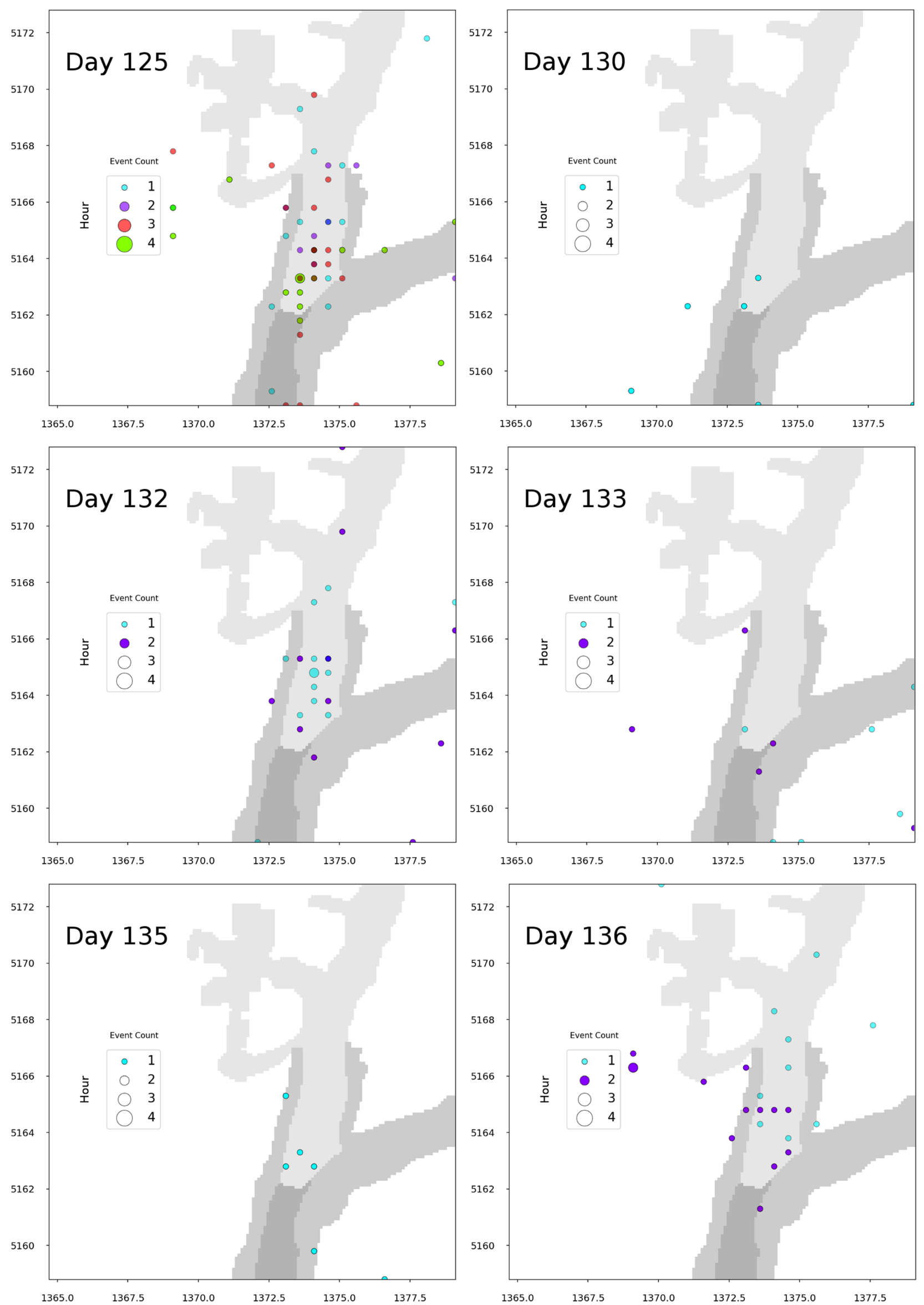

Figure 4.21: Crevasse opening locations for six episodes of crevassing rate peaks. Scatter point size and colour show crevasse opening event count in each grid cell and the time of an event since each episode's onset, respectively. Points are plotted with translucency such that mixed colours indicate a location of repeated opening. 

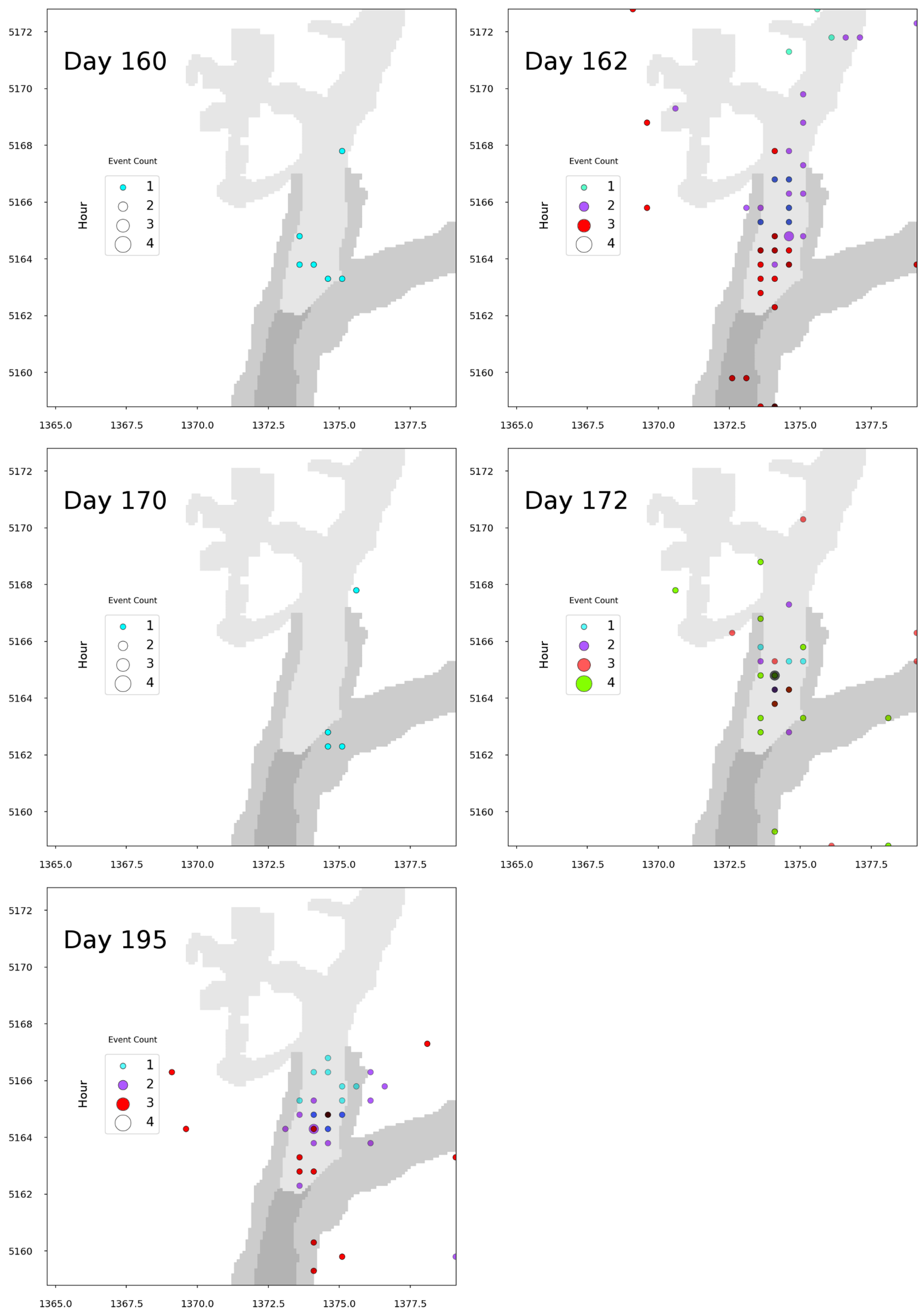

Figure 4.22: Crevasse opening locations for five episodes of crevassing rate peaks. Scatter point size and colour show crevasse opening event count in each grid cell and the time of an event since each episode's onset, respectively. Points are plotted with translucency such that mixed colours indicate a location of repeated opening. 


\subsection{Icequake Locations}

Icequakes are the seismicity observed within the glacier or at its bed. Icequake occurrence is distributed both temporally (Figure B.4) and spatially (Figures 4.23 and 4.25). However within this distributed record are three temporal and spatial clusters. Two clusters locate near the top of Ball Glacier (Figure 1.2), one at its western-most edge and another near its northern-most edge, and correspond to temporal event rate clusters on days 181-183 and 197-198, respectively. The remaining cluster, occurring over days 149-150, shows scattered locations across the Kirikirikatata/Mt. Cook Range south of Ball Glacier. In the remainder of the icequake catalogue event occurrence is sparse with at most 1-2 occurring in a given hour with no relationship between their locations.

The network-external nature of icequakes in the three observed clusters causes their positions to be poorly constrained. This manifests as a well-resolved event azimuth but elongate zones of near-optimal location PDF values in the direction of event back-azimuth (Figure 4.26). Therefore the events in these clusters may not originate from brittle ice deformation in Ball Glacier but rather may stem from the precursory seismicity (rock fracture) to rock avalanches in the adjacent unstable mountain slopes.

Ignoring those measurements made on sensors known to have coupling issues (these being TSNC3, TSNC4, TSNL3) the distribution of first motions over all observed icequakes is:

- Only Up $=75$

- Only Down $=110$

- Mixed $=25$

The nature of the first motions observed beneath the Haupapa/Tasman Glacier tongue is shown in Figure 4.24. Here first motions are separated into single polarity and mixed polarity only.

Uncertainty in the icequake hypocentres due to network geometry, velocity model structure, and arrival time picks is the RMS residual between observed and calculated wave arrival times for the hypocentre location. Thus the size of the RMS residual is considered representative of the location uncertainty when one PDF point 


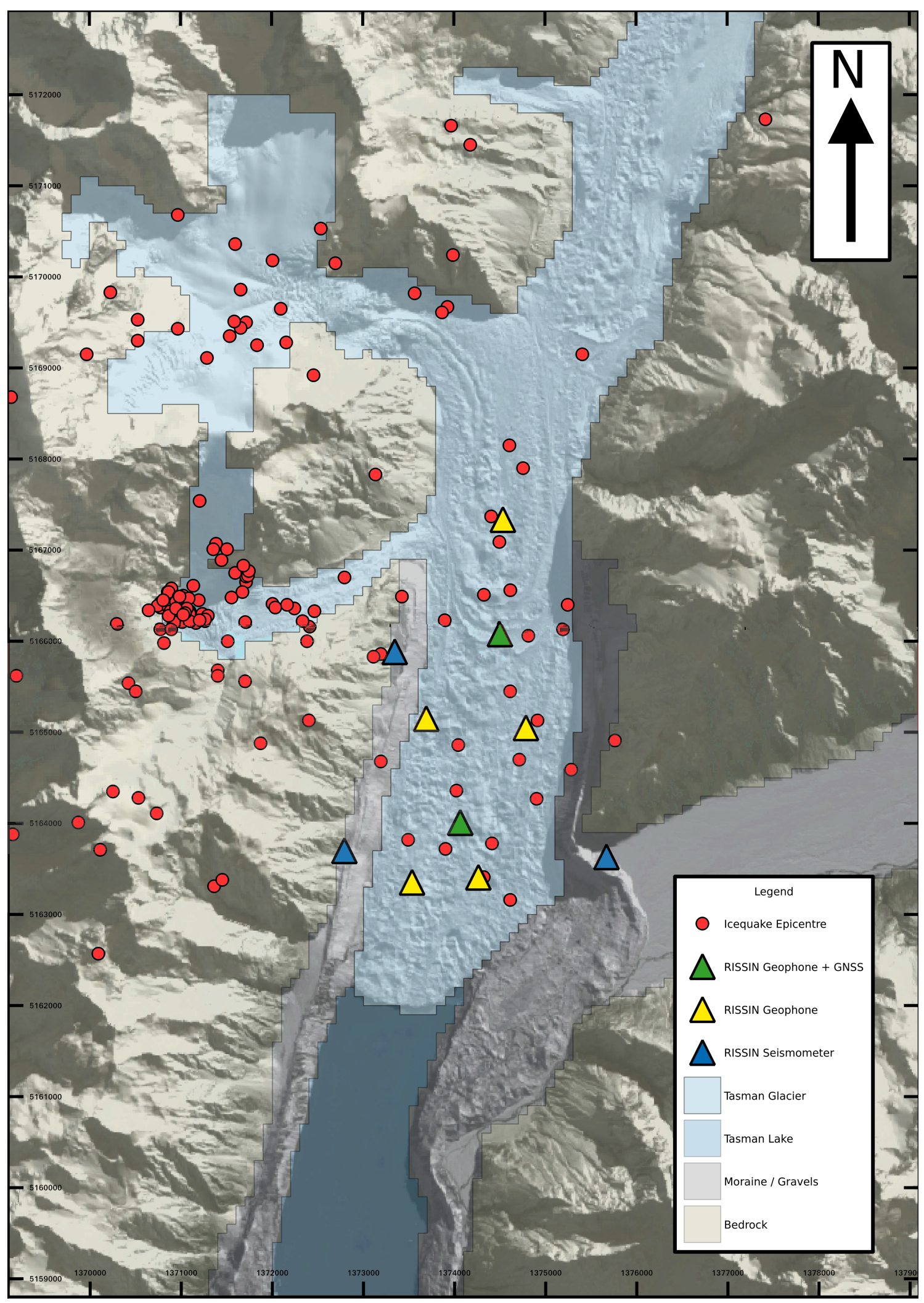

Figure 4.23: Icequake epicentres for 160 of the 211 detected icequakes over the RISSIN deployment. Ten epicentres are outside of the viewing extent shown.

is much more probable than all others. Icequake hypocentre locations are plotted in Figure 4.25 with hypocentre points scaled to show their corresponding RMS residual value. When the PDF is not peaked the RMS residual does not represent the location accuracy well. Here a measure of the spread in potential hypocentre location 


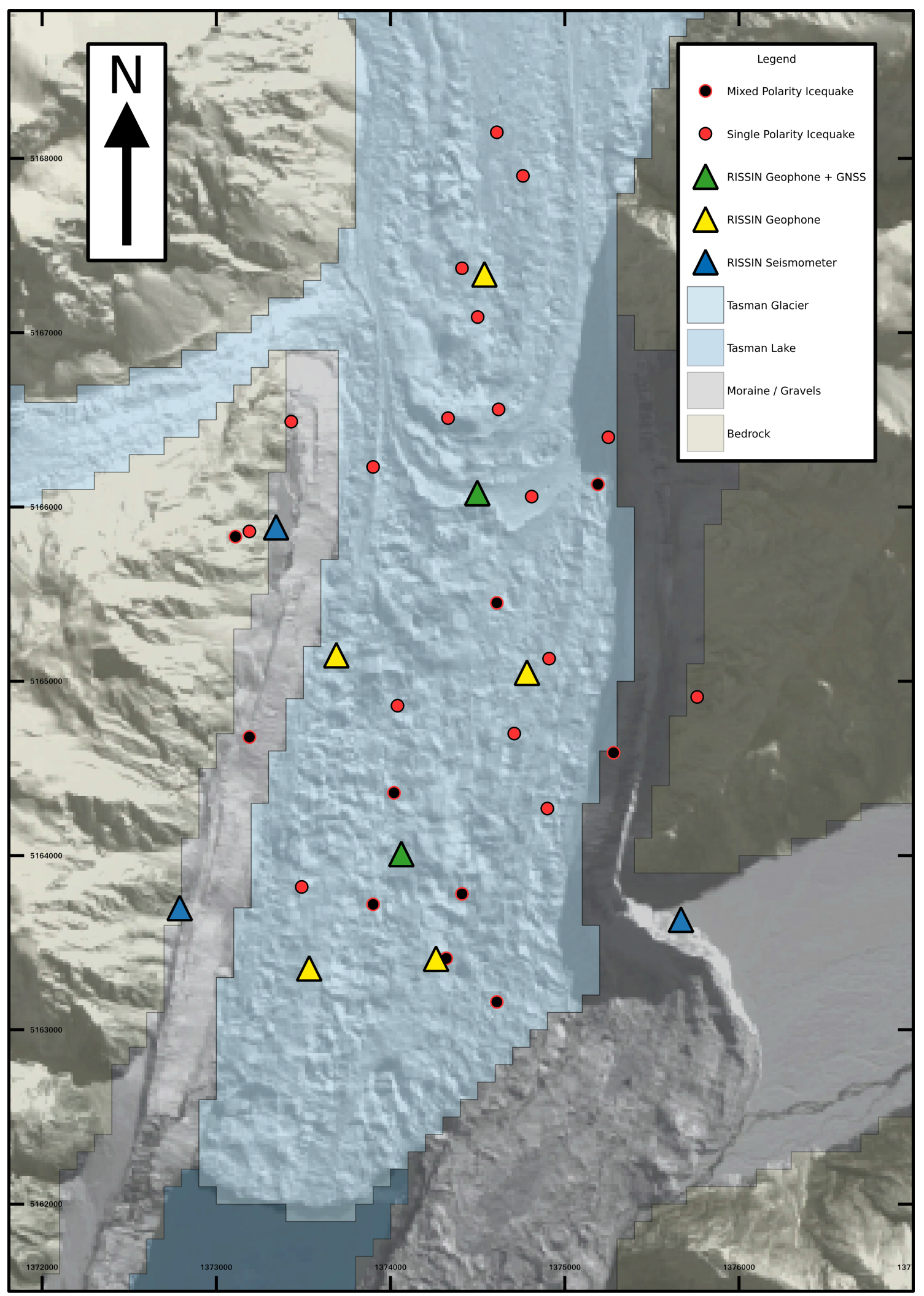

Figure 4.24: Icequake epicentres over the lower Haupapa/Tasman Glacier tongue showing first motion characteristics. First-order polarity measurements are shown by icequake epicentre shading.

is required. Representative uncertainties for network-central and network-external hypocentres in these cases in order of Easting, Northing, and depth are: 
- Network-central hypocentre (99\% confidence): $\pm 80 \mathrm{~m}, \pm 40 \mathrm{~m}, \pm 30 \mathrm{~m}$

- Network-external hypocentre (99\% confidence): $\pm 80 \mathrm{~m}, \pm 50 \mathrm{~m}, \pm 100 \mathrm{~m}$

- Network-external hypocentre (95\% confidence): \pm 350 m, \pm 170 m, \pm 1300 m

These uncertainties were calculated as one standard deviation of the PDF point locations in the given confidence interval, these points being discerned as those with probabilities that integrate to form the desired hypocentre confidence interval in the method of Moser et al. (1992). See Figure 4.26 for the distribution of PDF points in the $95 \%$ confidence interval of a network-external icequake. In general hypocentre accuracy will be the best over the lower Haupapa/Tasman Glacier tongue as the concentric nature of the surrounding seismic network provides optimal geometric constraints (Rost and Thomas, 2002). Here the approximate location of an icequake, as shown by its epicentre, is assumed to be reliable and moreover the relative position of epicentres can be used for general interpretations. However the resultant conclusions cannot be made with absolute certainty (Section 5.5).
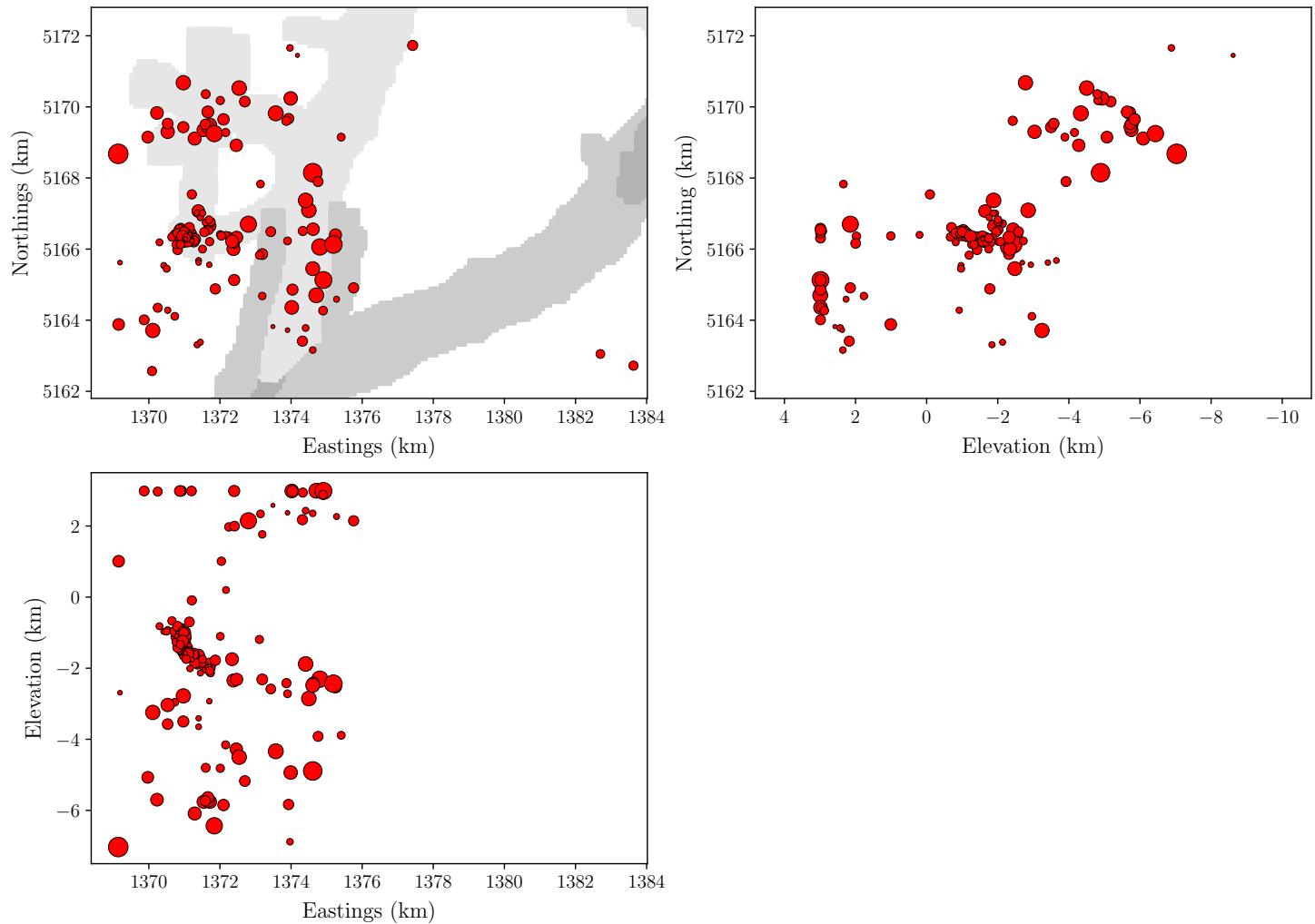

Figure 4.25: Icequake hypocentre locations for 160 of 211 detected icequakes scaled to represent the size of their RMS arrival time residual. Three $2 \mathrm{D}$ cross sections describe the $3 \mathrm{D}$ distribution of hypocentres. Surface exposure of different materials is shown on the horizontal cross section as shades of grey; from darkest to lightest: proglacial lake, moraine and gravels, glacier, bedrock (white). 


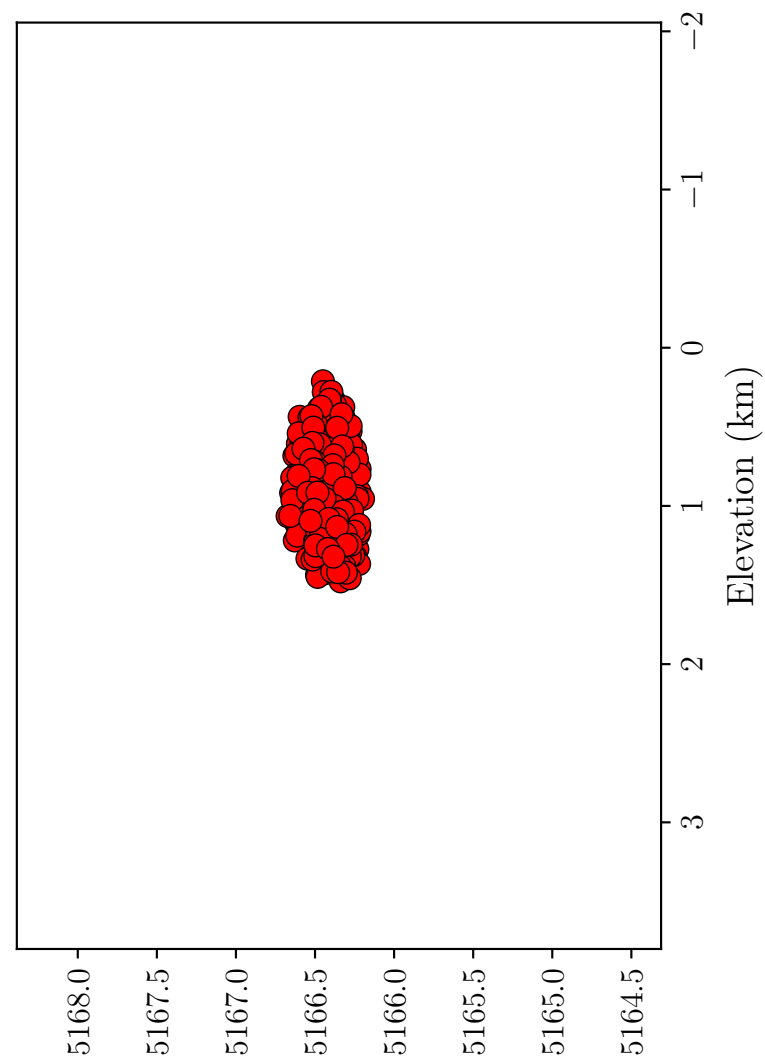

:

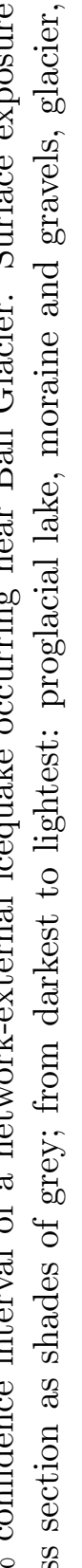

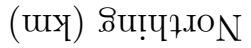

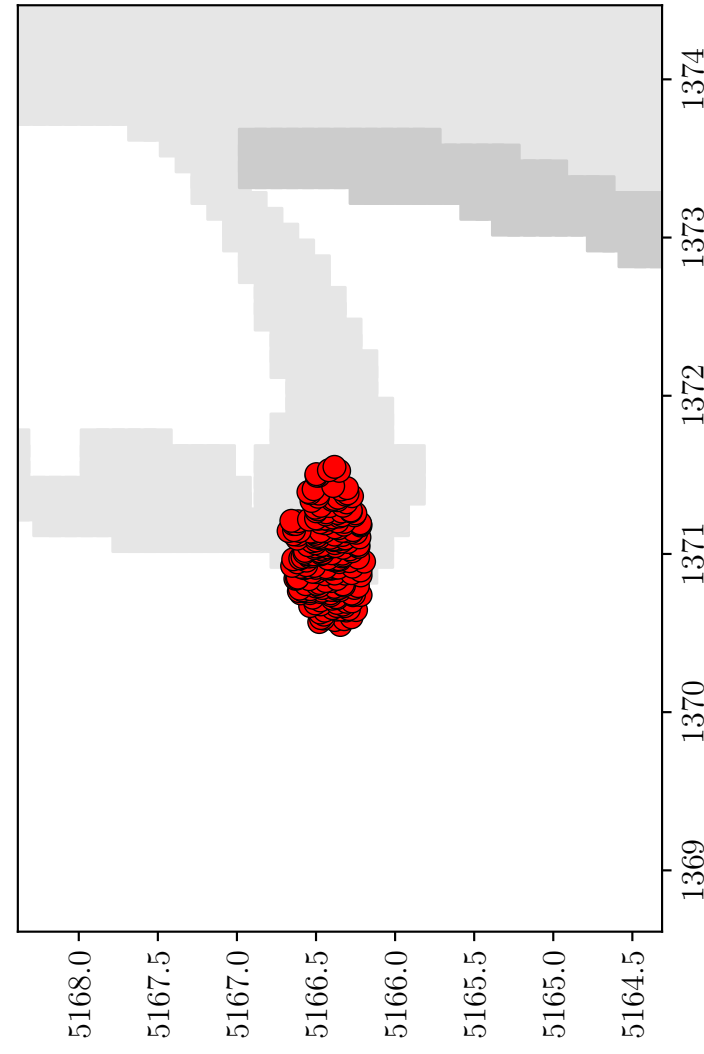

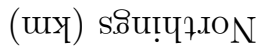

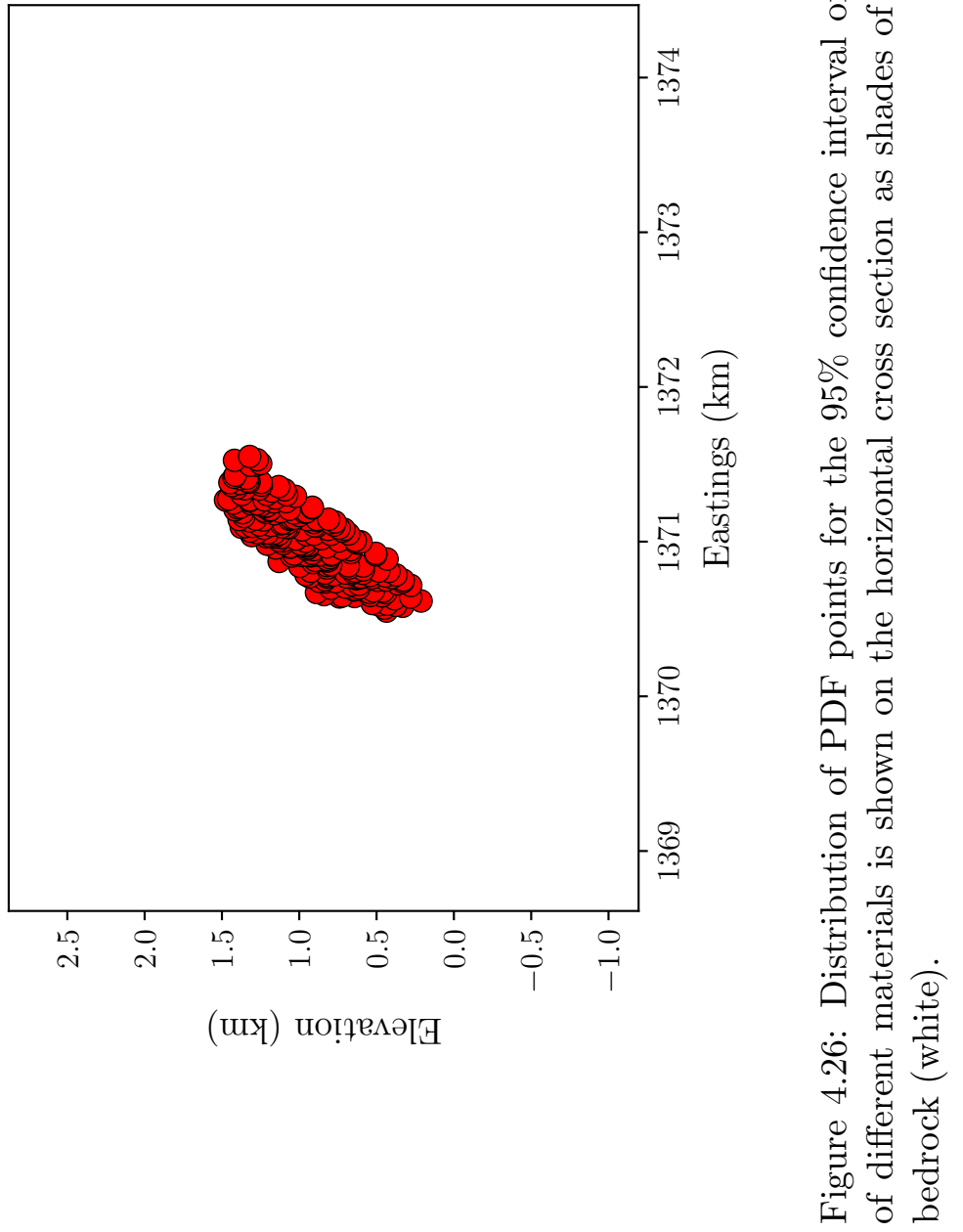




\section{Chapter 5}

\section{Discussion}

\subsection{Geodetic Relationships}

Horgan et al. (2015) studied the velocity variability of Haupapa/Tasman Glacier over several years. As well as the yearly variation in horizontal and vertical glacier velocities at Haupapa/Tasman Glacier, these authors also present periods of elevated glacier velocities following heavy rainfall. The presentation of geodetic relationships in this thesis are heavily influenced by the conclusions of Horgan et al. (2015), a summary of which is given below in context of this thesis' data.

As reported by Horgan et al. (2015) glacier surface elevation lowers continuously due to glacier thinning and down-valley ice advection in the absence of heavy rainfall (Figure 4.15). During heavy rainfall episodes rapid glacier uplift occurs as subglacial cavities fill and lift the glacier sole from its bed (see steps in glacier elevation and velocity in Figures 4.15-4.18). The rising limb and peak velocities during these periods (Figures 4.15-4.18) are the result of the glacier ratcheting over cavity-adjacent bedrock bumps while cavities are filling and the glacier is partially decoupled from its bed (Iken, 1981; Harper et al., 2007; Horgan et al., 2015). Following cavity collapse and cessation of the initial speed-up glacier velocity remains elevated (Figures 4.15-4.18). I interpret this protracted period of elevated velocity to result from the drowning of bed undulations by an expanded basal water film (Patterson, 1994). The rainfall threshold required to trigger accelerated glacier motion (Horgan et al., 2015) can be seen by the lack of accelerated glacier motion following rainfall event $\mathbf{R} 1$ in Figure 4.17. As slip at the ice-bed interface is the dominant mechanism of basal motion occurring during episodes of accelerated glacier motion (Section 2.2), the phenomena of transient accelerated glacier motion is summarised well by the term accelerated sliding and, in the case of Haupapa/Tasman Glacier, the accelerated sliding is initiated by large volumes of rain water entering the subglacial 
drainage system.

The level of Tasman Lake begins to rise sharply near the end of cavitation as the first substantial water volumes leave the subglacial drainage system (Figure 4.15). The lake level continues to rise until cavities have collapsed, at which point continued increase follows drainage from other components of the subglacial drainage system and inputs from non-glacial hydrological pathways in the Tasman Valley catchment (Figure 4.15). At Haupapa/Tasman Glacier the lake level does not appear to influence accelerated sliding. This follows from two trends in the data: the upper glacier accelerates before the lower glacier with typical delay times between the two glacier regions of 1-2 hours (Day 125 and 132 in Table 4.2), and the peak surface elevation of any part of the glacier is reached before that of the lake level (Figure 4.15). Therefore water migration likely occurs from the upper glacier to the lake. Further details supporting this argument are given by Horgan et al. (2015).

The equation describing basal slip, Equation 2.1, has two terms that can be varied to explain the accelerated sliding conceptually, $N$ and $k$. During cavitation the subglacial water pressure is increasing, causing the effective pressure $N$ to tend toward zero. If $N$ equals zero across the whole glacier sole an unbounded slip velocity occurs. This extreme scenario is not observed, though an initial rapid acceleration of the glacier does occur, suggesting that the glacier reaches flotation across a significant part of its sole following cavitation, this manifesting as the ratcheting forward of the glacier over bedrock bumps that forms the rising limb of the velocity peak.

Following cavitation I interpret that the basal water film expands to capture water from the collapsing cavities. As such a water film expands undulations in the glacier bed will become submerged. This results in an increase of the factor $k$ which is inversely proportional to the bed roughness (Patterson, 1994). As water drains from the water film the bed roughness and the effective pressure increase, thus lowering the sliding velocity. In my interpetation, the rate of this drainage determines the decay rate of the falling limb velocity.

Strain rate timeseries present further details as to the nature of glacier motion during rain-induced accelerated sliding episodes at Haupapa/Tasman Glacier. Here a recurrent trend exists between the two well-resolved velocity peaks on days 125 and 132: compressional strain rates between the upper and lower GNSS stations increase during the cavitation of upper parts of the glacier, then becomes extensional when lower parts of the glacier ratchet forward, and finally return to near-zero values when 
upper and glacier velocities become similar post-cavitation (Figures 4.17 and 4.18). This strain rate trend can be interpreted by considering the nature of subglacial water delivery for cavitation. A key term used in this interpretation is the cavitation front: the position beneath the glacier in which cavitation is occurring and allowing the ratcheting motion of the overlying glacier.

- Cavitation-sized water inputs reach upper parts of the glacier first due to their being higher in the catchment (closer to water flowing down-valley). The subsequent ratcheting forward of such segments enhances compressional strains in downstream parts of the glacier.

- When successive downstream parts of the glacier experience cavitation and ratchet forward, the upvalley ice - that in the lee of the cavitation front is already decelerating, and the glacier strain field is compressive downstream and extensional upstream of the cavitation front.

- Once the cavitation front has reached the glacier terminus the entire glacier sole is lubricated by a basal water film (synchronous velocity changes seen in Figures 4.17 and 4.18). The resultant hydraulic connectivity allows synchronised velocites across the glacier.

Glacier velocity bearing deflections seen during accelerated sliding (Figure 4.15 and Appendix B Figures B.1-B.3) have been attributed to cavitation by Sugiyama et al. (2010). These authors argue that the development of a flow-transverse velocity component occurs during the bed to surface transmission of the vertical displacement resulting from cavity expansion. Here the glacier movement direction is initially deflected margin-ward, but subsequent realignment returns it to its prior azimuth. This trend is visible in Figure 4.15 and Appendix B Figures B.1-B.3 as the westward deflection of the glacier during cavitation. However a clear eastward-deflection (realignment) following this westward-deflection is not apparent.

\section{$5.2 \quad$ Accelerated Sliding}

The process of accelerated sliding at Haupapa/Tasman Glacier can be described by considering pre-cavitation, cavitating, and post-cavitation sections of the glacier, hereafter called the background, ratcheting, and slow-sliding regimes for ease of distinction. The following is a simple summary of accelerated sliding in these terms which references Figure 5.1: 
- Water volumes sufficient to cause cavitation convert a background section of the glacier into a ratcheting section (Figure 5.1, b). This part of the glacier then lurches forward into a downstream background section of the glacier, increasing compressive strain between the two sections (Figure 5.1, b).

- The background section of the glacier then undergoes cavitation as a result of down-glacier subglacial water flow (Figure 5.1, c).

- The upstream ratcheting section then experiences cavity collapse, triggering the initiation of the slow-sliding regime (Figure 5.1, c). The previously compressed boundary between the two sections now undergoes extension (Figure $5.1, \mathbf{c})$.

- The cavitation front moves down-glacier, causing strong velocity gradients as it does so between background, ratcheting and slow-sliding parts of the glacier (Figure 5.1, c).

- Upstream regions of the glacier that are in the slow-sliding regime experience synchronous velocities from the controlling influence of the basal water film beneath them (Figure 5.1, d).

- Once the cavitation front has reached the glacier terminus the entire glacier sole is lubricated by the basal water film and slides at a velocity dependent on the thickness of this film (Figure 5.1, e). 

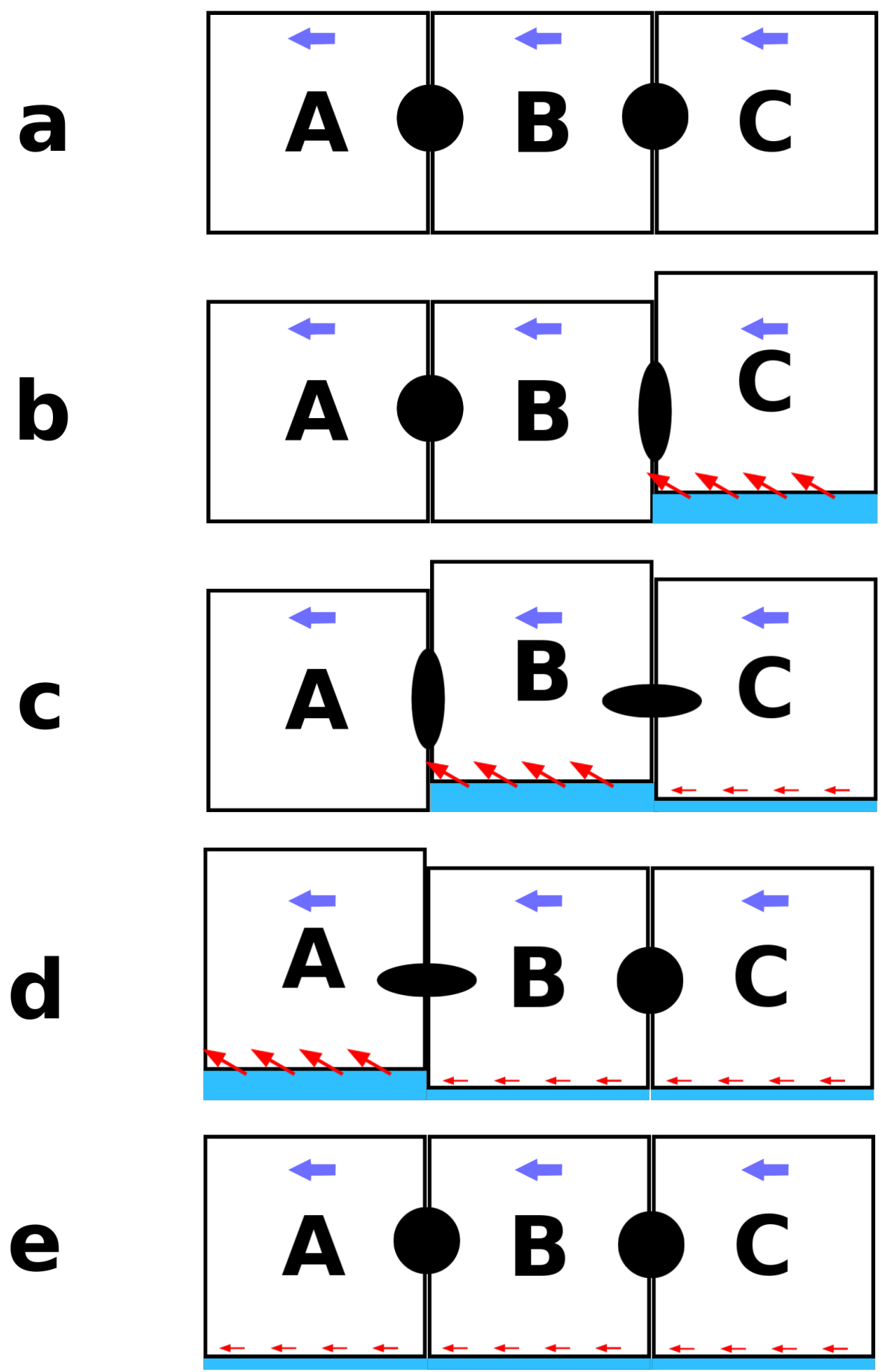

Figure 5.1: Sequential block model describing accelerated sliding at Haupapa/Tasman Glacier. Blue arrows show the background flow direction while red arrows show the velocity enhancements which occur during accelerated sliding. a shows three blocks of the glacier A, B, and $\mathbf{C}$ with strain ellipses at their boundaries. Subglacial flooding occurs between time $\mathbf{a}$ and time $\mathbf{b}$, causing cavitation beneath block $\mathbf{C}$. $\mathbf{b}$ shows block $\mathbf{C}$ ratcheting into block $\mathbf{B}$, causing compression of the strain ellipse at their boundary. At $\mathbf{c}$ block $\mathbf{B}$ is ratcheting into block $\mathbf{A}$ while block $\mathbf{C}$ enters the slow-sliding regime controlled by the post-cavitation basal water film. As block $\mathbf{B}$ moves much faster than block $\mathbf{C}$ the strain ellipse between the two blocks is stretched, while the strain ellipse between blockA and $\mathbf{B}$ is compressed. At time $\mathbf{d}$ block $\mathbf{A}$ is ratcheting while upstream blocks $\mathbf{B}$ and $\mathbf{C}$ are both in the slow-sliding regime with synchronised velocities. Once cavity collapse occurs beneath block $\mathbf{A}$ the glacier is fully underlain by the expanded water film and strain rates are near-zero, i.e. time e. 


\subsection{Strain-Driven Crevassing}

One result of accelerated sliding at Haupapa/Tasman Glacier is crevasse opening. This is controlled by extensional strains between adjacent sections of the glacier as the cavitation front passes through them (Figure 5.1). The crevassing rate peaks associated with this migration can be seen in Figures 4.17 and 4.18 as C2 and C4, respectively. These crevassing rate peaks are contained within the strain change from compression to extension, the latter state promoting the crevasse opening. The locations of the opening crevasses in these peaks migrate down the glacier over the duration of the crevassing rate peak (days 125, 132, 162, 174, 195 in Figures 4.20-4.22), this occurring at velocities between $0.62-0.82 \mathrm{~km} \mathrm{hr}^{-1}$ (Figure 4.20) which are similar to the average cavitation front velocity of $0.64 \mathrm{~km} \mathrm{hr}^{-1}$ (Horgan et al., 2015).

The magnitude, extent, and duration of strain-driven crevasse opening episodes is controlled by two factors: 1) the velocity of the cavitation front, and 2) the minimum spacing between adjacent crevasses. Slower propagation of the cavitation front stretches the strain rate reversal out over time and results in a greater number of crevasse opening events over a longer period (Compare that of Figures 4.17 to 4.18 and peaks on days 125 and 132 in Table 5.1). To examine this consider a fast-moving cavitation front; disparate parts of the glacier are all at similar stages of the ratcheting process at similar times, thus reducing the strain rate at their boundaries. This results in the points defining the boundary between a ratcheting section and a slow-sliding section of the glacier being at a greater separation than in the case of a slower moving cavitation front (Figure 5.1). As this boundary forms the locus of crevasse opening it follows that rapid cavitation front propagation reduces the potential for crevasse opening due to the smoothness of the velocity field it produces (see the narrow region of crevasse opening during the crevassing rate peak on day 132 in Figure 4.21).

The second controlling factor, the minimum spacing between adjacent crevasses, is required to explain the relatively sparse distribution of crevasse opening during accelerated sliding. Were there no resistance to crevasse opening the motion of the cavitation front could open crevasses along the entire length of the glacier at spacings comparable to crevasse width. Crevasses, especially deep crevasses, inhibit the formation of new crevasses via local extensional stress reduction (Van der Veen, 1998). This stress reduction may be responsible for the lack of glacier-wide crevasse opening as the stress intensity at a crevasse tip will only reach the opening value when the mitigating effect of other nearby or deep crevasses has subsided. The presence of wa- 
ter could aid or abate this crevasse opening: hydrofracture-driven deepening of the opening crevasses would increase the spacing between crevassing loci, while water in proto-crevasses would allow crevasse opening in zones of low extensional stress. However given that both occur the result would be a dense spacing of deep crevasses. Whether hydrofracture is the active mechanism of crevasse tip propagation during accelerated sliding has not be resolved from the data, though unregistered repeating seismicity observed during accelerated sliding related crevassing rate peaks may be a signature of sustained hydrofracture (section 3.3).

\section{$5.4 \quad$ Water-Driven Crevassing}

Those crevassing rate peaks that do not show the migratory trend of crevasse opening locations are poorly explained by the cavitation front theory due to the lack of strain change over their duration (days 133, 135, 136 in Figures 4.21 and 4.18). Similar crevasse opening locations between the crevassing rate peaks on days 133, 135, and 136 and those observed on days 130, 160, and 172 (predominantly marginal and flow-transverse opening in Figures 4.21 and 4.22) suggests that the peaks on days 133, 135, and 136 may be due to unforced crevasse opening that occurs over a short window, this being the inferred source for events in the crevassing rate peaks on days 130, 160, and 172. For the crevassing rate peaks on days 130, 160, and 172 the interpretation of unforced opening follows from the lack of visible correlation between crevassing and rainfall or velocity in Figure 4.16, and the positive cross-correlation lag times between crevassing and rainfall in row 5 of Table 4.2 (these indicating that crevasse opening preceds rainfall). Although the two sets of crevassing rate peaks share similarities in their seismic event locations, the peaks on days 133, 135, and 136 show a strong correlation with rainfall and zero lag time between rainfall and crevassing (row 5 in Table 4.2), suggesting that these peaks are not coincidental and rather result from an interaction between water and crevasses.

To study the role of rain-induced hydrofracture in generating crevassing rate peaks a model describing water accumulation in crevasses was developed. This model accounts for the quantiative relationships between crevassing and rainfall as summarised in Table 5.1.

The physical relationship inferred between rainfall and crevasse propagation for the model is: 


\begin{tabular}{|c|c|}
\hline 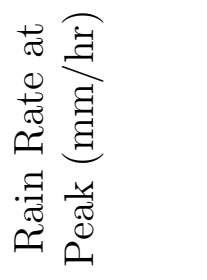 & 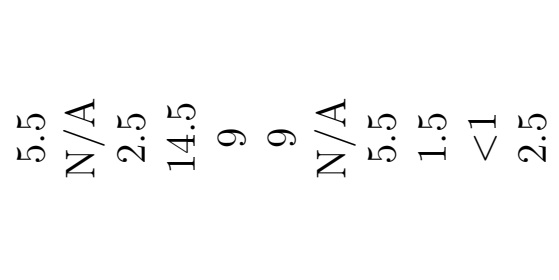 \\
\hline 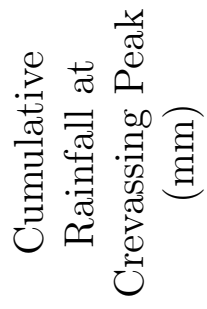 & 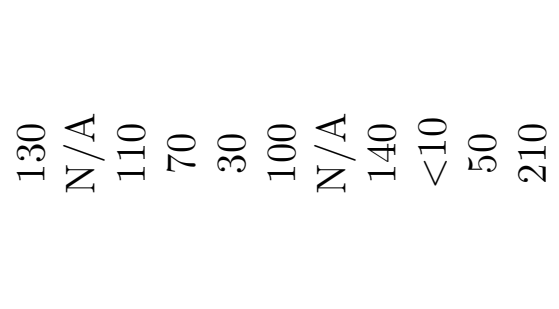 \\
\hline 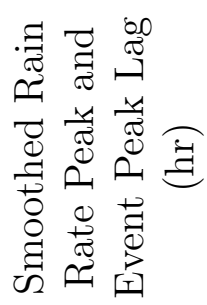 & 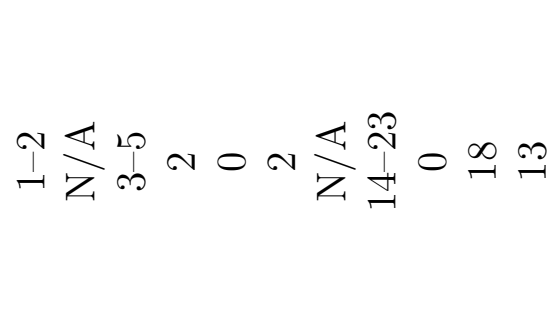 \\
\hline 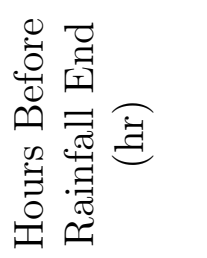 & 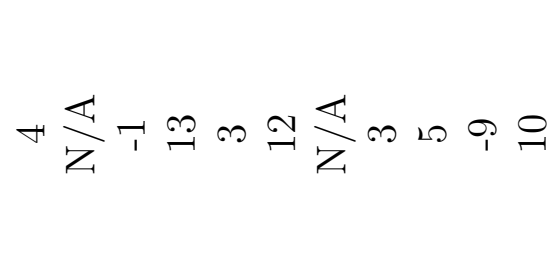 \\
\hline 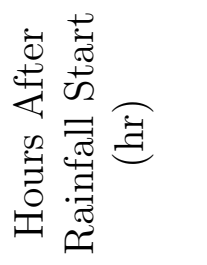 & 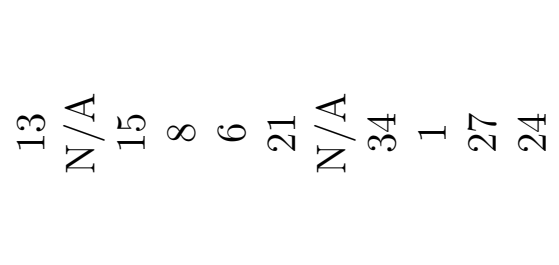 \\
\hline 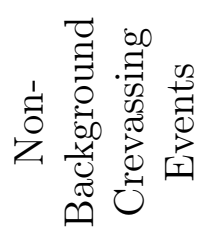 & 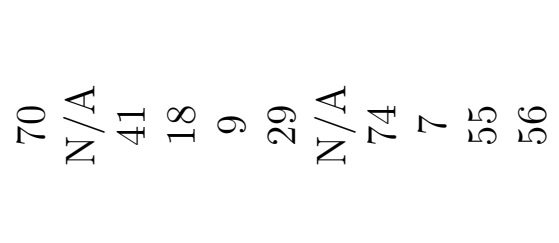 \\
\hline 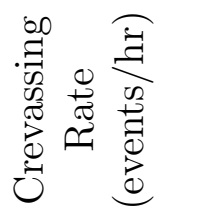 & 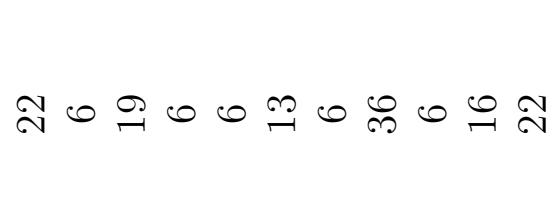 \\
\hline 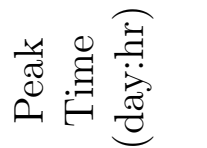 & 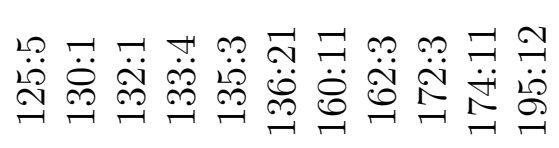 \\
\hline
\end{tabular}

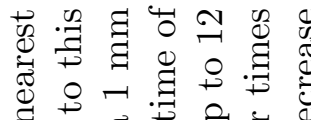
व

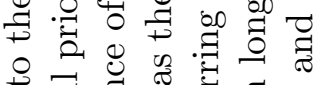
$\circ$ 궁 㱐 品

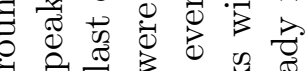
. $)$

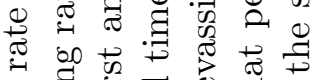
. 蛋 च

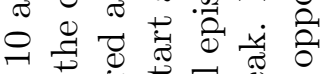

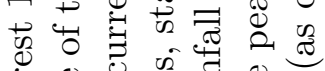

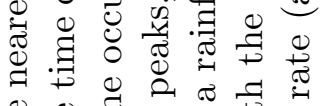

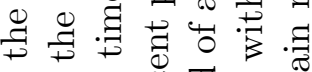

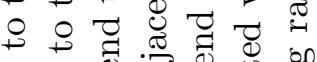

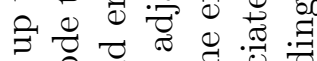
足.

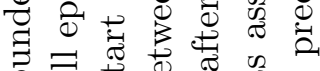

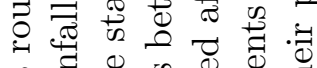

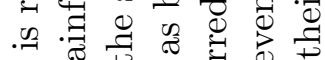
需 .

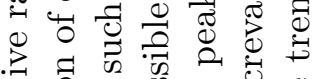

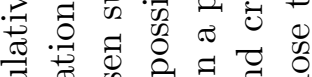
苯. 茎

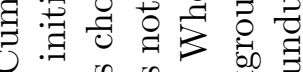

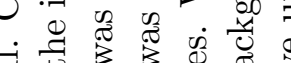
西声 3 is 节 ॠ

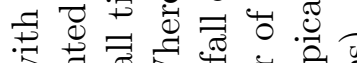

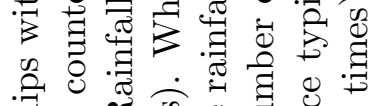

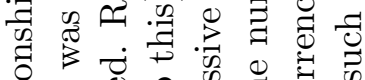
3 वं 0 के

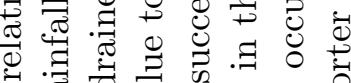
荇

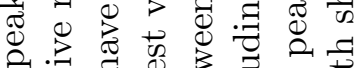
2.

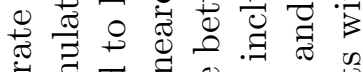
bo

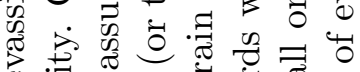
¿ $\begin{gathered}0 \\ 0\end{gathered}$

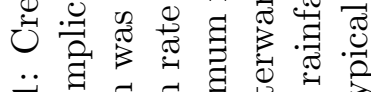
मे

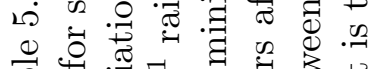

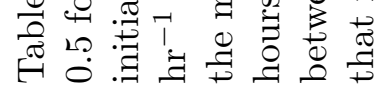


1. Rainfall initiates and rain rate increases over a period of $9+$ hours (Table 5.1). Some of this rainfall accumulates in crevasses when water inputs are higher than the crevasse drainage capacity.

2. If crevasses become sufficiently water filled hydrofracture occurs at their tip due to the outward pressure of the accumulated water (Van der Veen, 2007).

3. Given that water input continues hydrofracture can become sustained (Van der Veen, 2007).

4. High recurrence of hydrofracture in a crevasse can connect it to efficient drainage pathways (Benn and Evans, 2010). These hydraulically connected crevasses can then quickly transport surface water to the glacial drainage system and may not hydrofracture further due to their inability to accumulate water (Van der Veen, 2007).

5. Remaining rainfall and stored water is aseismically routed to the glacier bed.

The above requires that the initial state of any crevasse to be that of a dry crack that is vertically oriented and open to the surface with an extensional stress state at its tip. It also requires that each crevasse is connected to the glacial drainage system by englacial pathways of variable drainage efficiency, these forming the crevasse drainage capacity mentioned above. The crevasse drainage capacity is a key factor in the model. It is required to explain the lack of observed hydrofracture following any rainfall, this being expected when any water enters a crevasse (Van der Veen, 2007). The lack of zero-lag crevassing following rainfall episodes $\mathbf{R} \mathbf{1}-\mathbf{R} 4$ in the crevassing rates at $\mathbf{C 1 -} \mathbf{C} 4$ in Figures 4.17 and 4.18 requires that crevasses have some drainage capacity that is able to route small water inputs without triggering hydrofracture. Similarly the initiation of the crevassing rate peak C5 (following rainfall episode R5) and others on days 135 and 136 (Figure 4.18) on the falling limb of rainfall suggest that sufficient water must accumulate against the effect of this drainage before hydrofracture can begin. This variable drainage efficiency can account for pre- and post-peak crevasse propagation (Figure 4.18) as well as differences in rain rate - crevassing rate lag times (Table 4.2) and cumulative rainfall at the crevassing peak (Table 5.1) by allowing the water level required for hydrofracture to be reached earlier or later in time or after more or less water input. As the crevassing rate peaks on days 133, 135, 136 all follow large volumes of prior rainfall (Figure 4.18) it may be that crevasses only begin to accumulate water once the englacial drainage they are connected to becomes full from fresh water inputs following this rainfall. Scambos et al. (2009) observe a similar effect with ice shelf crevasses where water does not accumulate in the crevasses sufficiently to cause hydrofracture until the overlying firn is saturated and water can then migrate into the crevasses. 
The temporally clustered nature of the three crevassing rate peaks on days 133, 135, and 136, these having followed two large rainfall episodes (Figure 4.18), allows additional features of water-driven crevasse opening to be discerned:

1. Once crevasses become drained ice deformation acts to return them to their pre-hydrofracture size (Van der Veen, 1998).

2. Crevasses with lower drainage efficiency can hold their accumulated water for $>24$ hours. Closure by ice deformation will be resisted by this water content (Van der Veen, 1998) so these crevasses may retain a significant fraction of their post-rainfall depth while this water remains (potentially explaining the lack of repeating crevasse opening locations between days 133, 135, and 136 in Figure 4.21 and also the progressively lower number of crevasse opening events between days 133 and 135 in Table 5.1). Resupply of rainwater into these crevasses will raise their water levels to the hydrofracture level much faster than in the prior rainfall episode, thus allowing the early initiation of hydrofracture seen as the short rain rate - crevassing rate peak lag times in Table 5.1.

3. Given that a crevasse expanded via hydrofracture in the prior rainfall episode any renewed hydrofracture in that crevasse may cause hydraulic connection earlier than in the prior rainfall episode (again explaining the lower successive total peak event counts for days 133, 135 in Table 5.1).

4. The characteristic time for crevasse healing may be $>24$ hours as suggested by the longer rain rate - crevassing rate peak lag time and greater total number of crevasse opening events for the peak on day 136 (Table 5.1).

The model itself, taking into account all of the prior conceptual understanding, is presented in Appendix C. Ultimately this model could not be used to draw insightful conclusions due to the unknown state of the glacial drainage system throughout the study period. However the favoured interpetation of the crevassing rate peaks on days 133, 135, and 136 remains that of water-induced crevasse opening through hydrofracture. It is possible that the crevasse opening locations visible outside of the trend of down-glacier migration on days 125, 132, and 172 results from water-driven crevasse opening at the glacier margins (Figures 4.21 and 4.22). The combination of the two external forcings may then be responsible for the poor linear regression results for these peaks (Figure 4.20). In general it cannot be discerned whether hydrofracture in crevasses results from rain water accumulation or from the overflowing of water from the englacial drainage system. Both mechanisms have merit, though the overflowing of the englacial drainage system was observed following heavy rainfall in March of 2016 during instrument maintenance, thus providing additional 
feasibility to this as the process by which crevasse stored water levels required for hydrofracture are initiated.

The general lack of repeated crevasse opening locations in crevassing rate peaks (Figures 4.21 and 4.22), even when hydrofracture is discernable as the opening mechanism and repeating source locations are expected, is interpreted as the result of each crevasse opening via many small failures (these being observed as weak repeating seismicity in section 3.3) before expanding in a critical failure that is highly seismogenic and thus detectable over the network (Iverson, 1991a; Cohen et al., 2006). Further detectable opening events do not occur after the critical expansion event, owing to the overdeepening of the crevasse and the time required for it to heal back to the failure depth in the background strain rate field.

\subsection{Basal Seismicity}

Relating the nature of a seismic source to a glacial process is ambiguous as icequake hypocentres are often scattered around the ice-bed interface with uncertainties too large to constrain them to the interface, the substrate, or the glacier sole (Walter et al., 2013). However, in the RISSIN catalogue hypocentre depths for located icequakes are often hundreds of metres from the ice-bed interface (Figure 4.25) with uncertainties too small to account for this separation. In general icequake hypocentres are poorly constrained as seen by the RMS residual of many events located at tectonic depths being smaller than those of events that appear to occur within the glacier (Figure 4.25). Similarly, the limited coverage of RISSIN sensors for the focal spheres of icequakes causes any inferred relationship between the first arrivals of these events and their source processes to be uncertain (Walter et al., 2013). Thus any inference of the source process of icequakes, as derived from their epicentres and first motions, cannot be made with great certainty.

The lack of icequake detections during rainfall episodes (Figure 4.16) adds additional limitations to interpetations made from the icequake catalogue. It is likely that this absence of icequake detections is due to an increase in the noise floor and a subsequent failure of the STA:LTA algorithm during rainfall. However, manual inspection of seismograms over rainfall episodes showed that the occurrence rate of icequakes over these episodes remains similar to the pre- and post-rainfall occurrence rate, suggesting that rainfall episodes do not influence the glacial processes leading to icequake generation and instead simply reduce the effectiveness of the detection algorithm (Section 3.3). Thus it is assumed that the background rate of icequake 
occurrence continues through rainfall episodes, though this assumption is based only on two episodes of rainfall and one accelerated sliding episode (days 122-126 in Figure 4.17) and as such may not be valid for time periods outside of those manually inspected.

The location of mixed-polarity icequakes, here assumed to result from double couple seismicity as described by Stein and Wysession (2002), suggests that these events result from basal stick-slip motion: 4 of the 11 events occur near the glacier margin and 5 of the remaining events occur over a known bedrock rise (Hart, 2014). These features form resistive zones to glacier motion (Patterson, 1994), causing basal shear stresses to accumulate locally and eventually rupture in a seismogenic motion (Winberry et al, 2011). This stick-slip motion occurs independently of accelerated sliding (Figures 4.17 and 4.18), suggesting that the stress accumulation and release cycle occurs on a greater timescale than that of accelerated sliding (Zoet et al., 2012; Winberry et al., 2013). The remaining events, not captured by this theory, may be due to shear dislocation during tensile crack opening/closing (Dalban Canassy et al., 2013) or stick-slip over unknown asperities.

The distributed temporal and spatial nature of the icequakes beneath the lower Tasman Glacier tongue (Figure 4.24) suggests that the subglacial drainage system here is efficient and remains so over the duration of the RISSIN deployment. By considering the distributed drainage system that would produce these observations the need for such a subglacial drainage system becomes clear. In a distributed drainage system water pressures increase with water flux (Section 2.1). As tensile crack opening/closing occurs in the glacier sole above basal cavities that experience high water pressure variations (Walter et al., 2013) a distributed drainage system in the form of a linked cavity network should show a dense spacing of single-polarity icequakes following subglacial flooding. Similarly if cavities in this system remain connected to the distributed drainage system they should appear as a repeating source of icequakes over numerous subglacial flooding events (Walter et al., 2008). The trend observed in the icequake catalogue is that of non-repeating, sparse, and rain-independent tensile crack opening/closing. If this distributed drainage system exists each cavity can only be connected briefly to the linked cavity network (no clustered single-polarity icequake epicentres in 4.24), the distance between adjacent cavities must be very large (300 $\mathrm{m}$ being the shortest distance between two singlepolarity icequake epicentres in 4.24), and the linked cavity network must experience negligible water inputs during subglacial flooding such that the rate of icequake occurrence does not differ from the pre-flooding rate (Section 3.3). It follows that an efficient drainage system better fits the observations. 
In such an efficient drainage system arborescent channels form the foundation of the subglacial drainage network with cavities scattered in the regions between these channels (Schoof, 2010). In this system a strong hydraulic gradient would exist between the high pressure cavities and the low pressure channels. Such a gradient drives the steady flow of any water in cavities to channels, maintaining low amplitude and smoothly varying cavity water pressures and avoiding the generation of seismicity. Seismogenic cavity collapse would occur only in those cavities where drainage is inefficient, these cavities existing independently of the efficient drainage network and thus experiencing high amplitude and rapidly changing cavity water pressures. Channel locations in this system would likely be dynamic, allowing isolated cavities to become hydraulically connected and vice versa. Following subglacial flooding cavities would fill, connect, and uplift the glacier sole, with their subsequent steady drainage avoiding the rapid changes in subglacial water pressure required to cause tensile crack opening/closing.

As the RISSIN deployment period spans the typical winter shutdown period of the subglacial drainage system an extension of the prior conclusion can be made. The subglacial drainage system of the lower Tasman Glacier is likely efficient at all times of the year. It is possible that the high volumes and frequency of rainfall episodes at Tasman Glacier are what invigorate the subglacial drainage system and allow it to remain channelised and efficient. This sustained efficiency is likely responsible for the critical rainfall threshold observed for accelerated sliding initiation; small rain water inputs are routed via the channel network without triggering basal water film expansion or cavitation (Figure 4.16).

This interpretation, that of a efficient subglacial drainage system, successfully explains the trends in the observed single-polarity basal seismicity. An alternative explanation is that of seismogenic subglacial erosion. Here cracks in subglacial bedrock propagate following elevated stresses during cavity collapse (Iverson, 1991a; Cohen et al., 2006; Zoet et al., 2013). Above a critical crack length this crack propagation is rapid (Benn and Evans, 2010) and may generate observable seismicity. Thus tensile cracking in rock may generate the isotropic icequakes detected, though unless rock cracks experience seismogenic closure this conceptual model cannot explain all of the observed single-polarity basal seismicity. Uncertainty between these source processes requires a combined interpetation: icequakes result from crack opening (isotropic or crack-plus-double-couple) in ice or rock and basal stick-slip of ice over rock. As the requirement for cracking in the glacier sole is the same for ice and rock fracture near the glacier bed the conclusion drawn prior remains valid, the subglacial drainage system beneath Tasman Glacier is likely efficient. 
Further insight into the nature of glacial processing occurring beneath Tasman Glacier, in particular those during accelerated sliding, is occluded by the lack of icequake detections. It is possible that the apparently aseismic nature of accelerated sliding at Tasman Glacier results from: 1) rapid enhanced creep of ice over resistive patches of the bed, 2) the ready yielding of the bed following increases in subglacial water pressure, or 3) the decoupling of the glacier from its bed during flotation.

Cross-correlation event detection techniques would aid in capturing a more complete record of basal seismicity. Subsequent double different location methods would improve the accuracy and hence understanding of icequake distributions and thereafter provide a basis for more reliable interpretations to be made. 


\section{Chapter 6}

\section{Conclusion}

Constraints provided by the analysis of seismic and GNSS observations made on Haupapa/Tasman Glacier during both quiescent periods and episodes of rain-induced accelerated sliding have allowed the identification of glacial process active during the accelerated sliding of glaciers. In order of their robustness, the following conclusions are drawn:

- Cavitation and basal water film expansion following rain-induced subglacial flooding form respectively the rising and falling limb of acceleration sliding velocity peaks. Extensional strain occurs between the fast cavitating sections of the glacier and the up-stream sections of the glacier, these being in the synchronous slow-sliding regime controlled by the thickness of the basal water film. The extensional strains in the lee of the cavitation front create a locus of crevasse opening as it migrates down glacier. Slower moving cavitation fronts and the availability of surface water increase the magnitude and duration of the resulting strain-driven crevassing rate peak and the extent of the associated crevasse opening.

- Sustained supply of rain water to the glacier can cause water to accumulate in crevasses either by overwhelming the drainage capacity of the crevasses or by causing the englacial drainage system to overflow. Once the water level in a crevasse increases hydrofracture initiates, rapidly deepening and widening the crevasse. Expanded crevasses then seal by aseismic ice creep following water drainage.

- The subglacial drainage system beneath Haupapa/Tasman Glacier is efficient year-round and consists of an arborescent channel network with sparse regions of cavities located between the channels. Basal seismicity is predominantly from tensile cracking in ice or rock following high pressure water variations in the lee of cavities, though a subset of the observed seismicity likely results 
from the stick-slip motion of the glacier sole against the glacier margins and resistive patches of the bed. The stress accumulation required to trigger this stick-slip occurs on a timescale greater than that of accelerated sliding.

- The accelerated sliding of Haupapa/Tasman Glacier is aseismic with basal motion occurring either through: 1) rapid enhanced creep of ice over resistive patches of the bed, 2) basal slip over an easily yielding soft bed or 3) basal slip over a decoupled glacier bed following cavitation-driven flotation.

Future work on the accelerated sliding and crevassing observable at Haupapa/Tasman Glacier should focus principally on providing seismicity locations of a greater accuracy and precision for an event catalogue that is expanded in its completeness by the use of cross-correlation and frequency-filtered detection routines. A denser seismic and geodetic instrument network with an extent reaching to the upper Haupapa/Tasman Glacier may aid in better resolving the initiation and nature of crevasse opening and any basal seismicity due to its lower magnitude of completeness and greater azimuthal constraints. However a more detailed view into the RISSIN data may provide conclusions of a similar quality to those from an expanded instrument network. 


\section{Bibliography}

Adams, J.

1980. Contemporary uplift and erosion of the southern alps, new zealand. Geological Society of America Bulletin, 91(1 Part II):1-114.

Alexander, L. V., S. K. Allen, N. L. Bindoff, F.-M. Breon, J. A. Church, U. Cubasch, S. Emori, P. Forster, P. Friedlingstein, N. Gillett, et al.

2013. Summary for policymakers.

Allen, R. V.

1978. Automatic earthquake recognition and timing from single traces. Bulletin of the Seismological Society of America, 68(5):1521-1532.

Allen, S., S. Gruber, and I. Owens

2009. Exploring steep bedrock permafrost and its relationship with recent slope failures in the southern alps of new zealand. Permafrost and Periglacial Processes, $20(4): 345-356$.

Ambuter, B. P. and S. C. Solomon

1974. An event-recording system for monitoring small earthquakes. Bulletin of the Seismological Society of America, 64(4):1181-1188.

Bartholomaus, T., C. Larsen, S. O'Neel, and M. West

2012. Calving seismicity from iceberg-sea surface interactions. Journal of Geophysical Research: Earth Surface, 117(F4).

Bartholomaus, T. C., J. M. Amundson, J. I. Walter, S. O'Neel, M. E. West, and C. F. Larsen

2015. Subglacial discharge at tidewater glaciers revealed by seismic tremor. Geophysical Research Letters, 42(15):6391-6398.

Bartholomaus, T. C., R. S. Anderson, and S. P. Anderson

2011. Growth and collapse of the distributed subglacial hydrologic system of kennicott glacier, alaska, usa, and its effects on basal motion. Journal of Glaciology, 57(206):985-1002. 
Bartholomew, I., P. Nienow, D. Mair, A. Hubbard, M. A. King, and A. Sole 2010. Seasonal evolution of subglacial drainage and acceleration in a greenland outlet glacier. Nature Geoscience, 3(6):408-411.

Bartholomew, I., P. Nienow, A. Sole, D. Mair, T. Cowton, S. Palmer, and J. Wadham

2011. Supraglacial forcing of subglacial drainage in the ablation zone of the greenland ice sheet. Geophysical Research Letters, 38(8).

Benn, D., D. J. Evans, et al.

2014. Glaciers and glaciation. Routledge.

Benn, D., J. Gulley, A. Luckman, A. Adamek, and P. S. Glowacki

2009. Englacial drainage systems formed by hydrologically driven crevasse propagation. Journal of Glaciology, 55(191):513-523.

Benn, D. I., C. R. Warren, and R. H. Mottram

2007. Calving processes and the dynamics of calving glaciers. Earth-Science Reviews, 82(3):143-179.

Bindschadler, R. A., S. Nowicki, A. Abe-Ouchi, A. Aschwanden, H. Choi, J. Fastook, G. Granzow, R. Greve, G. Gutowski, U. Herzfeld, et al.

2013. Ice-sheet model sensitivities to environmental forcing and their use in projecting future sea level (the searise project). Journal of Glaciology, 59(214):195224.

Bliss, A., R. Hock, and V. Radić

2014. Global response of glacier runoff to twenty-first century climate change. Journal of Geophysical Research: Earth Surface, 119(4):717-730.

Boese, C., J. Townend, E. Smith, and T. Stern

2012. Microseismicity and stress in the vicinity of the alpine fault, central southern alps, new zealand. Journal of Geophysical Research: Solid Earth, 117(B2).

Boon, S. and M. Sharp

2003. The role of hydrologically-driven ice fracture in drainage system evolution on an arctic glacier. Geophysical Research Letters, 30(18).

Boulton, G.

1996. Theory of glacial erosion, transport and deposition as a consequence of subglacial sediment deformation. Journal of Glaciology, 42(140):43-62.

Broadbent, M.

1973. A preliminary report on seismic and gravity surveys on the tasman glacier 1971-2. Unpublished report K/6/2/1, Geophysics Division, Department of Scientific and Industrial Research, Wellington. 
Chen, S.-P., M. Burkert, R. Berfelde, and C. Heuer

1998. Flat-top antenna apparatus including at least one mobile radio antenna and a gps antenna. US Patent 5,706,015.

Chinn, T.

2001. Distribution of the glacial water resources of new zealand. Journal of Hydrology(New Zealand), 40(2):139-187.

Church, J. A., P. U. Clark, A. Cazenave, J. M. Gregory, S. Jevrejeva, A. Levermann, M. A. Merrifield, G. A. Milne, R. S. Nerem, P. D. Nunn, et al.

2013. Sea level change. Technical report, PM Cambridge University Press.

Claridge, D.

1983. A geophysical study of the termini of the mount cook national park glaciers.

Collins, M., R. Knutti, J. Arblaster, J.-L. Dufresne, T. Fichefet, P. Friedlingstein, X. Gao, W. Gutowski, T. Johns, G. Krinner, et al.

2013. Long-term climate change: projections, commitments and irreversibility.

Cox, S. and D. Barrel

2007. Geology of the aoraki area, institute of geological and nuclear sciences 1: 250000 geological map. Lower Hutt, New Zealand (GNS Science), 71.

Cuffey, K. M. and W. S. B. Paterson

2010. The physics of glaciers. Academic Press.

Dalban Canassy, P., F. Walter, S. Husen, H. Maurer, J. Faillettaz, and D. Farinotti 2013. Investigating the dynamics of an alpine glacier using probabilistic icequake locations: Triftgletscher, switzerland. Journal of Geophysical Research: Earth Surface, 118(4):2003-2018.

Das, S. B., I. Joughin, M. D. Behn, I. M. Howat, M. A. King, D. Lizarralde, and M. P. Bhatia

2008. Fracture propagation to the base of the greenland ice sheet during supraglacial lake drainage. Science, 320(5877):778-781.

Deichmann, N., J. Ansorge, F. Scherbaum, A. Aschwanden, F. Bernardi, and G. Gudmundsson

2000. Evidence for deep icequakes in an alpine glacier. Annals of Glaciology, $31(1): 85-90$.

Deparis, J., D. Jongmans, F. Cotton, L. Baillet, F. Thouvenot, and D. Hantz 2008. Analysis of rock-fall and rock-fall avalanche seismograms in the french alps. Bulletin of the Seismological Society of America, 98(4):1781-1796. 
Doyle, S. H., A. Hubbard, R. S. Van De Wal, D. van As, K. Scharrer, T. W. Meierbachtol, P. C. Smeets, J. T. Harper, E. Johansson, R. H. Mottram, et al. 2015. Amplified melt and flow of the greenland ice sheet driven by late-summer cyclonic rainfall. Nature Geoscience, 8(8):647-653.

Dykes, R., M. Brook, C. Robertson, and I. Fuller 2011. Twenty-first century calving retreat of tasman glacier, southern alps, new zealand. Arctic, Antarctic, and Alpine Research, 43(1):1-10.

Dykes, R. C., M. S. Brook, and S. Winkler 2010. The contemporary retreat of tasman glacier, southern alps, new zealand, and the evolution of tasman proglacial lake since ad 2000. Erdkunde, Pp. 141-154.

Dyurgerov, M.

2003. Mountain and subpolar glaciers show an increase in sensitivity to climate warming and intensification of the water cycle. Journal of Hydrology, 282(1):164176.

Eibl, E. P., I. Lokmer, C. J. Bean, E. Akerlie, and K. S. Vogfjörd 2015. Helicopter vs. volcanic tremor: Characteristic features of seismic harmonic tremor on volcanoes. Journal of Volcanology and Geothermal Research, 304:108117.

Ekström, G., M. Nettles, and V. C. Tsai 2006. Seasonality and increasing frequency of greenland glacial earthquakes. Science, 311(5768):1756-1758.

Engelhardt, H., N. Humphrey, B. Kamb, and M. Fahnestock 1990. Physical conditions at the base of a fast moving antarctic ice stream. Science, 248(4951):57-60.

Fischer, U. H. and G. K. Clarke 1997. Stick slip sliding behaviour at the base of a glacier. Annals of Glaciology, 24:390-396.

Fountain, A. G., R. W. Jacobel, R. Schlichting, and P. Jansson 2005. Fractures as the main pathways of water flow in temperate glaciers. Nature, 433(7026):618.

Fountain, A. G. and J. S. Walder 1998. Water flow through temperate glaciers. Reviews of Geophysics, 36(3):299328.

GLIMS and NSIDC

2005. Glims glacier database. GLIMS and National Snow and Ice Data Center, Boulder, Colorado USA. 
Goelzer, H., P. Huybrechts, J. J. Fürst, F. Nick, M. L. Andersen, T. L. Edwards, X. Fettweis, A. J. Payne, and S. Shannon

2013. Sensitivity of greenland ice sheet projections to model formulations. Journal of Glaciology, 59(216):733-749.

Hammer, C., M. Ohrnberger, and V. Schlindwein

2015. Pattern of cryospheric seismic events observed at ekström ice shelf, antarctica. Geophysical Research Letters, 42(10):3936-3943.

Harper, J. T., N. F. Humphrey, W. T. Pfeffer, and B. Lazar

2007. Two modes of accelerated glacier sliding related to water. Geophysical research letters, 34(12).

Harrison, W., C. Raymond, and P. MacKeith

1986. Short period motion events on variegated glacier as observed by automatic photography and seismic methods. Annals of Glaciology, 8(1):82-89.

Hart, R.

2014. The ice thickness distribution of a debris-covered glacier: Tasman glacier, new zealand.

Havskov, J. and L. Ottemoller

1999. Seisan earthquake analysis software. Seismological Research Letters, $70(5): 532-534$.

Heeszel, D. S., F. Walter, and D. L. Kilb

2014. Humming glaciers. Geology, 42(12):1099-1102.

Henderson, R. and S. Thompson

1999. Extreme rainfalls in the southern alps of new zealand. Journal of Hydrology (NZ), 38(2):309-330.

Hochstein, M. P., D. Claridge, S. A. Henrys, A. Pyne, D. C. Nobes, and S. F. Leary 1995. Downwasting of the tasman glacier, south island, new zealand: changes in the terminus region between 1971 and 1993. New Zealand journal of geology and geophysics, 38(1):1-16.

Horgan, H. J., B. Anderson, R. B. Alley, C. J. Chamberlain, R. Dykes, L. M. Kehrl, and J. Townend

2015. Glacier velocity variability due to rain-induced sliding and cavity formation. Earth and Planetary Science Letters, 432:273-282.

Hubbard, B. and P. Nienow

1997. Alpine subglacial hydrology. Quaternary Science Reviews, 16(9):939-955. 
Huntington, T. G.

2006. Evidence for intensification of the global water cycle: review and synthesis. Journal of Hydrology, 319(1):83-95.

Iken, A.

1981. The effect of the subglacial water pressure on the sliding velocity of a glacier in an idealized numerical model. Journal of Glaciology, 27(97):407-421.

Iken, A. and R. A. Bindschadler

1986. Combined measurements of subglacial water pressure and surface velocity of findelengletscher, switzerland: conclusions about drainage system and sliding mechanism. Journal of Glaciology, 32(110):101-119.

Iken, A., H. Röthlisberger, A. Flotron, and W. Haeberli 1983. The uplift of unteraargletscher at the beginning of the melt seasona consequence of water storage at the bed? Journal of Glaciology, 29(101):28-47.

Iken, A. and M. Truffe

1997. The relationship between subglacial water pressure and velocity of findelengletscher, switzerland, during its advance and retreat. Journal of Glaciology, 43(144):328-338.

Iverson, N. R.

1991. Potential effects of subglacial water-pressure fluctuations on quarrying. Journal of Glaciology, 37(125):27-36.

Jansson, P., R. Hock, and T. Schneider

2003. The concept of glacier storage: a review. Journal of Hydrology, 282(1):116129.

Jónsdóttir, K., R. Roberts, V. Pohjola, B. Lund, Z. H. Shomali, A. Tryggvason, and R. Bödvarsson

2009. Glacial long period seismic events at katla volcano, iceland. Geophysical Research Letters, 36(11).

Kamb, B.

1987. Glacier surge mechanism based on linked cavity configuration of the basal water conduit system. Journal of Geophysical Research: Solid Earth, 92(B9):9083-9100.

Kirkbride, M.

1989. The influence of sediment budget on geomorphic activity of the tasman glacier, mount cook national park, new zealand. 
Kirkbride, M. P.

1995. Relationships between temperature and ablation on the tasman glacier, mount cook national park, new zealand. New Zealand Journal of Geology and Geophysics, 38(1):17-27.

Kirkbride, M. P. and C. R. Warren

1999. Tasman glacier, new zealand: 20th-century thinning and predicted calving retreat. Global and Planetary Change, 22(1):11-28.

Kohnen, H.

1974. The temperature dependence of seismic waves in ice. J. Glaciol, 13(67):144147.

Lomax, A. and A. Curtis

2001. Fast, probabilistic earthquake location in 3d models using oct-tree importance sampling. In Geophys. Res. Abstr, volume 3, P. 955.

Lomax, A., J. Virieux, P. Volant, and C. Berge-Thierry

2000. Probabilistic earthquake location in $3 \mathrm{~d}$ and layered models. In Advances in seismic event location, Pp. 101-134. Springer.

Lui, E.

2016. Ice dynamics of the Haupapa/Tasman Glacier measured at high spatial and temporal resolution, Aoraki/Mount Cook, New Zealand. Victoria University of Wellington.

Marzeion, B., A. Jarosch, and M. Hofer

2012. Past and future sea-level change from the surface mass balance of glaciers. The Cryosphere, 6(6):1295.

McKinnon, K. A., A. N. Mackintosh, B. M. Anderson, and D. J. Barrell 2012. The influence of sub-glacial bed evolution on ice extent: a model-based evaluation of the last glacial maximum pukaki glacier, new zealand. Quaternary Science Reviews, 57:46-57.

Meier, M. F., M. B. Dyurgerov, U. K. Rick, S. O'neel, W. T. Pfeffer, R. S. Anderson, S. P. Anderson, and A. F. Glazovsky

2007. Glaciers dominate eustatic sea-level rise in the 21st century. Science, 317(5841):1064-1067.

Métaxian, J.-P., S. Araujo, M. Mora, and P. Lesage

2003. Seismicity related to the glacier of cotopaxi volcano, ecuador. Geophysical research letters, 30(9). 
Mikesell, T., K. Wijk, M. M. Haney, J. H. Bradford, H.-P. Marshall, and J. T. Harper

2012. Monitoring glacier surface seismicity in time and space using rayleigh waves. Journal of Geophysical Research: Earth Surface, 117(F2).

Moore, P. L., J. P. Winberry, N. R. Iverson, K. A. Christianson, S. Anandakrishnan, M. Jackson, M. E. Mathison, and D. Cohen

2013. Glacier slip and seismicity induced by surface melt. Geology, 41(12):12471250.

Moser, T., T. Eck, and G. Nolet

1992. Hypocenter determination in strongly heterogeneous earth models using the shortest path method. Journal of Geophysical Research: Solid Earth, 97(B5):6563-6572.

Neave, K. and J. Savage

1970. Icequakes on the athabasca glacier. Journal of Geophysical Research, 75(8):1351-1362.

Nye, J.

1952. The mechanics of glacier flow. Journal of Glaciology, 2(12):82-93.

Nye, J.

1957. The distribution of stress and velocity in glaciers and ice-sheets. In Proceedings of the Royal Society of London A: Mathematical, Physical and Engineering Sciences, volume 239, Pp. 113-133. The Royal Society.

Nye, J. F.

1953. The flow law of ice from measurements in glacier tunnels, laboratory experiments and the jungfraufirn borehole experiment. In Proceedings of the Royal Society of London A: Mathematical, Physical and Engineering Sciences, volume 219, Pp. 477-489. The Royal Society.

Oerlemans, J.

2005. Extracting a climate signal from 169 glacier records. Science, 308(5722):675677.

O’Neel, S., H. P. Marshall, D. E. McNamara, and W. T. Pfeffer 2007. Seismic detection and analysis of icequakes at columbia glacier, alaska. Journal of Geophysical Research: Earth Surface, 112(F3).

O'Neel, S. and W. Pfeffer

2007. Source mechanics for monochromatic icequakes produced during iceberg calving at columbia glacier, ak. Geophysical Research Letters, 34(22). 
Paterson, W.

1994. The physics of glaciers, $480 \mathrm{pp}$.

Paul Winberry, J., S. Anandakrishnan, D. A. Wiens, and R. B. Alley

2013. Nucleation and seismic tremor associated with the glacial earthquakes of whillans ice stream, antarctica. Geophysical Research Letters, 40(2):312-315.

Pfeffer, W. T., J. Harper, and S. O'Neel

2008. Kinematic constraints on glacier contributions to 21st-century sea-level rise.

Science, 321(5894):1340-1343.

Podolskiy, E. A. and F. Walter

2016. Cryo-seismology. Reviews of Geophysics.

Purdie, H., P. Bealing, E. Tidey, C. Gomez, and J. Harrison

2016. Bathymetric evolution of tasman glacier terminal lake, new zealand, as determined by remote surveying techniques. Global and Planetary Change, 147:111.

Purdie, J. and B. Fitzharris

1999. Processes and rates of ice loss at the terminus of tasman glacier, new zealand. Global and Planetary Change, 22(1):79-91.

Qamar, A.

1988. Calving icebergs: A source of low-frequency seismic signals from columbia glacier, alaska. Journal of Geophysical Research: Solid Earth, 93(B6):6615-6623.

Quincey, D. and N. Glasser

2009. Morphological and ice-dynamical changes on the tasman glacier, new zealand, 1990-2007. Global and Planetary Change, 68(3):185-197.

Radić, V., A. Bliss, A. C. Beedlow, R. Hock, E. Miles, and J. G. Cogley 2014. Regional and global projections of twenty-first century glacier mass changes in response to climate scenarios from global climate models. Climate Dynamics, $42(1-2): 37-58$.

Redpath, T., P. Sirguey, S. Fitzsimons, and A. Kääb

2013. Accuracy assessment for mapping glacier flow velocity and detecting flow dynamics from aster satellite imagery: Tasman glacier, new zealand. Remote Sensing of Environment, 133:90-101.

Rost, S. and C. Thomas

2002. Array seismology: Methods and applications. Reviews of geophysics, 40(3). 
Röthlisberger, H.

1972. Water pressure in intra-and subglacial channels. Journal of Glaciology, 11(62):177-203.

Roux, P.-F., D. Marsan, J.-P. Métaxian, G. O’Brien, and L. Moreau 2008. Microseismic activity within a serac zone in an alpine glacier (glacier d'argentière, mont blanc, france). Journal of Glaciology, 54(184):157-168.

Roux, P.-F., F. Walter, P. Riesen, S. Sugiyama, and M. Funk 2010. Observation of surface seismic activity changes of an alpine glacier during a glacier-dammed lake outburst. Journal of Geophysical Research: Earth Surface, 115(F3).

Rubinstein, S. M., M. Shay, G. Cohen, and J. Fineberg

2006. Crack-like processes governing the onset of frictional slip. International Journal of Fracture, 140(1-4):201-212.

Scambos, T., H. A. Fricker, C.-C. Liu, J. Bohlander, J. Fastook, A. Sargent, R. Massom, and A.-M. Wu

2009. Ice shelf disintegration by plate bending and hydro-fracture: Satellite observations and model results of the 2008 wilkins ice shelf break-ups. Earth and Planetary Science Letters, 280(1):51-60.

Scambos, T. A., J. Bohlander, C. u. Shuman, and P. Skvarca 2004. Glacier acceleration and thinning after ice shelf collapse in the larsen b embayment, antarctica. Geophysical Research Letters, 31(18).

Scambos, T. A., C. Hulbe, M. Fahnestock, and J. Bohlander 2000. The link between climate warming and break-up of ice shelves in the antarctic peninsula. Journal of Glaciology, 46(154):516-530.

Schoof, C.

2010. Ice-sheet acceleration driven by melt supply variability. Nature, 468(7325):803-806.

Shreve, R.

1972. Movement of water in glaciers. Journal of Glaciology, 11(62):205-214.

Shreve, R. L.

1985. Esker characteristics in terms of glacier physics, katahdin esker system, maine. Geological Society of America Bulletin, 96(5):639-646.

Siegfried, M. R., H. A. Fricker, S. P. Carter, and S. Tulaczyk 2016. Episodic ice velocity fluctuations triggered by a subglacial flood in west antarctica. Geophysical Research Letters. 
Smith, A.

2006. Microearthquakes and subglacial conditions. Geophysical Research Letters, $33(24)$.

Sole, A. J., D. W. F. Mair, P. W. Nienow, I. Bartholomew, M. King, M. J. Burke, and I. Joughin

2011. Seasonal speedup of a greenland marine-terminating outlet glacier forced by surface melt-induced changes in subglacial hydrology. Journal of Geophysical Research: Earth Surface, 116(F3).

Stein, S. and M. Wysession

2003. An introduction to seismology, earthquakes, and earth structure.

Stenborg, T.

1973. Some viewpoints on the internal drainage of glaciers. na.

Stevens, L. A., M. D. Behn, J. J. McGuire, S. B. Das, I. Joughin, T. Herring, D. E. Shean, and M. A. King

2015. Greenland supraglacial lake drainages triggered by hydrologically induced basal slip. Nature, 522(7554):73-76.

Stuart, G., T. Murray, A. Brisbourne, P. Styles, and S. Toon

2005. Seismic emissions from a surging glacier: Bakaninbreen, svalbard. Annals of Glaciology, 42(1):151-157.

Subirana, J. S., M. Hernandez-Pajares, and J. e Miguel Juan Zornoza

2013. GNSS Data Processing: Fundamentals and Algorithms. European Space Agency.

Sugiyama, S. and G. Hilmar Gudmundsson

2004. Short-term variations in glacier flow controlled by subglacial water pressure at lauteraargletscher, bernese alps, switzerland. Journal of Glaciology, 50(170):353-362.

Sugiyama, S., P. Skvarca, N. Naito, H. Enomoto, S. Tsutaki, K. Tone, S. Marinsek, and M. Aniya

2011. Ice speed of a calving glacier modulated by small fluctuations in basal water pressure. Nature Geoscience, 4(9):597-600.

Sundal, A. V., A. Shepherd, P. Nienow, E. Hanna, S. Palmer, and P. Huybrechts 2011. Melt-induced speed-up of greenland ice sheet offset by efficient subglacial drainage. Nature, 469(7331):521-524.

Tarantola, A. and B. Valette

1982. Generalized nonlinear inverse problems solved using the least squares criterion. Reviews of Geophysics, 20(2):219-232. 
Trnkoczy, A.

1995. Understanding and parameter setting of sta/lta trigger algorithm.

Van der Veen, C.

1998. Fracture mechanics approach to penetration of surface crevasses on glaciers.

Cold Regions Science and Technology, 27(1):31-47.

Van der Veen, C.

2007. Fracture propagation as means of rapidly transferring surface meltwater to the base of glaciers. Geophysical Research Letters, 34(1).

Walder, J. S. and A. Fowler

1994. Channelized subglacial drainage over a deformable bed. Journal of Glaciology, 40(134):3-15.

Walter, F., J. F. Clinton, N. Deichmann, D. S. Dreger, S. E. Minson, and M. Funk 2009. Moment tensor inversions of icequakes on gornergletscher, switzerland. Bulletin of the Seismological Society of America, 99(2A):852-870.

Walter, F., P. Dalban Canassy, S. Husen, and J. F. Clinton

2013. Deep icequakes: What happens at the base of alpine glaciers? Journal of Geophysical Research: Earth Surface, 118(3):1720-1728.

Walter, F., N. Deichmann, and M. Funk

2008. Basal icequakes during changing subglacial water pressures beneath gornergletscher, switzerland. Journal of Glaciology, 54(186):511-521.

Watson, M. I.

1995. Geophysical and glaciological studies of the Tasman and Mueller Glaciers.

Wells, A., M. D. Yetton, R. P. Duncan, and G. H. Stewart 1999. Prehistoric dates of the most recent alpine fault earthquakes, new zealand. Geology, 27(11):995-998.

West, M. E., C. F. Larsen, M. Truffer, S. O’Neel, and L. LeBlanc 2010. Glacier microseismicity. Geology, 38(4):319-322.

Wiens, D. A., S. Anandakrishnan, J. P. Winberry, and M. A. King 2008. Simultaneous teleseismic and geodetic observations of the stick-slip motion of an antarctic ice stream. Nature, 453(7196):770-774.

Winberry, J. P., S. Anandakrishnan, and R. B. Alley 2009. Seismic observations of transient subglacial water-flow beneath macayeal ice stream, west antarctica. Geophysical Research Letters, 36(11). 
Winberry, J. P., S. Anandakrishnan, D. A. Wiens, R. B. Alley, and K. Christianson 2011. Dynamics of stick-slip motion, whillans ice stream, antarctica. Earth and Planetary Science Letters, 305(3):283-289.

Withers, M., R. Aster, and C. Young

1999. An automated local and regional seismic event detection and location system using waveform correlation. Bulletin of the Seismological Society of America, 89(3):657-669.

Wolf, L. W. and J. N. Davies

1986. Glacier-generated earthquakes from prince william sound, alaska. Bulletin of the Seismological Society of America, 76(2):367-379.

Zhou, H.-w.

1994. Rapid three-dimensional hypocentral determination using a master station method. JOURNAL OF GEOPHYSICAL RESEARCH-ALL SERIES-, 99:15439 .

Zoet, L., R. Alley, S. Anandakrishnan, and K. Christianson 2013. Accelerated subglacial erosion in response to stick-slip motion. Geology, 41(2):159-162.

Zoet, L. K., S. Anandakrishnan, R. B. Alley, A. A. Nyblade, and D. A. Wiens 2012. Motion of an antarctic glacier by repeated tidally modulated earthquakes. Nature Geoscience, 5(9):623-626.

Zwally, H. J., W. Abdalati, T. Herring, K. Larson, J. Saba, and K. Steffen 2002. Surface melt-induced acceleration of greenland ice-sheet flow. Science, 297(5579):218-222. 
Appendices 


\section{A Manual Inspection Seismograms}

In this appendix on-glacier sensor seismograms are presented in two minute windows, these showing characteristic seismicity observed during manual inspection of two rainfall episodes as described in Section 3.3. The four figures show: 1) helicopter noise prior to rainfall (Figure A.1), 2) near-station impulsive seismicity prior to rainfall (Figure A.2), 3) near-station seismicity near a rainfall peak (Figure A.3), and 4) high rates of impulsive seismicity associated with a crevassing rate peak (Figure A.4), this potentially being the signature of small hydrofracture expansion of crevasses prior to large network detectable crevasse opening. All seismograms shown are normalised independently. 


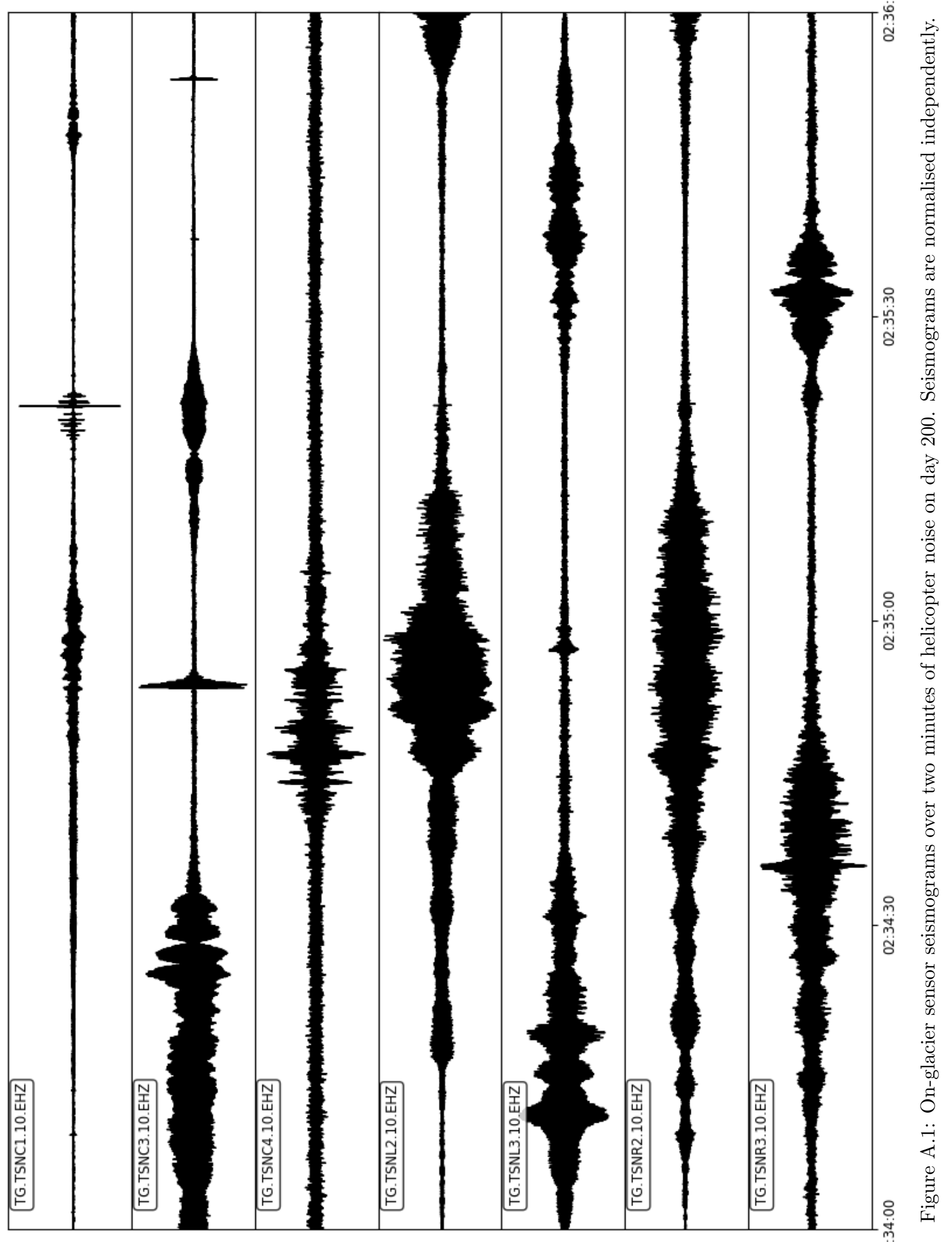




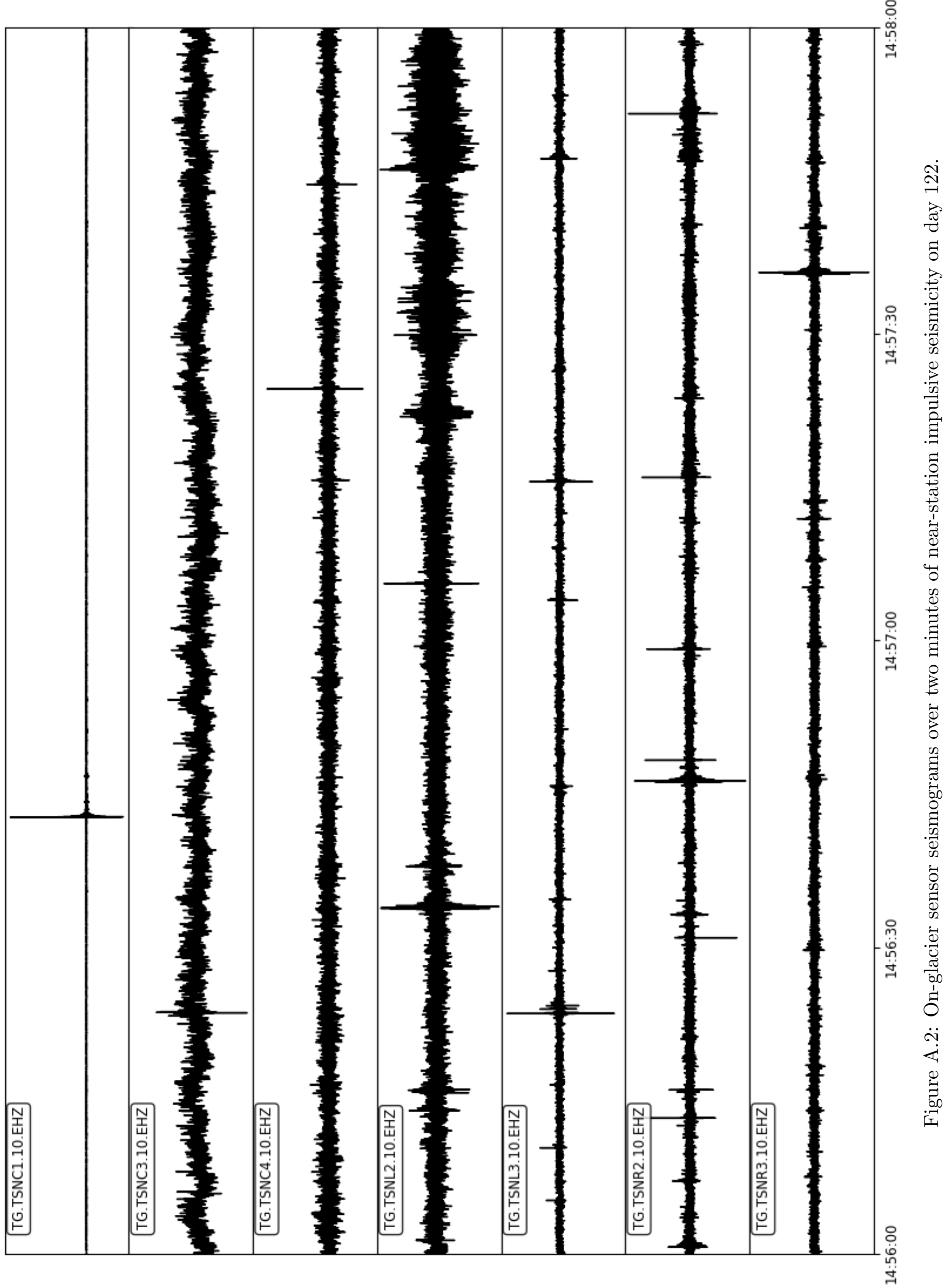




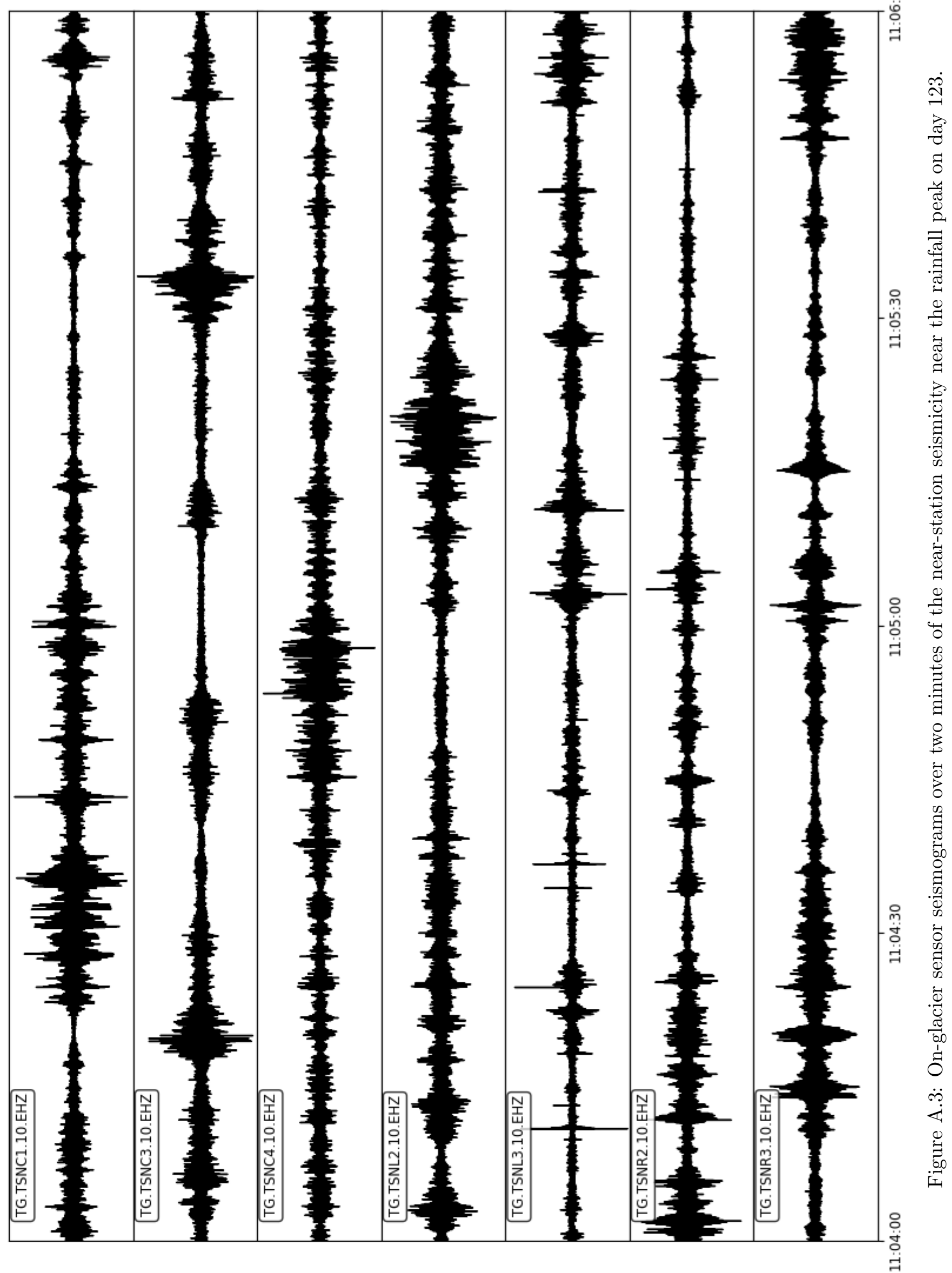




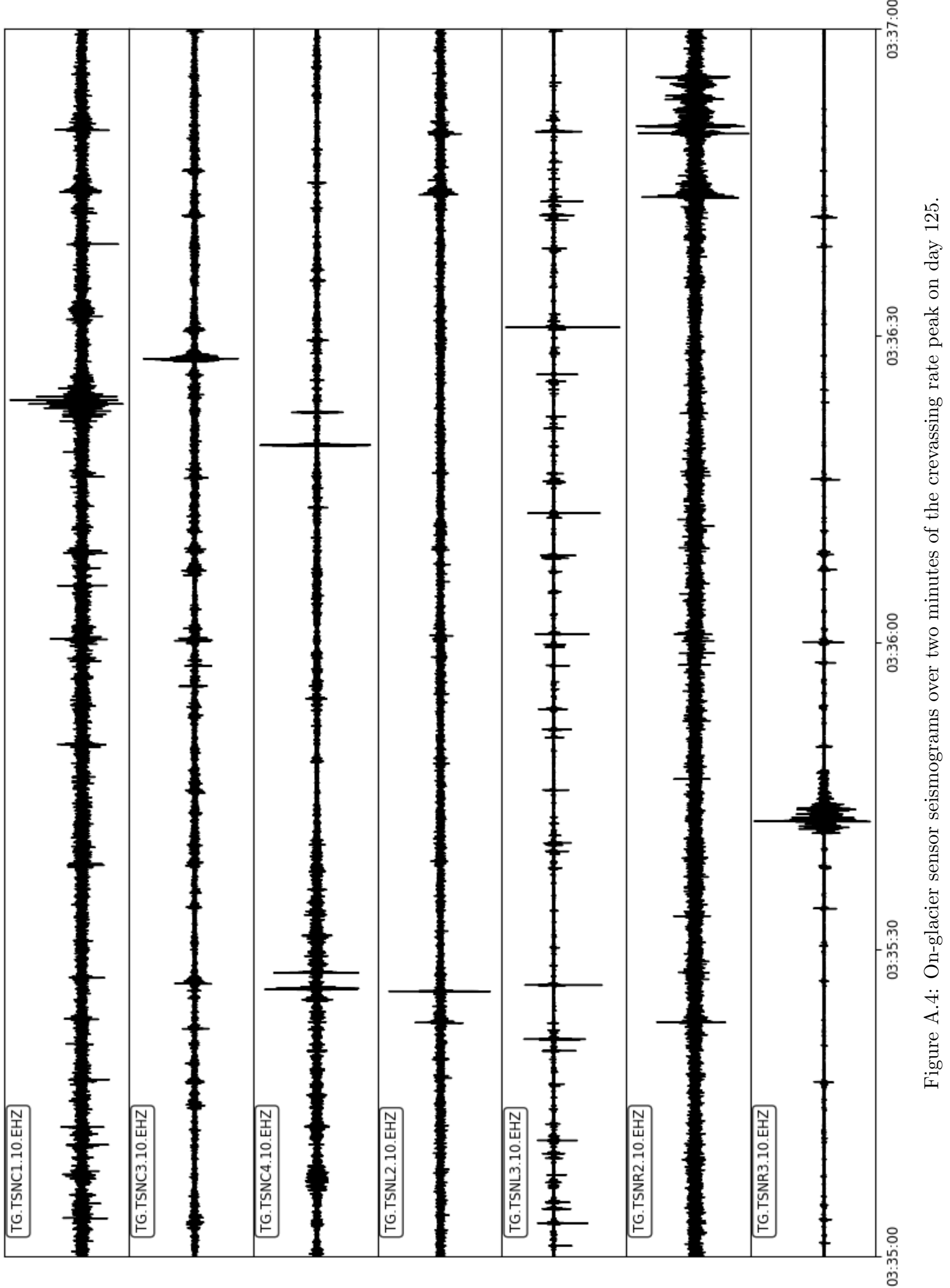




\section{B Timeseries Plots}

In this appendix the timeseries plots for velocities calculated from 24 hour sampling intervals and supporting seismic, geodetic, meteoric, and lake level data are presented in Figures B.1-B.4. Figures B.2 and B.3 are focused sections of Figure B.1 around the accelerated sliding episodes on days 125 and 132 (A and $\mathbf{B}$ in Figcrackingure B.1), respectively.

For Figures B.1-B.4 purple and green geodetic data are from the upper and lower GNSS sensors respectively, strain rate is positive during compression and negative during extension between the upper and lower GNSS sensors, velocities are calculated every 60 minutes from data in the surrounding 12 hours. In Figures B.1 and B.4 bar plot width is thickened to better show data relationships, and bounded sections $\mathbf{A}$ and $\mathbf{B}$ are shown with data relevant to accelerated sliding in Figures 4.17 and 4.18, respectively. 
Lake Level

Rate of Change

$\left(\mathrm{m} \mathrm{s}^{-1}\right)$

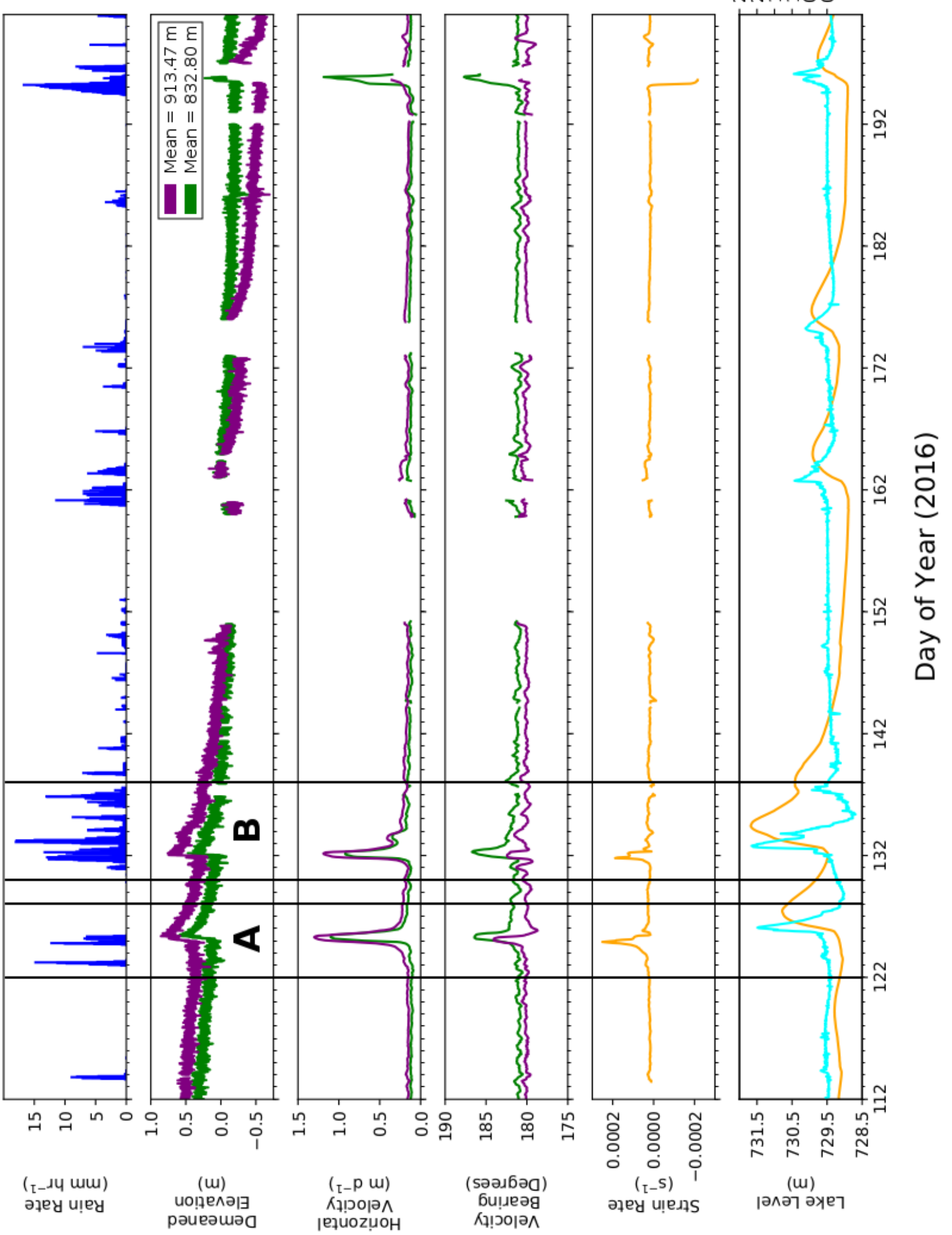

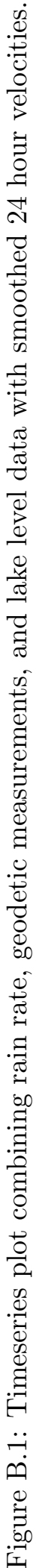

$($ t $-\mathrm{S})$
әдеу uाed

(u)
әләา әхеา 

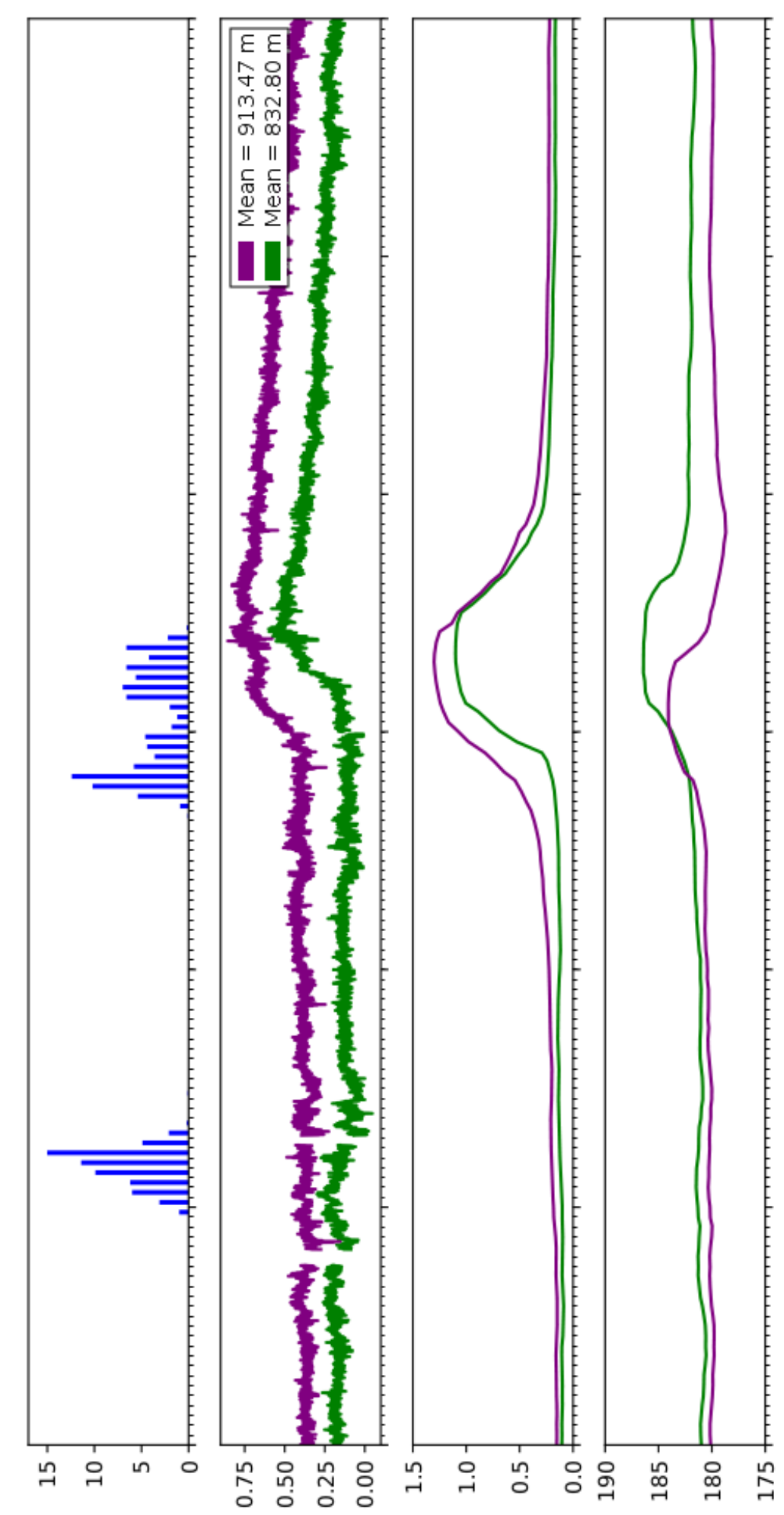

( I- גу wu) әұеy uाएу

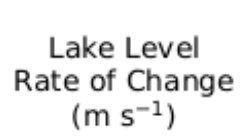

nกํำํำ

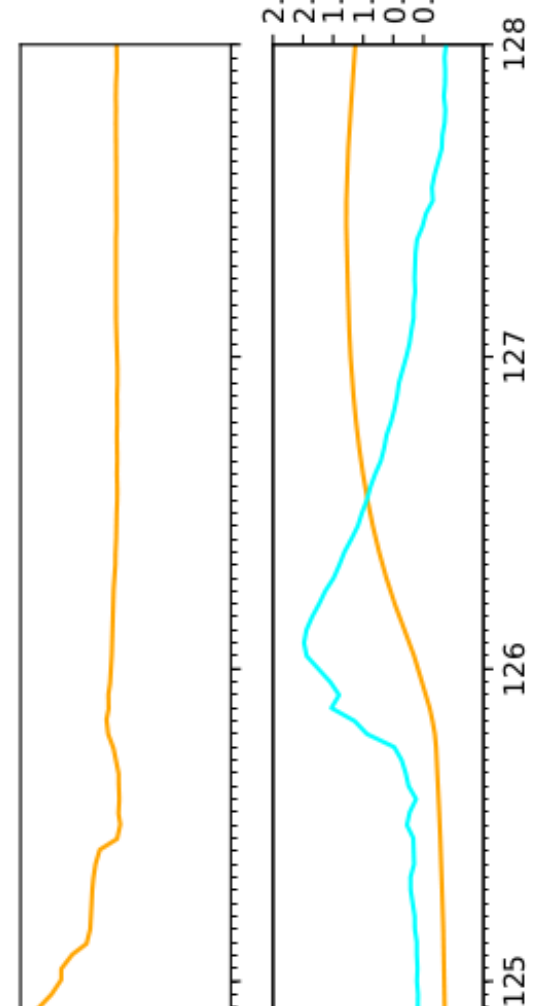

$=\frac{1}{-1}$

.0

亏

건

త్త

\&

常

$\stackrel{\infty}{\sim}$

ป

䨔

$\dot{0}$

$\stackrel{0}{-1}$

$-7$

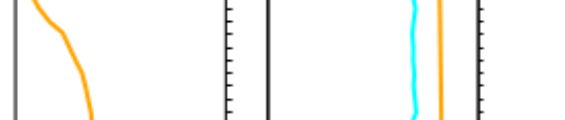

(6)

늠

ㄴ.

ญ

告

สั

$=$

䓠

8

壱

.

를

웅

.

กับ

(w)

юәләך әхеך 


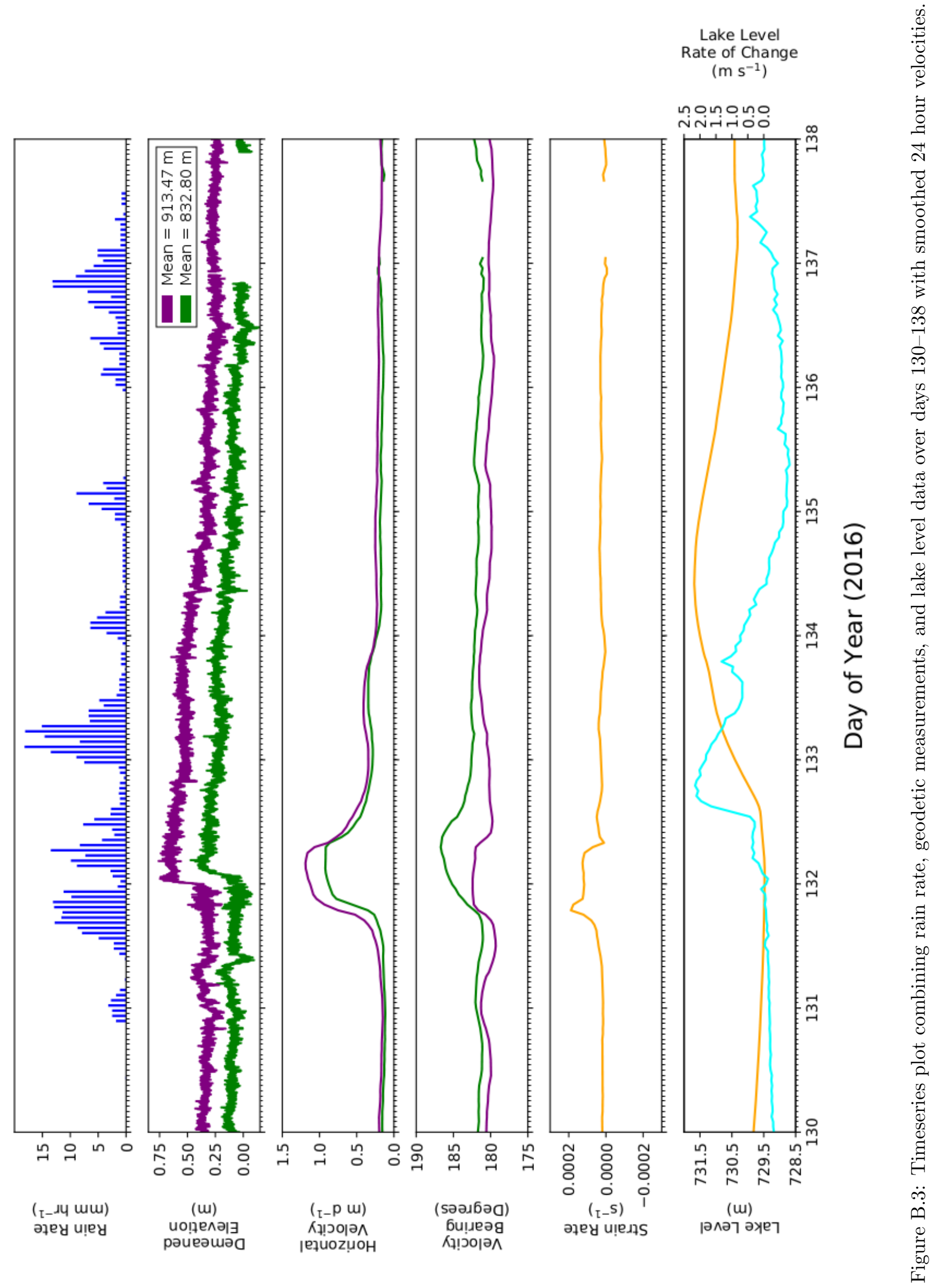



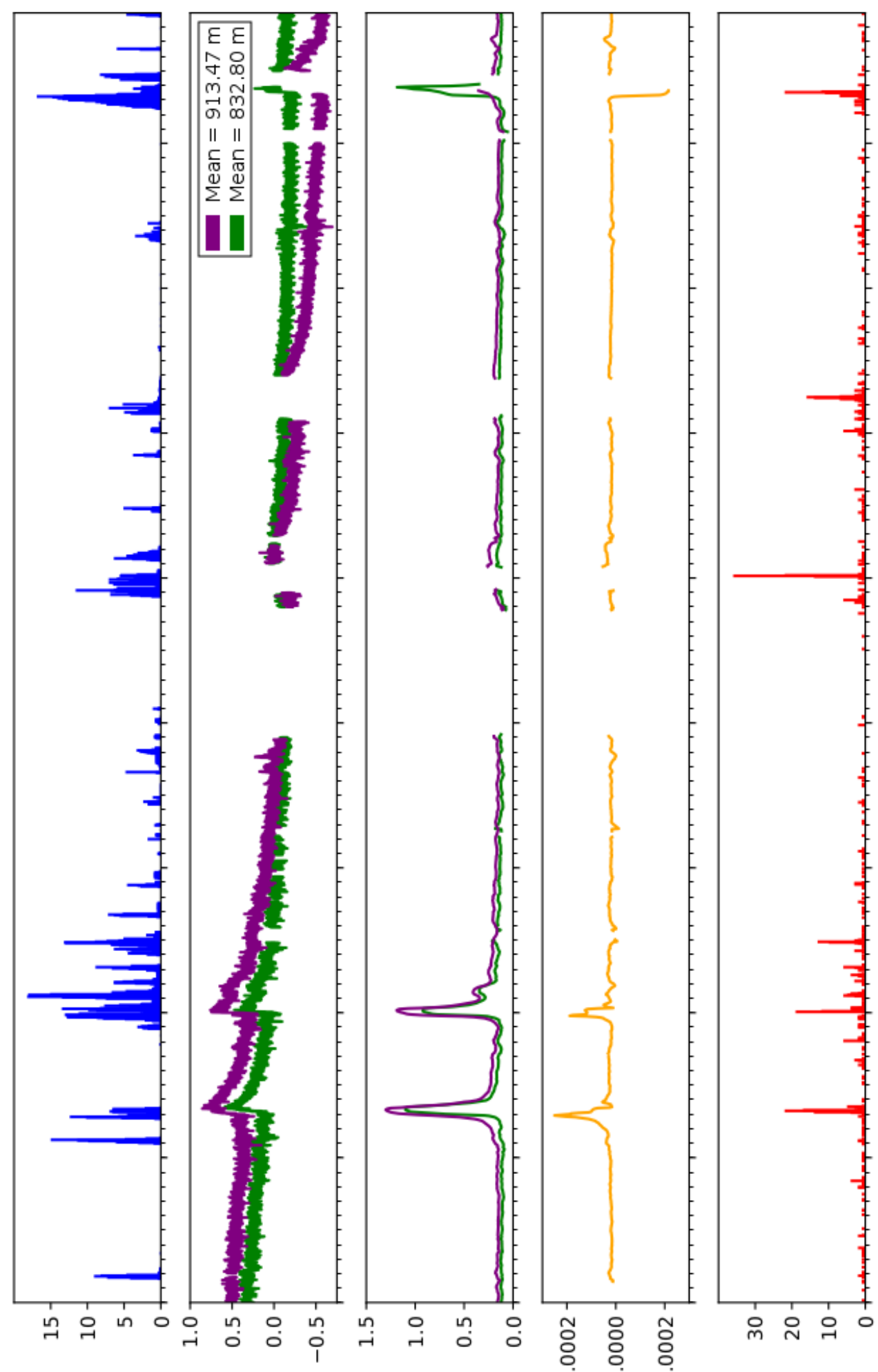

(t_dy mu)

(u)

(

әұеy uा̣ey

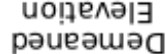
ןетuozuon

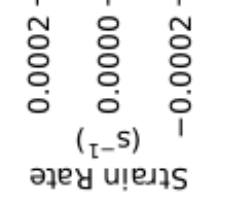

әдеप u!euts
(4-dY zunoว)

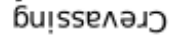

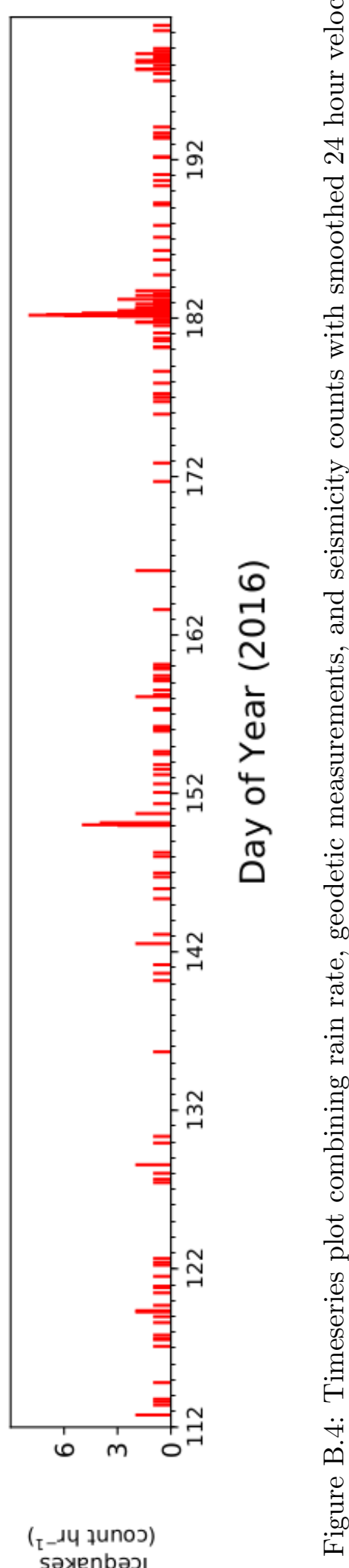

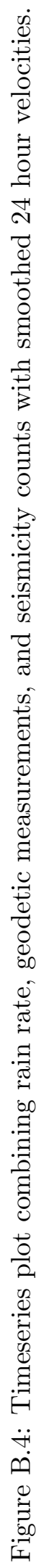

səxenbəગ 


\section{Crevasse Water Storage and Hydrofracture Model}

\section{Crevasse Water Storage Model}

The physical basis of the crevasse water storage model is the same as that of the hydrofracturing interpretation but here the crevasse drainage occurs through a passage of some form connecting the crevasse to the englacial drainage system. In this model (Figure C.5) the crevasse system (reservoir A: consisting of water input $I_{A}$, water output $D_{A}$, and internal storage $S_{A}$ ) is superimposed on the glacial drainage system (reservoir B: consisting of water input $I_{B}$, water output $D_{B}$, and internal storage $S_{B}$ ). For simplicity rainfall is assumed to fall only in the crevasse before being drained through the englacial passage into the glacial drainage system. The glacial drainage system then drains this input into a reservoir of effectively infinite storage (physically interpreted as the glacier bed). The model is applicable to individual crevasses, but given that similar stress states and drainage efficiencies exist in other crevasses the model could describe the crevasse storage state across large parts of a glacier.

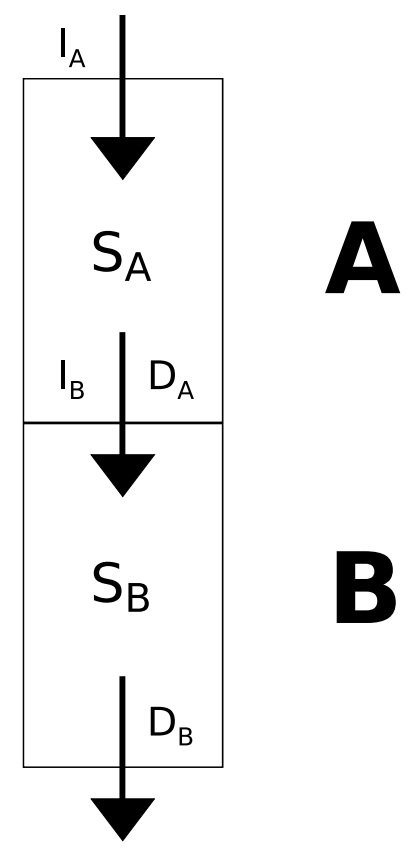

Figure C.5: Schematic diagram for a one-dimensional crevasse water storage model.

Water input and drainage occurs over model time step $\Delta t$ and storage is calculated at time $t$, the instantaneous time between model time steps. After the storage is calculated the maximum drainage and storage capacity $\left(D_{M A X}\right.$ and $\left.S_{M A X}\right)$ of each reservoir is adjusted due to the effects of frictional melt and creep closure over the 
model time step. Storage capacity increase due to hydrofracture is not considered in this model.

Key assumptions of the model are 1) rainfall is uniform spatially and temporally over each model time step, 2) rainfall is the only significant water input during rainfall episodes, 3) drainage from a reservoir occurs instantaneously, 4) all stored water in a reservoir is available as drainage when the water input over a time step is less than the maximum drainage capacity, and 5) changes in drainage and storage maxima occur at the end of each model time step and not over the time step itself.

The resolution of available data is insufficient to resolve the magnitude of any uncertainties stemming from these assumptions. Overall uncertainties are thought too small to skew the model results beyond their representative purpose. The complete model calculation is described below:

Prior to rainfall each reservoir is in a dry state with a minimum drainage and storage capacity maintained by the balance between melt water inputs and ice deformation. At time $t_{0}$ the model variables are:

$$
\begin{aligned}
& I_{A}\left(t_{0}\right)=0, D_{A}\left(t_{0}\right)=0, S_{A}\left(t_{0}\right)=0, D_{M A X, A}\left(t_{0}\right)=D_{0, A}, S_{M A X, A}\left(t_{0}\right)=S_{0, A} \\
& I_{B}\left(t_{0}\right)=0, D_{B\left(t_{0}\right)}=0, S_{B\left(t_{0}\right)}=0, D_{M A X, B}\left(t_{0}\right)=D_{0, B}, S_{M A X, B}\left(t_{0}\right)=S_{0, B}
\end{aligned}
$$

At the onset of rainfall water accumulates in reservoir A and drains into reservoir B over time step $\Delta t$. As water enters reservoir B it drains into the infinite reservoir.

The input into reservoir $\mathrm{A}$ is the rain rate, $R$, and the drainage from reservoir $\mathrm{A}$ is calculated at the end of the time step $\left(t=t_{0}+\Delta t\right)$ as:

$$
D_{A}(t)=\left\{\begin{array}{lr}
R(t), & \text { for } R(t)<D_{M A X, A}(t) \\
& \text { and } S_{A}(t-\Delta t)=0 \\
D_{M A X, A}(t), & \text { for } R(t) \geq D_{M A X, A}(t) \\
R(t)+D_{S, A}(t), & \text { for } R(t)<D_{M A X, A}(t) \\
& \text { and } S_{A}(t-\Delta t)>0
\end{array}\right.
$$

here:

$$
D_{S, A}(t)= \begin{cases}D_{M A X, A}(t)-R(t), & \text { for } S_{A}(t-\Delta t) \geq D_{M A X, A}(t)-R(t) \\ S_{A}(t-\Delta t), & \text { for } S_{A}(t-\Delta t)<D_{M A X, A}(t)-R(t)\end{cases}
$$


$D_{S}$ is the drainage term describing water input from storage, $S_{A}$, that fills any available drainage capacity for non-zero storage volumes.

The input into reservoir B is the drainage from reservoir A:

$$
I_{B}(t)=D_{A}(t)
$$

and the equations describing drainage from reservoir B have the form of Equations .1 and .2 with the variables changed to reference reservoir B.

The storage in reservoir A at the end of the time step is:

$$
S_{A}(t)=S_{A}(t-\Delta t)+R(t)-D_{A}(t)
$$

Whereby the drainage and storage maxima of A can be written as:

$$
D_{M A X, A}(t)=\left\{\begin{array}{r}
D_{M A X, A}(t-\Delta t)+a D_{A}(t)-b D_{M A X, A}(t-\Delta t), \\
\text { for } D_{M A X, A}(t-\Delta t)+a D_{A}(t)-b D_{M A X, A}(t-\Delta t) \geq D_{0, A} \\
\\
D_{0, A}, \\
\text { for } D_{M A X, A}(t-\Delta t)+a D_{A}(t)-b D_{M A X, A}(t-\Delta t)<D_{0, A}
\end{array}\right.
$$

and

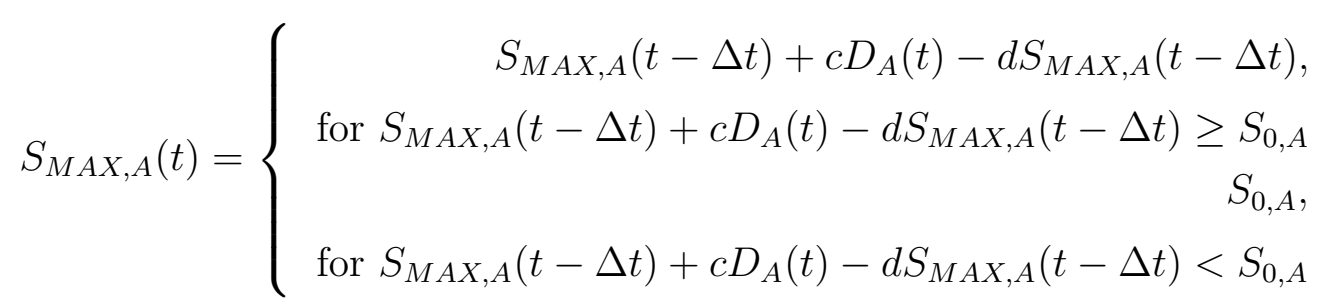

Here $a, c$ are terms describing the effect of frictional melting and $b, d$ are terms describing the effect of ice deformation on reservoir drainage and storage capacity, respectively. Note that high drainage rates will expand reservoir drainage and storage capacity quickly but a large drainage and storage capacity is prone to rapid collapse due to its distance from the melt-sustained state. A hard lower limit is applied to these capacities such that they never fall below their equilibrium state values. This lower limit ensures model stability with large values of $b$ and $d$.

The equivalent formulae for reservoir B have the form of Equations .4, .5 and .6 with the variables changed to reference those of reservoir B.

Following maxima adjustment system storage is calculated for each reservoir at the end of the next time step for the given rainfall over that time step and the preexisting 
storage in the system. If the storage capacity of reservoir B is met then the model simplifies such that any further storage that would occur in reservoir B occurs in reservoir A on top of any storage that would occur in reservoir A independently. In this case the model equations for reservoir storage are expanded such that:

$$
S_{B}(t)= \begin{cases}S_{B}(t-\Delta t)+R(t)-D_{B}(t), & \text { for } S_{B}(t) \leq S_{M A X, B}(t-\Delta t) \\ S_{M A X, B}(t-\Delta t), & \text { for } S_{B}(t)>S_{M A X, B}(t-\Delta t)\end{cases}
$$

and,

$$
S_{A}(t)= \begin{cases}S_{A}(t-\Delta t)+R(t)-D_{A}(t), & \text { for } S_{B} \leq S_{M A X, B}(t-\Delta t) \\ S_{A}(t-\Delta t)+R(t)-D_{B}(t), & \text { for } S_{B}>S_{M A X, B}(t-\Delta t)\end{cases}
$$

Here the two reservoirs act as one until the storage in reservoir B drops below its maximum. This scenario of reservoir overflow will occur when either the drainage efficiency and/or storage in reservoir B are initially small and/or do not grow at a fast rate.

\section{Crevasse Hydrofracture Model}

Van der Veen (2007) present a model to estimate the depth of hydrofracture-driven crevasse opening in a single crevasse (Figure C.6). This model reduces to an equation describing the depth of a surface crevasse in an extensional stress regime as a function of the water level in that crevasse.

The key theoretical points and assumptions of this model are:

1. Ice density is constant over depth.

2. The ratio of crevasse depth to ice thickness is small.

3. Crevasse opening is due to a far field extensional normal stress that acts perpendicular to the plane of the crevasse.

4. Crevasses are vertically oriented and propagate downward perpendicular to the applied extensional stress.

5. Resistive stress, $R_{x x}$, the difference between total stress and lithostatic stress, is equal to the normal stress associated with crevasse opening. 
6. The density of water, $\rho_{w}$, is greater than that of ice, $\rho_{i}$, and so the pore pressure in a water filled crevasse can negate or overcome the lithostatic stress exerted on it by the overlying ice.

7. The water input during sustained hydrofracture equals the crevasse volume increase due to hydrofracture. Thus the water level, $b$, remains high enough to resist closure by the increased lithostatic stress at the new crevasses depth $d$.

8. The crevasse depth above the water level is small enough to be negligible $(b \approx d)$.

9. When the net stress intensity factor at the crevasse tip is equal to the fracture toughness of the ice crevasse opening will occur.

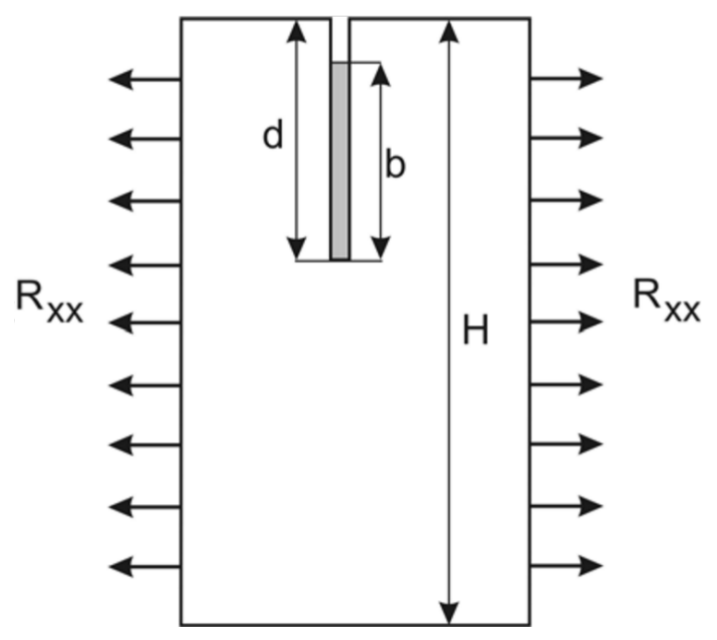

Figure C.6: Schematic diagram for a one-dimension crevasse hydrofracture model. A vertically oriented and water-filled crevasse with depth $d$ and water level $b$ extends into a glacier of thickness $H$. The crevasse exists in an extensional stress field described by the far-field extensional stress $R_{x x}$ which is constant with depth. Figure from Van der Veen (2007).

Van der Veen (2007) give the net stress intensity factor as:

$$
K_{I}=1.12 R_{x x} \sqrt{\pi d}-0.683 \rho_{i} g d^{1.5}+0.683 \rho_{w} g b^{1.5}
$$

The terms of the right hand side of Equation .9 describe the stress intensity factors from extensional stress, lithostatic stress and pore pressure respectively. Lithostatic stress and pore pressure are considered to be hydrostatic with $g$ being the acceleration due to gravity. Van der Veen (2007) found that after setting $K_{I}$ equal to the 
ice fracture toughness the crevasse depth could be calculated for a given extensional stress and crevasse water level. Their calculations showed the controlling model parameter to be the crevasse filling rate, which was defined as $Q$ in:

$$
b=Q t
$$

where $t$ is model time and $b$ is water depth.

They also found that the rate of crevasse propagation was effectively independent of the extensional stress term. Similarly variations in fracture toughness caused little change in the result. The reduced form of their model is thus independent of any extensional stress or fracture toughness value and describes simply the depth due to hydrofracture of a one-dimensional crevasse that fills with water over time:

$$
d=\left(\frac{\rho_{w}}{\rho_{i}}\right)^{2 / 3} Q t
$$

Use of Equation .11 requires an ice fracture toughness and extensional stress state sufficient to create small fractures that can develop into crevasses. Once hydrofracturedriven crevasse propagation has begun these values become negligible.

\section{Combined Storage And Hydrofracture Model}

By combining the crevasse storage model with the hydrofracture model the depth of a single crevasse can be estimated. Hydrofracture is assumed to occur at the end of a model time step when there is water in the crevasse. The crevasse depth due to this hydrofracture is calculated from Equation .11. An increase in water in each subsequent time step is a requirement for continued hydrofracture, but no mathematic constraint is applied to represent this. As crevasse depths increase the likelihood of hydraulic connection increases. Once crevasse depths approximate the glacier thickness hydraulic connection to the glacier bed is assumed. If true, crevassing rates following this connection should drop dramatically. Prior to this crevassing rates should correlate to the water storage volume.

The adjusted Equation .11 for the combined model is:

$$
d=\left(\frac{\rho_{w}}{\rho_{i}}\right)^{2 / 3} S_{A}
$$

An example of the model is provided in Figure C.7 for days 131-134 with assumptions of: infinite englacial drainage and storage capacity, and constant crevasse 
drainage capacity expansion and collapse over time. It is likely that this time independence is what causes the model result to be only representative for the crevassing rate peak on day 133 and not function at all for the crevassing rate peak on day 132, though this is though to result from accelerated sliding and not hydrofracture. For the model used here to be more practical a detailed understanding of how drainage capacity changes in response to flux and lithostatic pressure needs to be implemented. Given that overflow of water from the englacial drainage system may drive hydrofracture this simplification of the model is very limited, as such it should be considered only as an example of how the model functions.
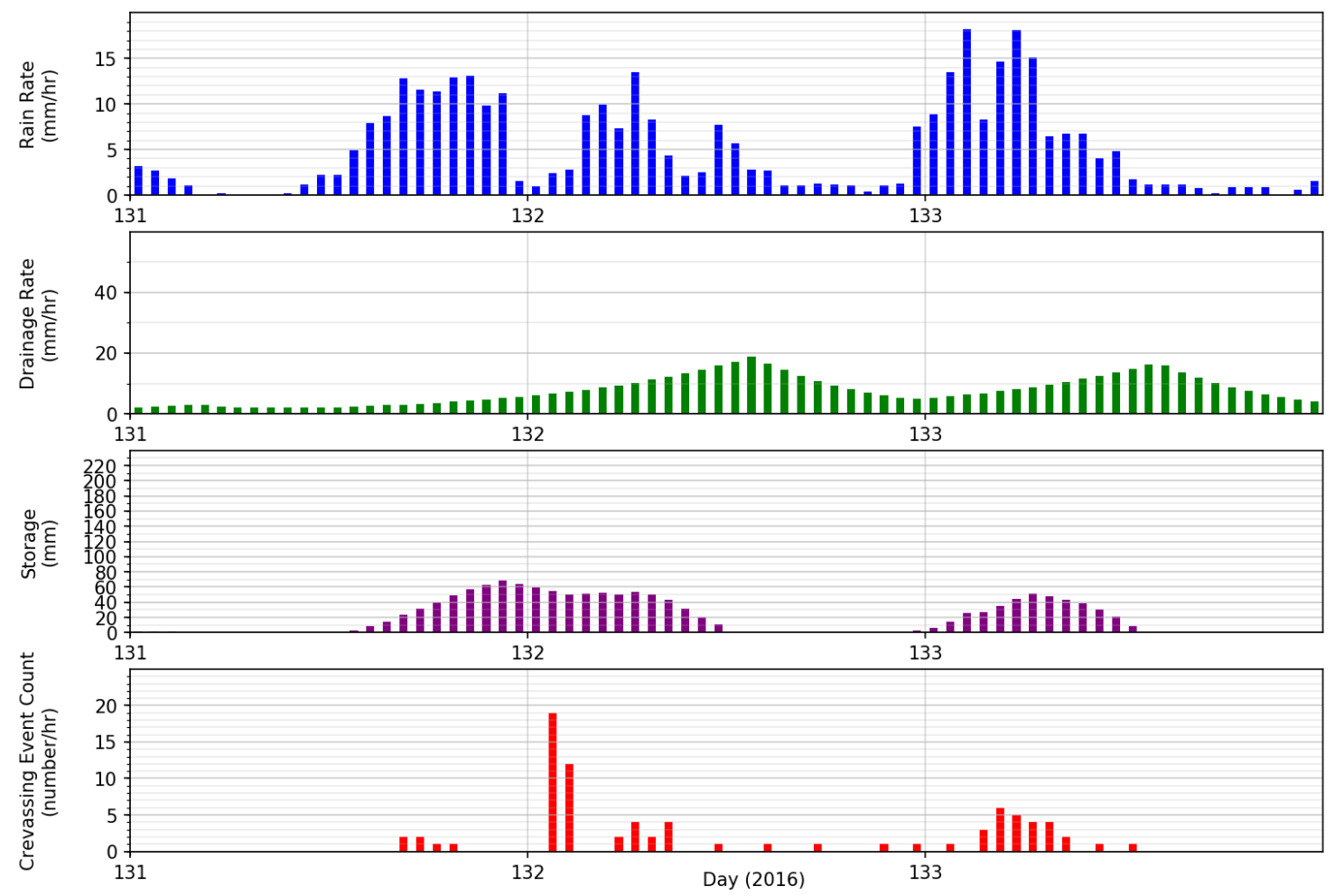

Figure C.7: Combined water storage and hydrofracture model result for days 131-134. In this model recorded rain rate over days 131-134 forms the water input, calculated drainage rate forms the model output, the storage volume $(\mathrm{mm})$ is the cumulative difference between rain rate and drainage rate over time, and crevassing event count is observed data shown for comparison. Model parameters were set as: initial drainage capacity $2 \mathrm{~mm} \mathrm{hr}^{-1}$, expansion rate $2 \%$ drainage, collapse rate $16 \%$ drainage. Here the model is simplified such that the englacial system behaves as an infinite reservoir and so storage is calculated only in the crevasse.

\section{Model Limitations and Interpetation}

Though conceptually sound this model cannot provide unique solutions to the water storage problem. The lack of prior knowledge of any variable values leads to an infinite number of solutions describing the desired trend. No suitable constraint exists to limit the number of such results and so the model is only appropriate for 
use conceptually. 